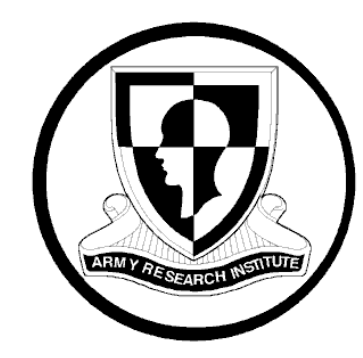

Research Report 1973

\title{
Tailored Training in Vehicle Maintenance Courses
}

\author{
M. Glenn Cobb \\ Peter S. Schaefer \\ U.S. Army Research Institute \\ Gary M. Stallings \\ Paul N. Blankenbeckler \\ Richard L. Wampler \\ Northrop Grumman Corporation
}

July 2014

United States Army Research Institute for the Behavioral and Social Sciences

Approved for public release; distribution is unlimited. 


\title{
U.S. Army Research Institute for the Behavioral and Social Sciences
}

\author{
Department of the Army \\ Deputy Chief of Staff, G1
}

\section{Authorized and approved for distribution:}

\section{MICHELLE SAMS, Ph.D. Director}

Research accomplished under contract

for the Department of the Army by:

Northrop Grumman Corporation

Technical Review by:

Victor J. Ingurgio, U.S. Army Research Institute

Rodney W. Maupin, Director, Ordnance Training Divisions, Fort Benning, GA

\section{NOTICES}

DISTRIBUTION: This Research Report has been submitted to the Defense Information Technical Center (DTIC). Address correspondence concerning ARI reports to: U.S. Army Research Institute for the Behavioral and Social Sciences, Attn: DAPE-ARI-ZXM, $60006^{\text {th }}$ Street Building 1464 / Mail Stop: 5610), Fort Belvoir, VA 22060-5610

FINAL DISPOSITION: Destroy this Research Report when it is no longer needed. Do not return it to the U.S. Army Research Institute for the Behavioral and Social Sciences.

NOTE: The findings in this Research Report are not to be construed as an official Department of the Army position, unless so designated by other authorized documents. 


\begin{tabular}{|c|c|c|c|}
\hline \multicolumn{3}{|c|}{ REPORT DOCUMENTATION PAGE } & $\begin{array}{c}\text { Form Approved } \\
\text { OMB No. 0704-0188 }\end{array}$ \\
\hline $\begin{array}{l}\text { 1. REPORT DATE (DD-MM-YYYY) } \\
\text { July } 2014\end{array}$ & \multicolumn{2}{|c|}{$\begin{array}{l}\text { 2. REPORT TYPE } \\
\text { Final }\end{array}$} & $\begin{array}{l}\text { 3. DATES COVERED (From - To) } \\
\text { May } 2012 \text { to September } 2013\end{array}$ \\
\hline \multirow{2}{*}{\multicolumn{3}{|c|}{ Tailored Training in Vehicle Maintenance Courses }} & $\begin{array}{l}\text { 5a. CONTRACT NUMBER } \\
\text { W5J9CQ-11-D-0001 }\end{array}$ \\
\hline & & & 5b. GRANT NUMBER \\
\hline \multicolumn{3}{|c|}{ Tailored Training in Vehicle Maintenance Courses } & $\begin{array}{l}\text { 5c. PROGRAM ELEMENT NUMBER } \\
63007\end{array}$ \\
\hline \multirow{3}{*}{\multicolumn{3}{|c|}{$\begin{array}{l}\text { 6. AUTHOR(S) } \\
\text { M. Glenn Cobb, Peter S. Schaefer; } \\
\text { Gary M. Stallings, Paul N. Blankenbeckler, Richard L. Wampler }\end{array}$}} & $\begin{array}{l}\text { 5d. PROJECT NUMBER } \\
\text { A792 }\end{array}$ \\
\hline & & & $\begin{array}{l}\text { 5e. TASK NUMBER } \\
409\end{array}$ \\
\hline & & & 5f. WORK UNIT NUMBER \\
\hline \multicolumn{3}{|c|}{ 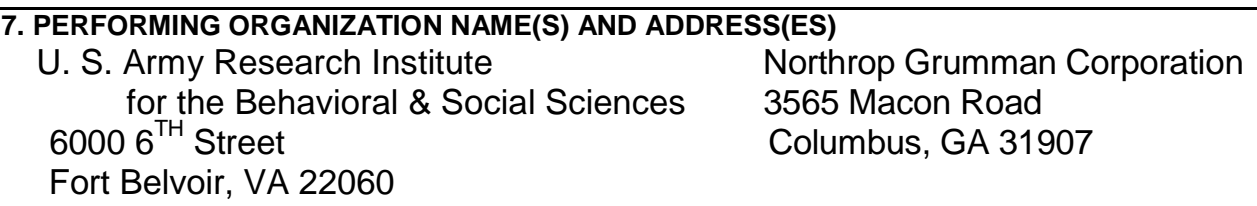 } & $\begin{array}{l}\text { 8. PERFORMING ORGANIZATION REPORT } \\
\text { NUMBER }\end{array}$ \\
\hline \multirow{2}{*}{\multicolumn{3}{|c|}{$\begin{array}{l}\text { 9. SPONSORING / MONITORING AGENCY NAME(S) AND ADDRESS(ES) } \\
\text { U. S. Army Research Institute } \\
\text { for the Behavioral \& Social Sciences } \\
60006^{\mathrm{TH}} \text { Street (Bldg. } 1464 \text { / Mail Stop 5610) } \\
\text { Fort Belvoir, VA 22060-5610 }\end{array}$}} & $\begin{array}{l}\text { 10. SPONSOR/MONITOR'S ACRONYM(S) } \\
\text { ARI }\end{array}$ \\
\hline & & & $\begin{array}{l}\text { 11. SPONSOR/MONITOR'S REPORT } \\
\text { NUMBER(S) } \\
\text { Research Report } 1973\end{array}$ \\
\hline
\end{tabular}

12. DISTRIBUTION/AVAILABILITY STATEMENT: Distribution Statement A: Approved for public release; distribution is unlimited.

13. SUPPLEMENTARY NOTES

Contracting Officer's Representative and Subject Matter Expert: Dr. M. Glenn Cobb

14. ABSTRACT

A central tenet within the Army Learning Concept 2015 (ALC 2015) and Army Learning Model (ALM) is the need to transition to learner-centric methods and processes that develop critical competencies through rigorous, tailored, outcomeoriented learning experiences. Previous research conducted by the U.S. Army Research Institute (ARI) Ft. Benning Research Unit showed that tailored training in the Army is most likely to occur in technical, functional courses where graduates must be proficient in clearly defined skills, based on specified performance standards, upon graduation. However, there has been little research focused on identifying the actual different tailored training strategies employed in divided small group training based on interpersonal interactions or how the nature and frequency of these interactions affect subsequent student learning or task performance. This effort addresses gaps identified in previous research conducted on tailored training approaches and examines specific training issues raised by the 3-81st AR BN at Ft. Benning, GA. The first objective of the research was to identify potential predictors of performance at different stages of training in the 91A and 91M AIT courses that will enable instructors to better identify strong and weak Soldiers. The second objective was to examine small group processes in both courses to identify the nature and extent of tailored training, peer-to-peer interaction, and how tailoring varies with group composition. The final objective was to examine the effectiveness and other impacts of the Blended Rotation Interactive Technology Environment (BRITE) technologies employed in training (91M course only) on training outcomes.

15. SUBJECT TERMS

Training, Tailored training, Armored vehicle maintenance, Bradley Fighting Vehicle maintainer

\begin{tabular}{|c|c|l|l|l|l|}
\hline \multicolumn{2}{|l|}{ 16. SECURITY CLASSIFICATION OF: } & $\begin{array}{l}\text { 17. LIMITATION } \\
\text { OF ABSTRACT }\end{array}$ & $\begin{array}{l}\text { 18. } \\
\text { NUMBER } \\
\text { OF } \\
\text { PAGES }\end{array}$ & $\begin{array}{l}\text { 19a. NAME OF RESPONSIBLE } \\
\text { PERSON } \\
\text { Dorothy Young }\end{array}$ \\
\cline { 1 - 1 } $\begin{array}{c}\text { a. REPORT } \\
\text { Unclassified }\end{array}$ & $\begin{array}{c}\text { b. ABSTRACT } \\
\text { Unclassified }\end{array}$ & $\begin{array}{l}\text { c. THIS PAGE } \\
\text { Unclassified }\end{array}$ & $\begin{array}{l}\text { Unlimited } \\
\text { Unclassified }\end{array}$ & 88 & (70) TELEPHONE NUMBER \\
\end{tabular}




\title{
Research Report 1973
}

\section{Tailored Training in Vehicle Maintenance Courses}

\author{
M. Glenn Cobb \\ Peter S. Schaefer \\ U.S. Army Research Institute \\ Gary M. Stallings \\ Paul N. Blankenbeckler \\ Richard L. Wampler \\ Northrop Grumman Corporation
}

Fort Benning Research Unit

Scott E. Graham, Chief

U.S. Army Research Institute for the Behavioral and Social Sciences $60006^{\text {th }}$ Street, Building 1464

Fort Belvoir, VA 22060

July 2014

Approved for public release; distribution is unlimited. 
The authors would like to express their gratitude to the leaders, training developers, and instructors of the 3-81 ${ }^{\text {st }}$ AR BN, Fort Benning, GA, who provided expert advice, shared hardwon insights, and opened their doors for us to conduct this research effort. We wish to especially recognize and acknowledge the invaluable contributions provided by the BN training directors, i.e. Mr. Rodney Maupin (Director, Ordinance Training Divisions), Mr. Frank Yerkins (Chief, Abrams Training Division), and Mr. James Hand (Chief, Bradley Training Division), whose assistance and insights were so essential to this research. 


\section{TAILORED TRAINING IN VEHICLE MAINTENANCE COURSES}

\section{EXECUTIVE SUMMARY}

Research Requirement:

A central tenet within the Army Learning Concept 2015 (ALC 2015) and Army Learning Model (ALM) is the need to transition to learner-centric methods and processes that develop critical competencies through rigorous, tailored, outcome-oriented learning experiences. The ALM also emphasizes the use of pretests and training assessments to effectively predict and tailor training to individual Soldiers' needs as defined by their experiences and proven competencies. Previous research conducted by the U.S. Army Research Institute (ARI) Ft. Benning Research Unit showed that tailored training in the Army is most likely to occur in technical, functional courses where graduates must be proficient in clearly defined skills, based on specified performance standards, upon graduation. However, there has been little research focused on identifying the actual different tailored training strategies employed in divided small group training based interpersonal interactions or how the nature and frequency of these interactions affect subsequent student learning or task performance. This effort addresses gaps identified in previous research conducted on tailored training approaches and examines specific training issues raised by the $3-81^{\text {st }} \mathrm{AR}$ BN at Fort Benning, GA. The first objective of the research is to identify potential predictors of performance at different stages of training in the 91A and 91M AIT courses that will enable instructors to better identify strong and weak Soldiers. The second objective is to examine small group processes in both courses to identify the nature and extent of tailored training, peer-to-peer interaction, and how tailoring varies with group composition. The final objective is to examine the effectiveness and other impacts of the Blended Rotation Interactive Technology Environment (BRITE) technologies employed in training (91M course only).

Procedure:

Following approval of the initial research proposal and participating AIT units by DCGIMT, this research effort was completed in two phases. During Phase 1, researchers assessed the utility of demographic characteristics, prior knowledge, and cognitive measures for predicting later performance in Abrams tank and BFV maintainers' training. Based upon training schedules and class availability, this data, as well as unit documented training outcomes, were collected from five consecutive 91A and three consecutive 91M classes. In Phase 2, researchers expanded this effort by collecting data on instructional methodologies and techniques, tailored training strategies, and student performance and interactions through direct observation of scheduled training events and activities and unit provided training summaries and records. Training was observed during three one-week periods a week after the assignment of Soldiers to their training groups and the initiation. Following the completion of all training observations, focus group interviews were conducted with the participating students and instructors. 
Findings:

Our analyses showed that traditionally available measures, e.g. GT scores, are not strong predictors of later student performance. Our research indicated that measures designed to discern a student's entering knowledge of and ability to complete basic underlying tasks relevant to later learning content are much more predictive of later performance at different stages of training. This research also indicated that instructors found effectively addressing their Soldiers' needs by dividing their attention between two subgroups an often impossible task. It also found that providing problems for observing Soldiers to work on and asking them simple, direct questions were the most common strategies instructors used to gauge their comprehension and understanding of the ongoing training event. It also showed that the ability alter or overlap the sequence of training events within broadly defined boundaries was key to 91A instructors' effectiveness to tailor training in a manner that enhanced student engagement. Finally, this research indicated the degree to which facilitation strategies used to engage students using the BRITE mobile classroom trainer (MCT) were effective depended upon the ability of instructors, either individually or in collaboration, to engage a large group of students in active learning using the technology, the availability of preprogrammed content, and the level of comfort an instructor had with operating and troubleshooting the MCT. However, it also indicated that lower performing and less knowledgeable students appeared to benefit most from the learning environment created when using the MCT.

Based on our findings, we provide recommendations for developing tailored predictor measures based on critical basic concepts and skills underlying course content, tailoring small group training, and integrating BRITE technologies within training to enhance student learning and engagement.

Utilization and Dissemination of Findings:

The results of this effort were reviewed with the Commander and training directors in the 3-81st Armor Battalion, Fort Benning GA. A written summary of the overall findings and recommendations from this presentation was also provided to DCG-IMT, as requested. 


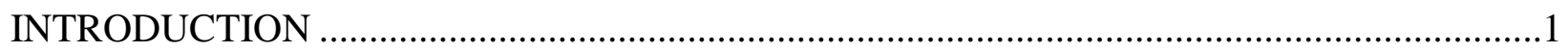

Armored Vehicle Maintainer Training .................................................................................

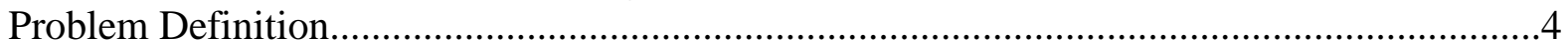

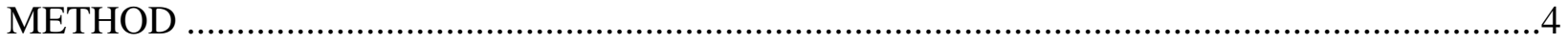

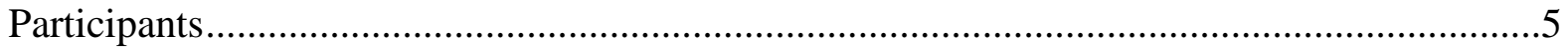

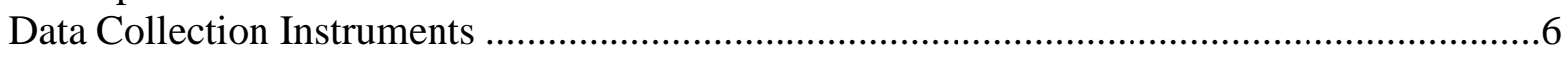

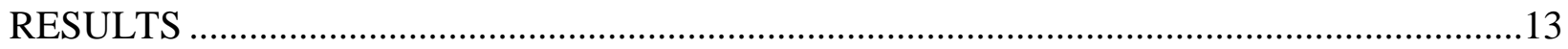

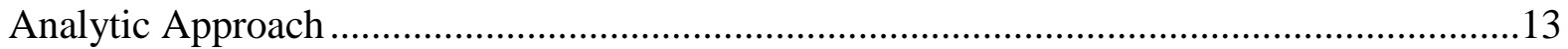

Data Screening and Scale Constructions …………….......................................................14

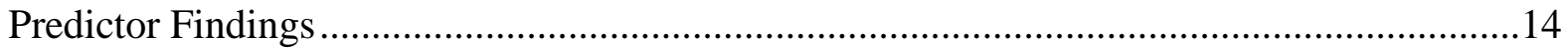

Training Observations Findings..........................................................................................16

BRITE Technology Assessment .......................................................................................21

Qualitative Training Observation Themes and Issues .............................................................22

Focus Group Interview Themes and Findings .........................................................................2

CONCLUSIONS AND RECOMMENDATIONS ……….......................................................

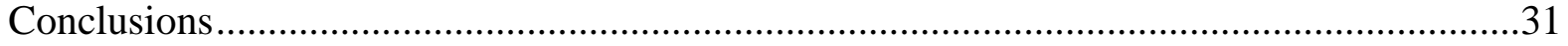

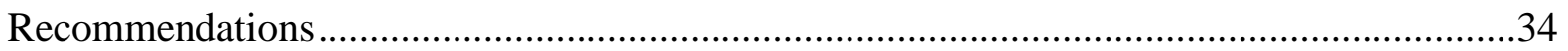

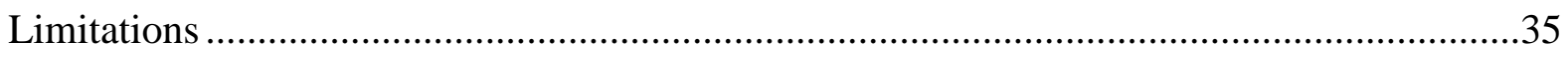

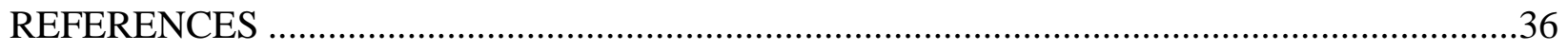

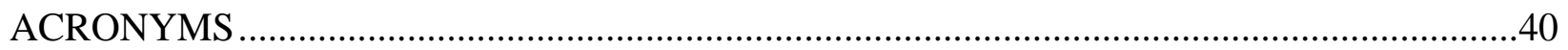

APPENDICES

APPENDIX A. BACKGROUND QUESTIONNAIRE ......................................................... A-1

APPENDIX B. TRAINING OBSERVATION FORMS …………….....................................

APPENDIX C. TRAINING CONFIGURATIONS ………………………………...............

APPENDIX D. FOCUS GROUP INTERVIEW PROTOCOLS ……………………............. D-1

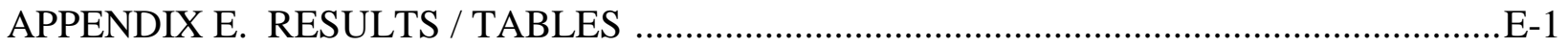


TABLES

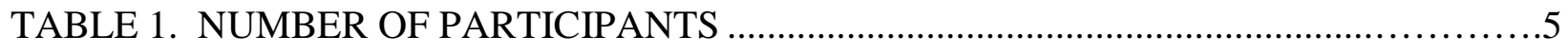

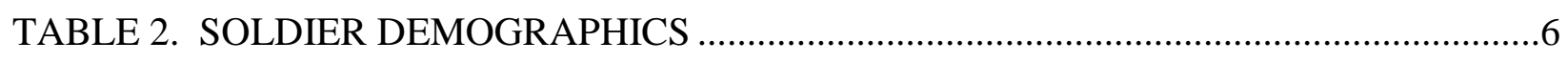

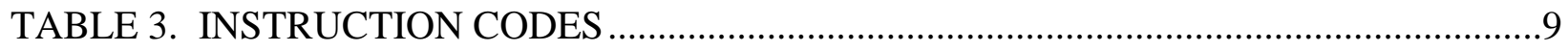

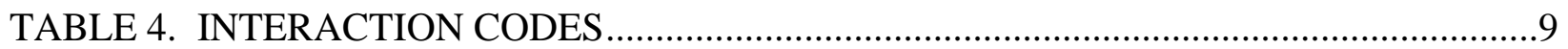

TABLE 5. TRAINER/INSTRUCTOR PRE- AND POST EVALUATION ROLE(S).................10

TABLE 6. TAILORED TRAINING STRATEGIES …………………………........................11

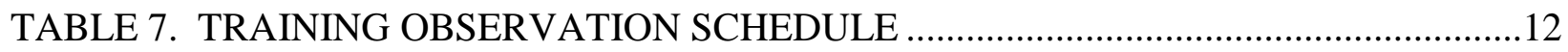

FIGURES

FIGURE 1. COMPARISON WITH SCHMIDT, HUNTER, AND OUTERBRIDGE (1986)

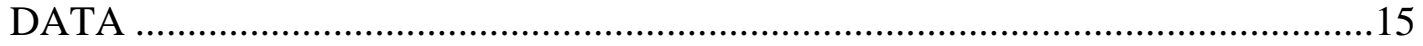

FIGURE 2. COMPARISON OF BRADLEY CONTROL AND BRADLEY BRITE COURSE

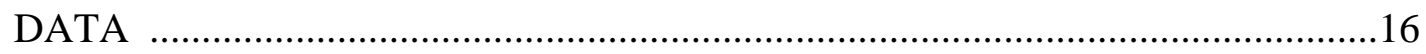

FIGURE 3. DIVIDED SMALL GROUP SETTING ……………………………...............18

FIGURE 4. FREQUENCY OF GROUP SETTING IN BRADLEY CONTROL AND BRITE

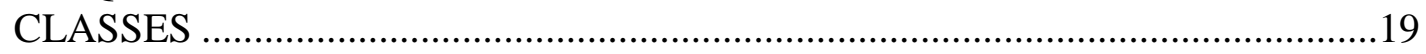

FIGURE 5. INSTRUCTOR INTERACTIONS IN BRADLEY CONTROL AND BRITE

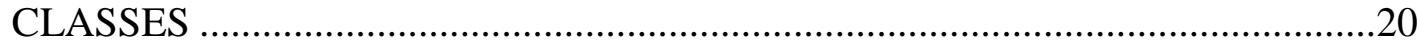

FIGURE 6. MODIFIED DIVIDED SMALL GROUP SETTING IN BRADLEY BRITE ..........21 


\section{Tailored Training in Vehicle Maintenance Courses}

\section{Introduction}

A central tenet within the Army Learning Concept 2015 (ALC 2015), according to U.S. Army Training and Doctrine Command (TRADOC) Pamphlet 525-8-2 (TRADOC, 2011), and Army Learning Model (ALM) is the need to transition to learner-centric methods and processes that develop critical competencies through rigorous, tailored, outcome-oriented learning experiences. The ALM described in the ALC 2015 also emphasizes the use of pretests and training assessments to effectively tailor training to individual Soldiers' needs as defined by their experiences and proven competencies (see TRADOC, 2011). While not dependent on any particular type of technology, the ALM recognizes the value of institutional training programs employing blended learning approaches incorporating virtual and constructive simulations, gaming technology, and other technology-delivered instruction to deliver the types of experiences needed to "...engage learners to think and understand the relevance and context of what they learn” as specified in the ALC 2015 (TRADOC, 2011, p.9). By emphasizing the use of pretests and assessments to identify individual learner needs and to effectively tailor training to meet those needs, the ALM has increased the need to identify and develop accurate, effective predictive measures of performance, as well as blended, learner-centric tailored training strategies and techniques.

Previous research conducted by the U.S. Army Research Institute (ARI) Ft. Benning Research Unit identified the learning contexts in which tailored training most often occurred and which tailored training strategies were most commonly employed in current Army courses (Dyer, Wampler, \& Blankenbeckler, 2011). The results of this effort showed that tailored training in the Army is most likely to occur in technical, functional courses where graduates must be proficient in clearly defined skills, based on specified performance standards, upon graduation. This research indicated that instructors in these courses often use small groups, typically comprised of four to five individuals, to more effectively tailor training to meet individual students' needs. It also found that one-on-one instruction was still the preferred method for training in practical exercises (PEs) (Dyer et al., 2011). However, direct observations of small groups in actual training settings, e.g., classrooms or hands-on PEs, or of critical training interactions, i.e. instructor-student, student-student, and student-instructor, needed to identify the exact tailored training strategies and techniques being employed was not possible in this effort (see Dyer et al., 2011).

An extensive review of published tailored training research by Schaefer and Dyer (2013) pointed out that Cohen (1994) found group interactions were impacted by both the perceived status of group members and the nature of the task or problem. In essence, the nature of a task or problem places greater or lesser emphasis on the unique skills and experiences of individuals within any group based on their relevance to a specific situation. Concurrently, the task or problem frequently limits or channels the type and flow of interactions within the group by its imposed structure. Therefore, it's easy to imagine how a group's internal interactions could be affected by having a recognized leader or "expert" within it or completing a task that physically separates members or portions of the group at various times. For example, in military settings, it's not uncommon to have situations where an instructor is actively working with one student on 
a problem or technical task while the remaining students are expected to follow along the best they can from largely passive observation positions. It's common for organizations to identify stronger, more skilled students early in training in order to have them act as informal peer instructors assisting the instructor in advancing the group's training through active problemsolving and student led exercises or, at a minimum, keeping other students engaged in constructive, engaging activities while they wait their turn. However, there has been little research focused on identifying the actual different tailored training strategies, e.g. scaffolding, backwards fading, or comprehension gauging, employed in these divided small group training settings based on interpersonal interactions or how the nature and frequency of these interactions subsequently affect student learning or task performance.

Efforts to identify more advanced students early in training in order to effect later peerto-peer learning strategies and exercises, or enhance student engagement in learning activities, highlights a need to develop or identify suitable predictive measures. Previous tailored training research conducted by ARI identified a number of behavioral dimensions that predict course performance in professional military courses and enable instructors to better distinguish between weak and strong individuals in time to address these individual differences during training. This research has shown that domain-specific, prior military knowledge is the best, most consistent predictor of later course performance (see Schaefer, Blankenbeckler, \& Lipinski, 2011; Schaefer, Blankenbeckler, \& Brogdon, 2011) when compared with other basic background dimensions, such as the number of deployments a Soldier had prior to training or the duration of their service in the Army.

As Schaefer and Dyer (2013) point out in their review of the tailored training literature, previous research (e.g. Schmidt, Hunter, \& Outerbridge, 1986; Chen \& Paul, 2003; Palumbo, Miller, Shalin, \& Steele-Johnson, 2005) has maintained that the relationship between experience and job performance can be direct or indirect depending upon opportunities to learn (i.e. job experiences) and the impact of other moderating variables, such as general mental ability (i.e. a measure of the capacity one has to learn). Generally, one would expect these moderating variables to have less of an impact if the relationship between experience and job performance is directly linked than if it's predominately indirect. Schaefer and Dyer (2013) concluded that this research has consistently shown that prior knowledge can frequently better predict performance in a narrow domain, such as typify the technical training found in Army Advanced Individual Training (AIT) programs, than general mental ability and job experience alone. However, these findings provide little practical guidance to Army training developers and instructors on how exactly to identify or develop effective predictive measures that could be efficiently used in actual training settings.

\section{Armored Vehicle Maintainer Training}

A practical example of the types of military training programs discussed previously are the Abrams tank (91 $\mathrm{A}^{1}$ ) and Bradley Fighting Vehicle (91M) maintainers' AIT courses executed by the Ordnance Training Detachment, 3-81st Armor Battalion (3-81st AR BN), at Fort Benning, GA. These courses are $14(91 \mathrm{~A})$ and $13(91 \mathrm{M})$ weeks in length with a maximum class size of 24

\footnotetext{
${ }^{1}$ 91A and 91M are the military occupational specialties (MOSs) for Abrams and Bradley maintainers, respectively.
} 
and 40 Soldiers, respectively. Both courses rely on small groups of four to five Soldiers during PEs and hands-on training, which, according to discussions with current training managers, constitutes about $80 \%$ of scheduled course time.

Soldiers are assigned to their training groups based on performance outcomes documented during the first two to three weeks of training, including physical fitness test performance, academic test scores, and instructors' subjective assessments. Using these criteria, the students determined to be "strongest" are designated as excellence in maintenance (EIM) Soldiers. While separate EIM groups are normally created in 91A classes, significant effort is made in $91 \mathrm{M}$ classes to balance high and low performers across assigned training groups. In this way, the stronger EIM Soldiers can help weaker students overcome problems during the $91 \mathrm{M}$ course and provide a peer leader or coaching resource for the instructors. The EIM group within each 91A class experiences an accelerated and more challenging training program, involving additional vehicle types and more advanced tasks that are not covered in the standard program of instruction (POI). However, 91A EIM students can be called upon by instructors to tutor or assist members of the remaining groups during training.

Additionally, the 91M course introduced a number of new instructional technologies in 2012 under the Blended Rotation Interactive Technology Environment (BRITE) initiative. A key component of this initiative was the use of a mobile smartboard for presenting training materials. Routinely referred to as the "mobile classroom trainer" (MCT), this technology extends the advantages of a classroom setting to other training environments, while providing instructors with an additional means for facilitating student learning. Additionally, a portable, head or structure mounted camera enables other Soldiers to "see" what the Soldier being trained sees or watch, from a neutral vantage point or the instructor's perspective, the Soldier's actions during PEs or other hands-on activities. This capability enables an instructor to overcome the physical limitations within the Bradley Fighting Vehicle (BFV), which normally allow at most two Soldiers within a group of four to actively participate in a hands-on training event or a PE at any one time. The smartboard/camera combination, comprising the MCT, enables all or groups of Soldiers to see the actions performed by the Soldier being trained, providing some familiarization and opportunities for vicarious or instructor facilitated learning prior to their rotation. Digitally videotaped student sessions can also be saved for either group or individual after action reviews (AARs) later in training. Finally, the MCT can be used for more traditional training purposes (e.g. show videos, use as a white board, show slides, present PEs) using content developed by the unit for this purpose.

Recent research relevant to examining the potential impact of the BRITE initiative on learning and student engagement involved pairs of students watching a tutoring session and simultaneously collaborating to solve a problem (see Chi, 2009; Craig, Chi, \& VanLehn, 2009). Based on Schaefer and Dyer's (2013) review, the results of this research showed that active observing was an effective learning process in these situations. As described by Craig et al. (2009), active observing reflects observing a demonstration, training event, video, etc. in a way that facilitates working with or engaging the training materials in a manner encouraging deeper cognitive processing. Craig et al. pointed out that the most effective means to achieve this outcome is to ensure students solve problems while observing, work in pairs rather than alone, 
and watch videos or, by inference, modeled training demonstrations or events involving highability, knowledgeable students.

\section{Problem Definition}

The intent of this research was to address gaps identified in previous research conducted on tailored training approaches and examine specific training issues raised by the 3-81st AR BN at Fort Benning, GA. As described earlier, these armor vehicle maintainers' AIT courses provided an excellent opportunity to examine how small groups function in technical military courses and the nature of tailored training strategies used by instructors in these settings. In addition, as these courses focus on unique technical skills required for maintaining critical combat resources, most Soldiers do not possess a substantial amount of prior domain-specific knowledge or skills before reporting for training. Therefore, prior military knowledge predictors that worked in previous research using graduates of prerequisite courses, such as the research by Schaefer, Blankenbeckler, and Brogdon (2011), are not appropriate for these training settings and require expanding the base of potential performance predictors. Working with $3-81^{\text {st }} \mathrm{AR} \mathrm{BN}$ leaders and training managers, the following objectives were identified for this research:

- Identify potential predictors of performance at different stages of training in the 91A and 91M AIT courses that will enable instructors to better identify strong and weak Soldiers.

- Examine small group processes in both courses to identify the nature and extent of tailored training, peer-to-peer interaction, and how tailoring varies with group composition.

- Examine the effectiveness and other impacts of the BRITE technologies (91M course only) employed by the 3-81st AR BN.

\section{Method}

This research was completed in two phases. During Phase 1, researchers assessed the utility of demographic characteristics, prior knowledge, and cognitive measures for predicting later performance in Abrams tank and BFV maintainers' training. Based upon training schedules and class availability, this data, as well as unit documented training outcomes, were collected from five consecutive 91A and three consecutive 91M classes. In Phase 2, researchers expanded this effort by collecting data on instructional methodologies and techniques, tailored training strategies, and student performance and interactions through direct observation of scheduled training and unit provided training summaries and records. Training was observed during three nonconsecutive one-week periods, interspersed over the duration of the course, beginning a week after assignment of Soldiers to their training groups. Following the completion of training observations for each class, focus group interviews were conducted with the participating students and instructors.

Multiple meetings with the Ordnance Training Detachment (OTD), 3-81st AR BN, provided a practical overview of 91A and 91M training and training challenges, as well as several opportunities to informally observe hands-on training in small group settings at different points in the courses. Feedback and information provided by OTD leaders, instructors, and training developers highlighted critical graduation requirements and training priorities, provided 
practical background information on the most common techniques used by instructors in small group settings, and reviewed standards and procedures for course examinations and practical evaluations. Additionally, these discussions were critical to understanding the scope of the BRITE initiative and the milestones associated with its planned rollout.

It is important to note that the BRITE class identified for this research effort was the first class where instructors had complete access to the MCT. At this stage, the amount of training content on the single, operational MCT was limited to a few embedded, basic automations and schematic exercises. Some instructors had also received a basic familiarization orientation on the equipment's operation and capabilities prior to the start of this research and were expected to pass on this knowledge to other instructors. Unit leaders encouraged the instructors to explore the MCT's range of capabilities as they saw fit and make extensive use of the head-mounted camera link whenever possible. The use of the MCT was limited to the 91M test class during this research effort. There were no other limitations imposed by unit leaders on the MCT's use by instructors. However, it remains important to note that there was only one operational MCT available for use during this research effort.

\section{Participants}

A total of 164 Soldiers participated in Phase 1 of this effort. As can be seen in Table 1, the level of participation during Phase $2(n=69)$ was limited to the number of small training groups that could be directly observed by qualified subject matter experts (SMEs) from the research team. In the case of 91A classes, smaller class sizes allowed each of the resulting four training groups of four to five students to be observed. In the case of $91 \mathrm{M}$ classes, it was not possible to directly observe each training group. Four groups were selected for observation based on the number of available qualified SMEs and discussions with each class lead instructor regarding the most appropriate groups to observe in order to gain a subjectively accurate picture of the full range of instructor styles and student potential within a typical class. Over the period of observations, some instructors and Soldiers moved between groups, but efforts were made to consistently observe the four primary groups for all three observation periods. The number of Soldiers in the observed groups varied from three to five at a time, with four Soldiers per group being the predominant composition (i.e. $75 \%$ of groups observed).

Table 1.

\section{Number of Participants}

\begin{tabular}{|lcccc|}
\hline Course & Classes & $\begin{array}{c}\text { Observed } \\
\text { Groups }\end{array}$ & Soldiers & Instructors \\
\hline 91A & & & & \\
\hline Phase 1 & 5 & N/A & 81 & N/A \\
\hline Phase 2* & 2 & 8 & 35 & 16 \\
\hline $91 \mathrm{M}$ & & & & \\
\hline Phase 1 & 3 & N/A & 83 & N/A \\
\hline Phase 2* & 2 & 8 & 34 & 8 \\
\hline
\end{tabular}

*Note: Observed groups are subsets of final two classes participating in Phase 1; regarding the 91A instructors observed, eight were hull instructors and eight were turret instructors. 
At the beginning of each participating class, the training units provided the research team with basic demographic data on all participating Soldiers. This data is summarized in Table 2 and indicated there were no statistically significant differences in the general make-up of the classes selected for this effort. Table 2 identifies non-normally distributed variables (i.e., rank and education) by the most frequently occurring value (mode). General Technical (GT) scores and ages are represented by their mean values. Demographic information was not provided for Abrams Course 91A04A. In the judgment of the instructors assigned to these classes, the rank and age of the Soldiers participating in this research were typical of past Abrams and Bradley courses. Data for all participating Abrams and Bradley Soldiers were compared to archival data from past courses in terms of GT Scores and Go Percent (defined as the total number of handson evaluations on which a 'Go' was achieved, divided by the number of total evaluations conducted on a given Soldier). A similar pattern emerged for both the Abrams and Bradley courses in that, while GT scores were similar in the participating and prior courses, the percentage of "Go" ratings was higher in the participating courses. However, when the data is examined in greater detail, it appears that this difference was more a function of smaller standard deviations than a real appreciable difference in performance (see Table E-1, Appendix E).

Table 2.

\section{Soldier Demographics}

\begin{tabular}{|ccccc|}
\hline $\begin{array}{c}\text { Course* } \\
\text { Class }\end{array}$ & $\begin{array}{c}\text { Rank } \\
\text { (Mode) }\end{array}$ & $\begin{array}{c}\text { Age } \\
\text { (Mean) }\end{array}$ & $\begin{array}{c}\text { GT Score } \\
\text { (Mean) }\end{array}$ & $\begin{array}{c}\text { Education** } \\
\text { (Mode) }\end{array}$ \\
\hline 91A & & & & \\
\hline 04A & N/A & N/A & N/A & N/A \\
\hline 05A & PVT & 23 & 107 & HSG \\
\hline 06A & PVT & 22 & 98 & HSG \\
\hline 07A & PVT & 22 & 110 & HSG \\
\hline 08A & PVT & 22 & 103 & HSG \\
\hline 91M & & & & \\
\hline 04M & PVT & 23 & 103 & HSG \\
\hline 05M & PVT & 21 & 102 & HSG \\
\hline 06M & PFC & 21 & 106 & HSG \\
\hline
\end{tabular}

*Note: The shaded classes participated in both Phase 1 and Phase 2. The remaining classes only participated in Phase 1.

**Note: HSG=high school graduate.

\section{Data Collection Instruments}

Predictor measures. As discussed earlier, a review of published literature was conducted to provide a foundation for this research and the development of all data collection instruments. Specific attention was given to previous research on armor vehicle training (e.g. Drucker \& O'Brien, 1982; Roth, Cherry, \& Strasel, 1988), predictive performance tests (e.g. Schaefer, Blankenbeckler, \& Lipinski, 2011; Schaefer, Blankenbeckler, \& Brogdon, 2011; Heuckeroth \& Smith, 1990), and conducting training observations in field settings (Leibrecht, Goodwin, Wampler, \& Dyer, 2007). Based on this review and discussions with unit leaders and 
SMEs, it became readily apparent that our most viable options for developing additional predictive measures would need to focus on cognitive and general domain related skills beyond the unit's current reliance on GT scores ${ }^{2}$ and initial test results.

Reviewing information and feedback provided by unit SMEs, the established POI, current training support packages (TSPs), and our initial, informal training observations, it became apparent that a few basic skills seemed centrally prevalent throughout the training. Based on the TSPs' and instructors' consistent emphasis on the ability of Soldiers to effectively execute complex checklists integrating information from multiple technical manuals and system (i.e. electronic and mechanical) schematics, a few basic abilities seemed to consistently differentiate stronger students from weaker ones early in training: (1) able to follow detailed instructions that set conditions on required actions or decision options (i.e. integrative processes), (2) able to accurately remember and reference blocks of information or visual images from multiple manuals (i.e. working, visual memory), and (3) able to correctly interpret and follow schematic diagrams (i.e. spatial scanning).

Reviewing established, reliable cognitive tests that paralleled these requirements and that could be easily administered within the time allotted for Phase 1 assessments, the research team identified three standardized measures available through the Education Testing Service (ETS), as meeting our needs for this effort. The team secured an agreement from ETS to use the following tests from their 1976 kit (see Ekstrom, French, Harman, \& Derman, 1976) for this research effort: ${ }^{3}$

- “Following Directions.” Soldiers were given a complex set of instructions, then asked to identify the points in a matrix of letters in response to 10 questions. Soldiers were given 7 minutes to complete the measure. [integrative processes]

- "Building Memory.” Soldiers were asked to identify the location of 12 different buildings on a map without access to the original map. Soldiers were given 4 minutes to select the correct location for each of 12 buildings from five options reflected on a copy of a street map without any buildings, after being given 4 minutes to study the original map with all 12 buildings in place. [visual memory]

- “Choosing a Path.” Soldiers were asked to identify which of a network of lines (similar to that found in electronic schematics) fulfilled the specified requirements to start and finish in the same block while passing through a circle at the top of the drawing and following a set of imposed movement restrictions. Soldiers were given 7 minutes to complete 16 items. [spatial scanning]

\footnotetext{
${ }^{2}$ The GT score is a composite score derived from the sum of Word Knowledge and Paragraph Comprehension (VE) and Arithmetic Reasoning (AR) sections of the Armed Services Vocational Aptitude Battery (ASVAB). In order to enter $91 \mathrm{~A}$ or $91 \mathrm{M}$ training, Soldiers must have a minimum mechanical maintenance (MM) score of 99 or a minimum MM of 88 combined with a minimum GT score of 92.

${ }^{3}$ While ETS allowed the use of these tests for this research effort, copies of the tests cannot be provided in this report. Any requests for copies or use of these or any ETS tests must be addressed to ETS through their offices in Princeton, NJ.
} 
As discussed earlier, Schaefer and Dyer (2013) found that published research consistently indicated prior knowledge could frequently better predict performance in a narrow domain, such as found in the armor vehicle maintainers' technical training, than general mental ability and job experience alone. Given unit feedback indicating prior experience using digital technologies, including personal computers and laptops, and conducting mechanical vehicle servicing and repairs were most relevant to Soldiers excelling in the technical skills emphasized during armor vehicle training, a general background questionnaire was created to measure the degree to which Soldiers entered training with these experiences. Additionally, course instructors emphasized that having prior experience and knowledge of basic electrical processes and schematics enabled Soldiers to excel in the early portion of training. Therefore, the questionnaire included three items developed by an experienced unit instructor that tested incoming Soldiers' prior knowledge of basic electrical circuits and symbols. A copy of this questionnaire is provided in Appendix A.

Training observations. Previous research conducted by Liebrecht, Goodwin, Wampler, and Dyer (2007), Dyer, Singh, and Clark (2005), and Sanders (2001) showed that focused training interactions could be reliably recorded in real-time using trained SMEs. Additionally, data gained during direct observations of training interactions reduced the potential for over relying on self-reported subjective assessments gathered from questionnaires and interviews. The instruments and strategies employed in this earlier research provided a sound foundation for developing similar instruments for recording data on the various types of interactions occurring during training.

Based on the objectives of this effort, it was essential to document the type and frequency of training related interactions occurring between instructors, Soldiers, and peers in various training settings in order to identify the nature and extent of tailored training, peer-to-peer interaction, and variations in tailored training strategies used by the instructors. The observation instrument developed for this effort was comprised of four parts and is provided in Appendix B. While Part I gathered information about the initial training setting and purpose at the start of the day's observations, Part II provided detailed information about instructors' training styles and the training interactions between instructors and Soldiers during the observation periods. Part III captured data about the nature of activities and interactions occurring before and after observed practical evaluations. Finally, Part IV provided the SME observers an opportunity to assess the entire day's training and to summarize end-of-day conclusions based on their observations.

Based on preliminary observations of training and discussions with instructors and training managers, it became apparent that the nature of instructor styles and degree of interactions differed significantly depending upon the group size. During the course of training, the size of the group being instructed varied from the entire class to the defined small groups to multiple groups (two or more) throughout any given day. Thus, Part II of the observation instrument allowed observers to group their observations based on changes from one group size to another. Since previous discussions with unit training managers indicated about $80 \%$ of all training was designed to be executed in designated small training groups of four to five Soldiers, it was decided that individual observers would be assigned to collect data on only one of the defined small groups, regardless of the group size. These measures also supported later analyses comparing changes in instruction styles (see Table 3) and interaction patterns across different training group settings, as well as providing insights into the degree to which efforts to move to 
more learner-centric instructional styles from more traditional, instructor-centered or platform instructional practices, in accordance with the ALM, were impacting instructional strategies.

Table 3.

\section{Instruction Codes}

\begin{tabular}{|l|l|}
\hline Codes & Instructional Styles \\
\hline D1 & Demonstration \\
\hline D2 & Guided Demonstration \\
\hline GD & Guided Discussion \\
\hline RC & Review/reinforce Content \\
\hline L1 & Lecture \\
\hline ID & Informal Discussion \\
\hline PS & Problem Solving \\
\hline Ot & Other \\
\hline
\end{tabular}

Following methods validated in previous research by Liebrecht, et al. (2007), observers recorded the number of times they observed the instructor and Soldiers in their assigned group engage in each of the interaction behaviors identified in Table $4 .{ }^{4}$

Table 4.

\section{Interaction Codes}

\begin{tabular}{|c|c|}
\hline Trainer/Instructor Interaction Codes: & Student Interaction Codes \\
\hline A-Asks question & $\mathbf{A}-$ Asks question of Instructor \\
\hline $\mathbf{P}$ - Provides feedback on action/performance & $\mathbf{Q}$ - Answers or responds to a question from Instructor \\
\hline $\mathbf{R}$ - Restates or refocuses the question/problem & $\mathbf{L}$ - Takes leadership role or initiative (w/o being directed) \\
\hline S - Directly answers the student’s question & $\mathbf{O}$ - Offers/provides help or support to peer(s) \\
\hline E - Provides additional examples & A_s - Asks question of a peer \\
\hline C - Reviews previous/related content & Q_s - Answers or responds to a question from a peer \\
\hline $\mathbf{L}$ - Designates a task or group leader & H - Accepts help/support from peer(s) \\
\hline $\mathbf{T}$ - Directs a task & $\mathbf{T}$ - Completes/attempts a directed task \\
\hline Ot - Other & Ot - Other \\
\hline
\end{tabular}

Instructors also indicated during initial discussions with research team members that they usually worked directly with one or two students at a time in small group settings due to the physical restrictions of the equipment or the demands of the task being trained. Therefore, a variation of the original Part II form was developed, Part IIa, to gather detailed data about the instructional styles used and interactions occurring in this unique training setting. This setting required instructors to divide their attention between the student(s) directly engaged in the learning activity and the remainder of the group who observed the training, as best they could,

\footnotetext{
${ }^{4}$ Due to positioning of the observers, it was easier to determine when a given student asked a question or responded to a question than it was to determine if the question had been addressed to the instructor (Student Interaction Code A) or a peer (Student Interaction Code A_s). A similar problem arose in distinguishing responses to instructor questions (Student Interaction Code Q) from responses to peer questions (Student Interaction Code Q_s). Therefore, more global categories of 'Asks questions' and 'Answers or responds to question' were used. (See Tables E-10, E-13, and E-16 in Appendix E for examples.)
} 
while waiting for their turn. Thus, observers needed to simultaneously attend to the instructor and student(s) completing the hands-on training event and the level of student engagement occurring outside of the instructor and student(s) comprising the instructional focal group.

Due to the normally high level of instructor-student interaction in the one-on-one or oneon-two instructional group and the physical impossibility of placing an observer in a position to accurately document the nature of the interactions occurring within both subgroups without disrupting training, observers were directed to focus on changes in the instructional strategies used by the instructor with the focal training student(s) and training related interactions among the observing students. Illustrations of the typical physical configurations of equipment and personnel during the training observations are provided in Appendix C.

Similar to what is found in many other military training settings, initial observations indicated that Soldiers engaged in a great deal of social interactions during "dead time" that were unrelated to training activities. ${ }^{5}$ Therefore, it was determined that data collection during the training observations would focus only on interactions clearly related to training content and activities. This allowed us to also focus our observations on how training was being tailored to different conditions and student needs, as well as key training outcomes of interest to the unit. As described earlier, Part III of the observers' package provided a means for collecting data on instructor roles (listed in Table 5) and the frequency of student peer coaching or instruction (e.g., one-on-one, small group (3-5 Soldiers), etc.) interactions occurring before and after the practical evaluations (see Appendix B).

Table 5.

\section{Trainer/Instructor Pre- and Post Evaluation Role(s)}

\begin{tabular}{|l|l|}
\hline Code & Trainer/Instructor Roles \\
\hline D1 & Demonstration \\
\hline D2 & Guided Demonstration \\
\hline GD & Guided Discussion \\
\hline RC & Review/reinforce Content \\
\hline L1 & Lecture \\
\hline ID & Informal Discussion \\
\hline PS & Problem Solving \\
\hline Ot & Other \\
\hline
\end{tabular}

This data also provided insights into non-directed student-led and peer-to-peer interactions aimed at ensuring group and class members were prepared for pending evaluations. It also provided a means for documenting unstructured, student generated or instructor initiated AARs following the completion of evaluations throughout the day.

Finally, Part IV of the observation form provided a means for capturing the SMEs' overall impressions of the training interactions they observed throughout the day. This was

\footnotetext{
5 "Dead time" is a colloquialism referring to periods of inactivity when individuals are left to their own discretion while waiting for their turn in an activity or for a change in events requiring their involvement.
} 
intended to provide an ongoing, general assessment of training outcomes central to our objectives. Key among the end-of-day assessments made by the SMEs was to rate the relative frequency they observed different tailored training strategies, described in Table 6, being employed by instructors during the training day (see Appendix B).

Table 6.

\section{Tailored Training Strategies}

\begin{tabular}{|c|c|c|}
\hline Strategy & Description & $\begin{array}{c}\text { Primary } \\
\text { Reference(s) }\end{array}$ \\
\hline Scaffolding & $\begin{array}{l}\text { Instructor enables the student to master a task or concept } \\
\text { that the student is initially unable to grasp on his/her own } \\
\text { by temporarily modeling or providing prompts, cues, and } \\
\text { feedback on those skills or steps that are currently beyond } \\
\text { the student's demonstrated capability. Once the student } \\
\text { begins to show he/she can accomplish the steps or task, } \\
\text { the instructor withdraws help (often referred to as } \\
\text { "fading" or removing the scaffolding) to allow the } \\
\text { student to proceed on his/her own. }\end{array}$ & VanLehn (2011) \\
\hline $\begin{array}{l}\text { Backwards } \\
\text { Fading }\end{array}$ & $\begin{array}{l}\text { Instructor provides a complete demonstration of the task } \\
\text { or procedure, followed by a progressive reduction of } \\
\text { instructor guidance and an increasingly autonomous role } \\
\text { by the student in subsequent repetitions of the task. }\end{array}$ & $\begin{array}{l}\text { Renkl, Atkinson, } \\
\text { Maier, \& Staley } \\
\text { (2002) }\end{array}$ \\
\hline $\begin{array}{l}\text { Didactic / } \\
\text { Lecture }\end{array}$ & $\begin{array}{l}\text { Instructor provides information with little to no } \\
\text { opportunity for student/instructor interaction or } \\
\text { discussion beyond the clarification of presented facts or } \\
\text { points; student largely passive. }\end{array}$ & Chi \& Roy (2010) \\
\hline $\begin{array}{l}\text { Comprehension } \\
\text { Gauging }\end{array}$ & $\begin{array}{l}\text { Instructor confirms students are attending to and } \\
\text { following the presented content; may or may not involve } \\
\text { a brief knowledge check of recent content. }\end{array}$ & $\begin{array}{l}\text { Chi, Siler, Jeong, } \\
\text { Yamauchi, \& } \\
\text { Hausmann (2001); } \\
\text { Chi (2009) }\end{array}$ \\
\hline $\begin{array}{l}\text { Simple } \\
\text { (Yes/No) }\end{array}$ & $\begin{array}{l}\text { Simple and direct assessment of or reaction to the } \\
\text { accuracy of a student's answer, explanation, statement, } \\
\text { etc., with no further elaboration. }\end{array}$ & $\begin{array}{l}\text { Graesser \& Person } \\
\text { (1994) }\end{array}$ \\
\hline Other & $\begin{array}{l}\text { (Open ended category to provide SMEs an opportunity to } \\
\text { identify other tailored training strategies they saw } \\
\text { employed during their observations) }\end{array}$ & \\
\hline
\end{tabular}

Frequency ratings were based on a four-point scale ranging from seldom/rarely (1) to regularly (3) observed, with an additional rating point for "not observed” (4) (see Appendix B).

During Phase 2 of this research, three one-week periods of training observations were completed during each of four identified classes, i.e. the latter two classes for each course (i.e. 91A and 91M) participating in Phase I. Researchers worked with unit leaders and SMEs to identify three one-week periods of training that would provide the broadest and most equivalent sampling of critical skills training across the identified classes. Based on discussions with unit 
leaders and training developers, each of the three selected observation periods covered generally equivalent blocks of training, in terms of training emphasis and priority, task complexity, and resource demands. Additionally, each of the practical evaluations covering material from the selected training periods were observed, even if they occurred on a day following the scheduled observation periods. In the case of $91 \mathrm{M}$ training, the first class observed acted as a control, while the second provided a setting for observing and assessing the impact on training of employing BRITE technologies. Observations were delayed by one week after the start of the course to allow the groups and instructors a chance to become familiar with each other.

Table 7 depicts the final training observation schedule. The lengthy period not observed between the second and third observations for the 91A classes was needed to observe the two different phases of the course, hull and turret training, which were conducted by different groups of instructors. All observations were completed 10 days before the planned graduation date.

Table 7.

\section{Training Observation Schedule}

\begin{tabular}{|c|c|c|c|c|c|}
\hline Course & $1^{\text {st }}$ Observation & Not Observed & $2^{\text {nd }}$ Observation & Not Observed & $3^{\text {rd }}$ Observation \\
\hline 91A \#1 & \multirow{4}{*}{$1 \mathrm{wk}$} & $1 \mathrm{wk}$ & \multirow{4}{*}{$1 \mathrm{wk}$} & $6 \mathrm{wks}$ & \multirow{4}{*}{$1 \mathrm{wk}$} \\
\hline 91A \#2 & & $1 \mathrm{wk}$ & & $6 \mathrm{wks}$ & \\
\hline $91 \mathrm{M} \# 1$ & & $2 \mathrm{wks}$ & & $1 \mathrm{wk}$ & \\
\hline $91 \mathrm{M} \# 2$ & & $1 \mathrm{wk}$ & & $1 \mathrm{wk}$ & \\
\hline
\end{tabular}

Focus group interviews. Protocols were developed for separate focus group interviews with Soldiers and instructors following the completion of training observations (at the end of Phase 2). Given the goals of this effort, these interviews were designed to supplement data collected through the training observations by focusing on the effectiveness of training, identifying various techniques used to tailor training to individual Soldier's needs, gaining insights into the degree to which the unit's efforts to fulfill the vision described in the ALM were successful, and gauging reactions to the employment of BRITE technologies during training. The research team recognized that, based on previous field research experiences, interviewers might have to select which questions to ask during the course of the discussions based on available time (no more than 1 hour for each interview session) and level of discussion. Therefore, the questions were listed in order of priority with critical questions, essential for gathering data needed for the planned analyses, further highlighted in bold font. Copies of the complete interview protocols are provided in Appendix D.

Soldier focus group interviews. The Soldier interviews sampled their reactions to the training and instruction they received, gathered feedback on the course content and exercises, and, if in the 91M class with access to the BRITE technology, sampled reactions to the technology and how it was employed during the course. Additionally, Soldiers were provided an opportunity to share their ideas regarding the course in general and applications of technology specifically. Accordingly, the interview protocol was divided into four sections: (1) Small Group Experience, (2) Course Content, (3) BRITE Technology, and (4) Recommendations. 
Interviews were conducted in the same groups of three to five Soldiers in which Soldiers were assigned for training. The assigned observer, who was already familiar with the training the group received, the nature of informal interactions within the group, and the Soldiers within the group, conducted the interview for each training group. These Soldier focus group interviews were conducted at the end of the third observation period with each class.

Trainer/instructor focus group interviews. As described earlier, the focus group interviews with instructors were designed to gather additional insights on the frequency and impact of tailored training strategies employed during the just completed classes. Information was also collected on the instructors' views about the designation of EIM students and, if applicable, the use of BRITE technologies and their respective impacts on Soldier engagement and performance. Accordingly, the interview protocol was divided into four sections: (1) Small Group Processes, (2) Tailored Training, (3) BRITE Technology, and (4) EIM Group.

Instructors were interviewed in one of three one-hour sessions for each of the two observed classes for a total of six interview sessions. Four instructors were interviewed at the end of the third observation period for each of the two 91M classes. Taking into account the fact that instructors focusing on Abrams hull maintenance completed their training by the end of our second observation period and did not conduct any training during the remainder of the course, two separate interview sessions were conducted for each 91A class. The four "hull" instructors were interviewed following the second observation period of each class and the four "turret" instructors were interviewed after the third observation periods.

\section{Results}

\section{Analytic Approach}

Quantitative data provided by the unit included basic demographic information maintained in their training records, documented test and evaluation results, and final course dispositions, i.e. graduate, recycle, or restart. Additional data regarding the amount of relevant general mechanical and electrical knowledge, skills, and experiences they had upon entering AIT was provided by the participating Soldiers in response to the background questionnaire (see Appendix A). This data was further augmented by the results from the standardized ETS tests described earlier, as well as data gathered during the training observations (see Appendix B).

All quantitative data were entered in an interface designed to streamline the data entry and to catch common data entry errors, such as out of range values due to typos, inadvertent transpositions, etc. The completed data entries were reviewed by two members of the research team and then transferred to the IBM SPSS Statistics program (v 19; 2010) for analyses. Separate databases appropriately reflecting systematic differences in the quantitative data from the predictor tests and training observations were created. In SPSS, the data were further checked for outliers and other types of anomalous responding before the planned analyses were performed. Once all data entries were verified and a few entry inconsistencies resolved, basic descriptive statistics were calculated using the data provided by the units (see Table 2) and the participants’ responses from the background questionnaire. 


\section{Data Screening and Scale Constructions}

All variables were examined both descriptively and graphically. When a decision was made to exclude a variable from further analysis, a reason for that exclusion was given. If no individual item level problems were found, Cronbach's alphas were computed to assess scale reliability. Unless removing an item resulted in an improvement in Cronbach's alpha by 0.10 or more (e.g., the scales Cronbach's alpha would increase from .80 to .90), the item was not removed. Unless otherwise stated, all items within a given scale were retained.

Background questionnaire. This instrument elicited 20 potential responses via 8 questions. An item-level analysis quickly revealed that questions asking respondents to indicate how recently they had engaged in the identified training-relevant activities (i.e., maintained a vehicle) reduced the Cronbach's alpha to unacceptable levels. Therefore, all such questions were excluded. This reduced the number of data points from 20 to 16, but yielded a robust Cronbach's alpha of .92 (see Table E-2, Appendix E).

No item-level problems emerged during the analysis of the three questions assessing Solders' prior knowledge of basic electrical processes and schematics. The overall Cronbach's alpha (.86) would not have been improved by removing any items within these questions. Therefore, all items were retained. (See Table E-3, Appendix E)

\section{Predictor Findings}

The first objective of this research was to identify potential predictors of performance at different stages of training in the 91A and 91M AIT courses to enable instructors to better identify stronger and weaker students. However, it quickly became apparent that the performance criterion (i.e. Go/No Go on various test events) was functioning similarly to single test items. That is, there was insufficient variance on the stand-alone test events to enable robust correlations with the predictor measures. Therefore, a more global measure of performance was calculated and used in this analysis. For each Soldier, a summary 'Go Percent' statistic was computed by dividing the total number of 'Go' ratings achieved by the total number of test events. For example, if Soldier X achieved 30 'Go's out of 50 test events, the Soldier would have a Go Percent of 60.

Three different regression models were computed: one for Abrams 91A and two for the Bradley 91M AIT courses. The 91A model was based on Soldier data from 5 classes (see Table 2 for details). The two Bradley regression models were based on 2 classes (04M and 05M, acting as Control classes reflecting established training conditions) and 1 class (06M, acting as a Test class), respectively. The computation of separate regression Bradley models was necessitated by the implementation of the BRITE technology in the 06M class.

Abrams regression model. Upon inspecting the correlation matrix (see Table E-4, Appendix E) for the six predictor and one criterion variables, three things became apparent. First, the only predictor statistically related to performance was the prior knowledge measure $(r$ $=.22, p<.05$ ). Second, the prior knowledge measure was more correlated with GT scores and 
the Experience Index than the three ETS measures. This also held for the remaining two regression models. Third, the pattern among Go Percent, GT Score, Experience Index, and Prior Knowledge Index replicates a well-known performance model developed by Schmidt, Hunter, and Outerbridge (1986), repeatedly supported in other Army course contexts (Schaefer, Blankenbeckler, \& Lipinski, 2011). Figure 1 illustrates the comparison of results from the original work by Schmidt et al. and that from our analysis of Abrams training. ${ }^{6}$

Schmidt, Hunter, \& Outerbridge (1986)

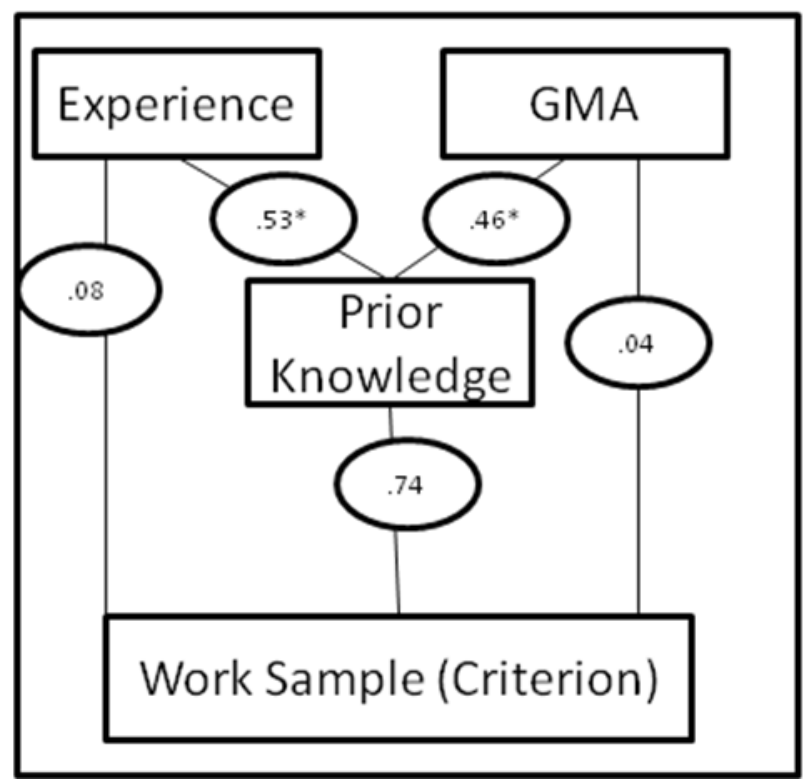

Abrams

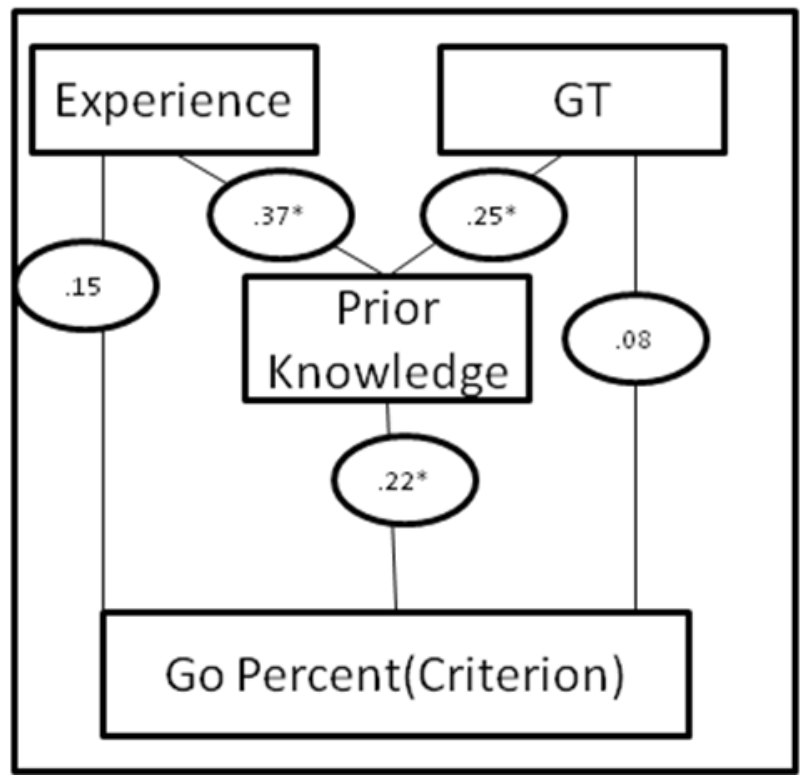

Figure 1. Comparison with Schmidt, Hunter, and Outerbridge (1986) data $(N=1,474)$. (Note.* $p$ $<.05)$

Before proceeding, a few comments comparing the left and side panels of Figure 1 are in order. In general, the correlations are much higher in Schmidt et al.'s research than we found for Abrams training. There are at least three reasons for this. First, Schmidt et al.'s research is (as is noted below the figure) based upon almost 1500 individuals, while our results are based on data collected from less than 200 Soldiers. The remaining two reasons revolve around the relationship between prior knowledge and the criterion. Namely, the prior knowledge measure used by Schmidt et al. involved generating a large number of items and empirically downselecting so that only the most predictive items were retained. This requires significant resources which were not available for this research. Third, the criterion in our research was dichotomous in nature (Go/No Go) which, through restriction of range, results in attenuated correlations. Since only one variable (prior knowledge) significantly predicted the performance criterion, the resulting regression model consisted of a simple correlation.

${ }^{6}$ Given that the Prior Knowledge measure was more correlated with GT Scores and Experience Index than the ETS tests for all three regression models, the discussion of variables in the remaining regression models is confined to the four variables represented in the right hand panel of Figure 1. This can be further justified on the grounds that GT Score is arguably a proxy for general mental ability (Jensen, 1998) and that the predictive power of GMA often swamps that of specific (i.e., more narrow) tests (Thorndike, 1985). 
Bradley regression models. Examination of the correlation matrix for the two Bradley Control classes (see Table E-5, Appendix E) echoed the trends found by Schmidt et al. and our previous analysis of Abrams training. For the most part, experience and general mental ability (as measured by GT score) impacted performance indirectly via their relationship with prior knowledge. Once again, prior knowledge was the most direct, powerful predictor of performance. ${ }^{7}$ However, the correlation matrix for the Bradley BRITE course (see Table E-6, Appendix E) looked markedly different.

Figure 2 illustrates the comparison of our results from the Bradley Control and BRITE classes. The most obvious difference between the datasets is that the correlations in the BRITE condition are noticeably smaller and, in the case of experience with performance, even negative. In essence, the impact of salient individual differences upon performance was lessened in the case of prior knowledge and general mental ability or even to some extent reversed in the case of experience. This suggests that individuals with less experience, prior knowledge, and general mental ability were somehow benefitting more from the use of the BRITE technologies-a point which will be examined further in our assessment of the impact of BRITE technology. The main conclusion for now, however, is that prior knowledge is the most proximate, and therefore most useful, predictor of course performance.

Bradley Control

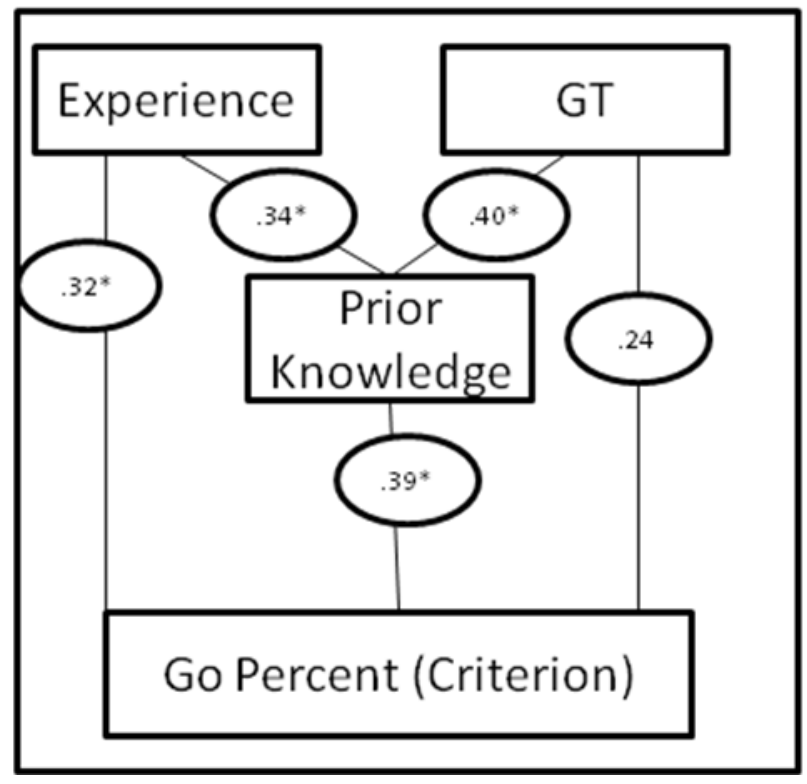

Bradley BRITE

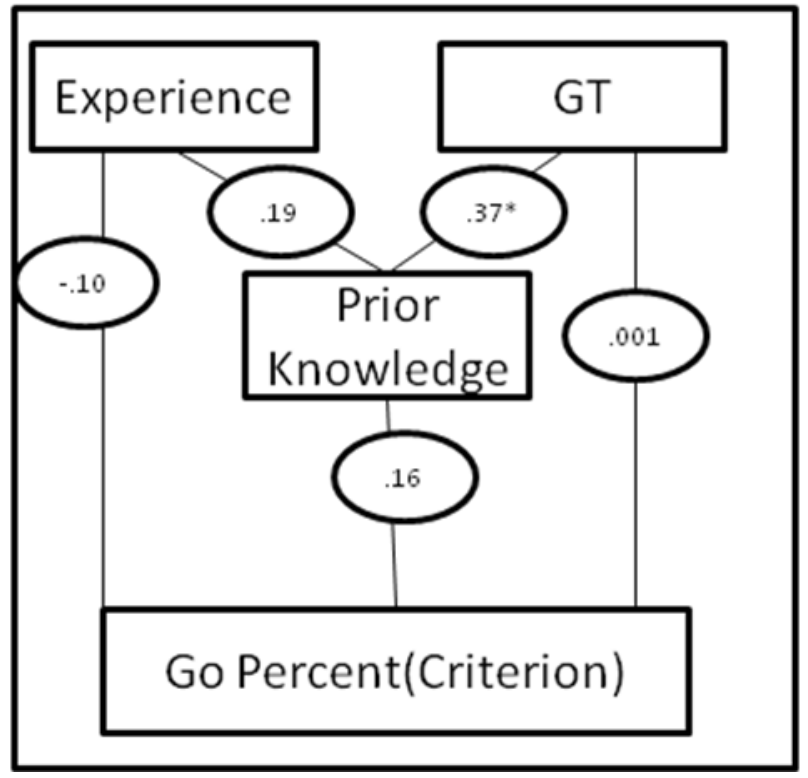

Figure 2. Comparison of Bradley Control and Bradley BRITE course data. (Note. ${ }^{*} p<.05$ )

\section{Training Observations Findings}

The training observation methodology we employed, as described earlier in this report, yielded a wealth of data. As can be seen in the information summarized by the tables provided in Appendix E, we observed 977 instances of training in various group settings, i.e. entire class,

\footnotetext{
${ }^{7}$ Although not the only significant predictor; note the significant correlation between experience and performance.
} 
half class, large group, small group, and divided small group. Within these settings, we collected data from 460 instructor interactions and 11,672 student interactions.

The second objective of this research was to examine small group processes to identify the nature and extent of tailored training, determine the frequency of peer-to-peer training interactions, and determine if, and how, tailoring varied with group size. Given the nature of the small group training we observed and the unit's interest in impacting the level students were engaged during training when not performing tasks, our analyses focused on what we termed a 'divided small group'. This setting was of major interest because (a) it was the most commonly used (and hence seen as effective) by the course instructors, ${ }^{8}$ (b) it had aspects of both a one-onone tutorial as well as a small group tutorial, and (c) involved hands-on procedural learning. This last point is of particular interest, as previous tailored training research has largely focused on cognitive tasks (see Schaefer \& Dyer, 2013).

While a few classes were observed as they watched a training video and worked in the computer lab, no data was collected during classroom training during this effort. Nearly all observed training was either conducted on the actual vehicles or in a Hands-on-Trainer (HOT). ${ }^{9}$ The M2/M3 A2 Bradley Operation Desert Storm (ODS) and the M1A2 Abrams System Enhanced Package (SEP) HOTs are full-scale replicas of the turret and portions of the driver's compartments of their respective vehicles (see Appendix $C$ for pictures of each HOT from Department of the Army (DA) Pamphlet 350-9 [DA, 2010]). Used to train Soldiers in maintenance and troubleshooting tasks, both HOTs have rotating turrets and main guns that elevate. However, these functions operate at slower speeds and with instructor override and emergency motion cut-off switches for safety. Both HOTs have stations that allow instructors to run lessons replicating various vehicle malfunctions and to track students' progress in following proper troubleshooting procedures. Computer programs control visual scenes displayed in the sights and system responses to inputs from switches and controls. Incorrect student actions are flagged automatically by the computer for future or additional training. Student records are saved on a central server to track individual student's progress over time, as well as to store class data, lessons in progress, and archival performance data. The HOTs support training in system operation, fault diagnosis, problem troubleshooting, system adjustments, component removal and replacement, and servicing and repairing tasks. Each HOT realistically reflects the appearance and internal layout of its operational Abrams and BFV counterparts.

Divided small group setting. In the typical divided small group setting, Soldiers and instructors were arranged as shown in Figure 3. A single student and instructor pair (indicated by the gray and black dots) are located on the equipment (either a HOT or an actual vehicle), while the 2-3 remaining members of the small group are seated at nearby tables and chairs.

\footnotetext{
${ }^{8}$ The programs of instruction (POIs) for both Abrams and Bradley courses stipulate that approximately $80 \%$ of the group settings occur in divided small groups. The occurrence rate of divided small group training observed during the three weeks of observation for the Abrams was 75\% and Bradley Control (71\%). However, this dropped to 7\% for the Bradley BRITE class (see Tables E-7 through E-9). As discussed later in this report, this was due to the manner in which the BRITE technologies were employed.

${ }^{9}$ Although the HOT used in 91A training was also referred to as the hands-on turret trainer (HOTT), the acronym, HOT, will be used throughout this report to refer to both types of maintenance trainer simulators.
} 


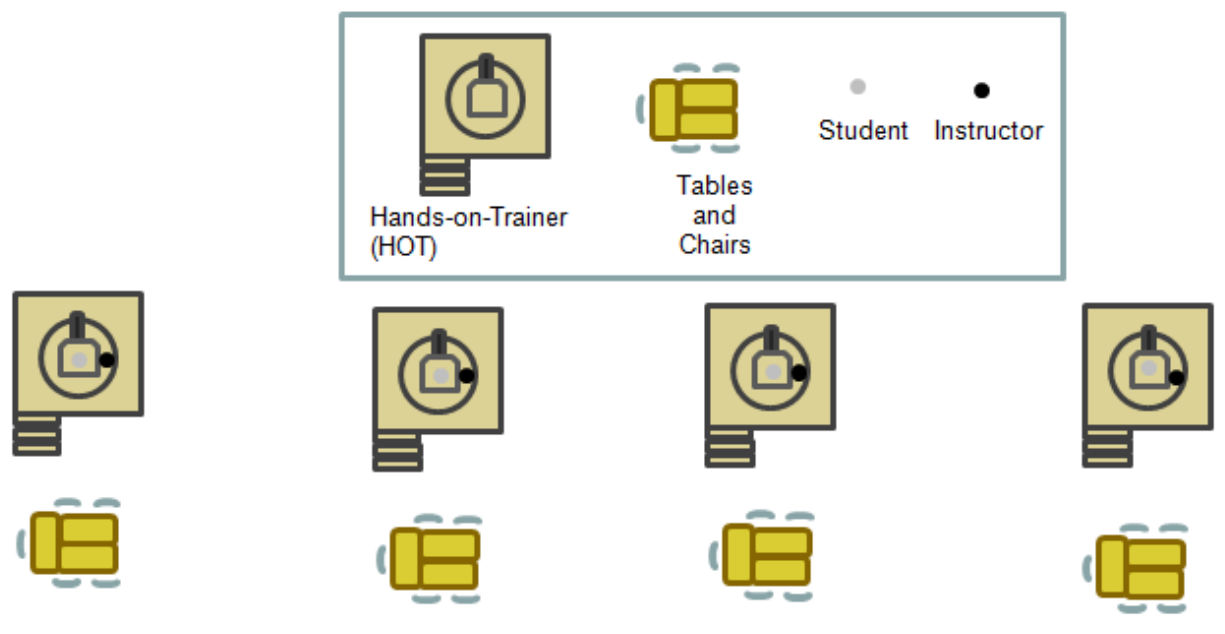

Figure 3. Divided small group setting.

The students at the table are ideally engaged in a related or preparatory task while waiting their turn. Instructors were careful to involve the students at the table in the learning process as they worked with the primary student collocated with them on the equipment. Given that training related interactions between the instructor and the student in the one-on-one setting within the vehicle or HOT would naturally occur with such frequency and rapidity as to make it nearly impossible to accurately track, it was decided to focus rather on the training related interactions between the instructor and the students located at the nearby chairs/tables and among those students. This information was gathered via Section IIa of the observation form (see Appendix B). As noted in Tables 3 and 4, the divided small group setting is described in terms of three types of behaviors: instructional styles (e.g., a global description of the type of activity the instructor is engaging in, e.g., problem solving, guided discussion), instructor interactions (e.g., asks students questions, directs students to complete a task, designates a leader) , and student interactions (e.g., answers questions, completes a directed task, takes on a leadership role).

Abrams divided small groups. By far the most common group setting (as expected) was the divided small group (75\% of group observations). The most common instructional style used to engage observing Soldiers in the divided small group was problem solving (84\%), with all other styles occurring $5 \%$ or less of the time. The most common instructor interactions with these Soldiers involved directing students to complete a task (83\%) and asking students a question (14\%). The most common behaviors exhibited by the observing Soldiers in the divided small group involved answering questions (36\%), completing directed tasks (25\%), and asking questions (23\%) (see Tables E-8 to E-10 for details).

Bradley control divided small groups. Again as expected, the most common small group training setting was the divided small group (71\%). The most common instructional style used to engage observing Soldiers was problem solving (90\%) with all other styles occurring less than $5 \%$ of the time. The most common instructor interactions with these Soldiers were directing tasks (43\%), asking questions (33\%), and reviewing content (24\%). The most common student behaviors were answering questions (38\%), completing directed tasks (26\%) and asking questions (24\%) (see Tables E-11 to E-13 for details). 
Bradley BRITE divided small groups. Contrary to the established pattern, the divided small group was not the most common group setting (7\%) in the BRITE training condition. Rather, undivided small groups and larger student groups were more frequently observed in this condition (see Figure 4). The most common instructional style used to engage observing Soldiers was still problem solving (89\%), but guided discussion were much more frequently used (11\%) than seen in the Bradley Control classes. The most common instructor interaction with observing Soldiers involved asking questions (92\%). The most common student behaviors in this subgroup were answering questions (38\%), asking questions (24\%), and completing directed tasks (26\%) (see Tables E-14 to E-16 for details). While the observing students' behavior patterns are similar between the Bradley Control and BRITE conditions, the frequency of group setting and nature of instructor interactions with this subgroup was not, as illustrated by Figures 4 and 5.

Divided small groups in Bradley control vs. BRITE conditions. In Figure 4, it is clear that the Bradley Control (91M05) class was most frequently small and divided group oriented. On the other hand, the Bradley BRITE (91M06) course was most frequently the large group, half class, and entire class settings, although it was still more small group oriented than not. Understanding why this happened is crucial, as it relates to the outcomes of our prediction models (the first research objective) and BRITE's potential impact on training. Figure 5 illustrates how heavily question-focused the instructional interactions became in the BRITE class.

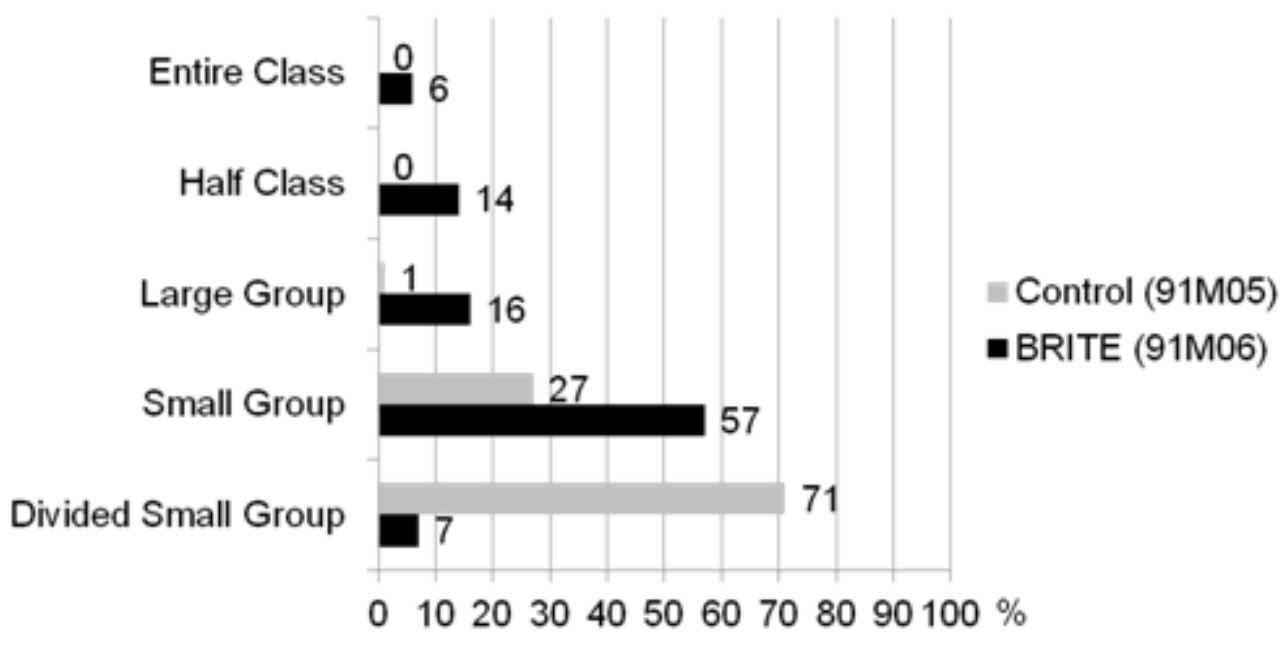

Figure 4. Frequency of group setting in Bradley Control and BRITE classes. 


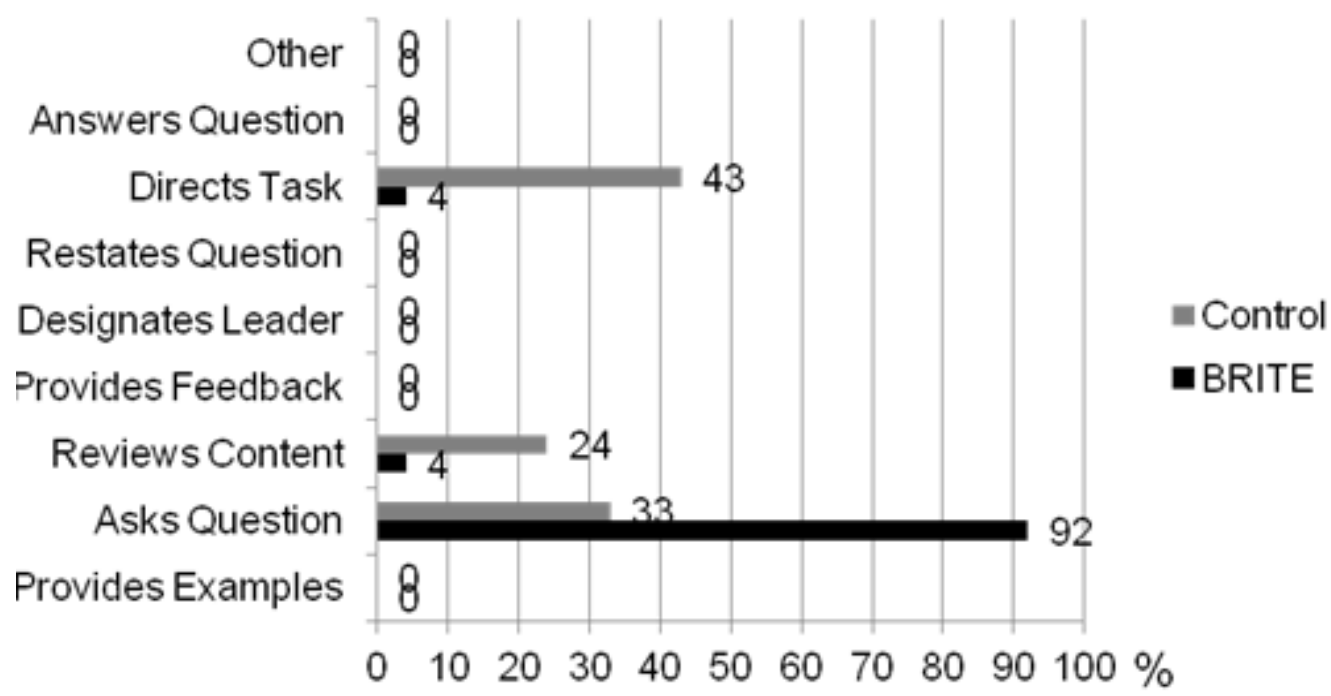

Figure 5. Instructor interactions in Bradley Control and BRITE classes.

Recall that Figure 3 introduced the typical divided group setting. However, the typical setting did not often occur in the Bradley BRITE class. This was due to the way in which the BRITE technology was employed. It was originally projected that the BRITE class would have multiple MCTs available for a class. However, only one was purchased and available for the class we observed during this research. In addition, the helmet cameras that were designed to project internal vehicle views onto the Smartboard so that observers could easily see and follow the training were unreliable and often not functional. Thus, much of the dynamic training capability envisioned for the MCT was not available. Therefore, the instructors opted to load schematics onto the Smartboard and drill students in their use, while one-on-one training occurred on the HOTs. When the camera-MCT connection worked, instructors had to experiment with it to get the best view of training within the vehicle or HOT since no prior training or guidance on its use had been provided.

Consider Figure 4 which illustrates how employing the technology in this fashion impacted the divided small groups. Instead of instructors interacting with 2-3 observing Soldiers located at nearby tables and chairs, observing Soldiers were combined in the larger group setting seen in the middle of Figure 4. Note that this setting also explains why, although documentation of instructor interactions showed many more questions being asked in the Bradley BRITE condition than in the Control, there was no appreciable shift in observing student interactions indicating they were answering more questions than students in the Control group. In the modified divided small group setting shown in Figure 6, an instructor may ask many more questions, but the odds that the students being tracked by the observers will answer that question is much lower since they are part of a much larger group of potential respondents. Observers described how this led to a 24:1 student to instructor ratio in the group seated near the Smartboard, compared to a 4:1 ratio in the typical small group setting. 


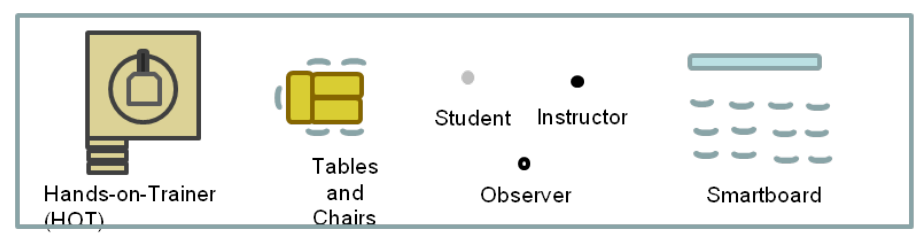

Soldiers practiced or observed practice with schematics and

diagrams.

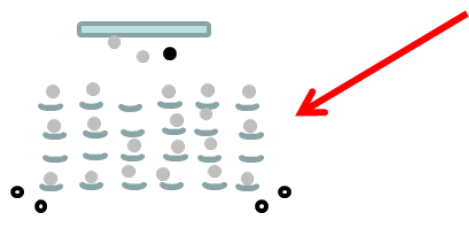

AND / OR

Uninterrupted 1 on 1 with trainers on the HOTs or
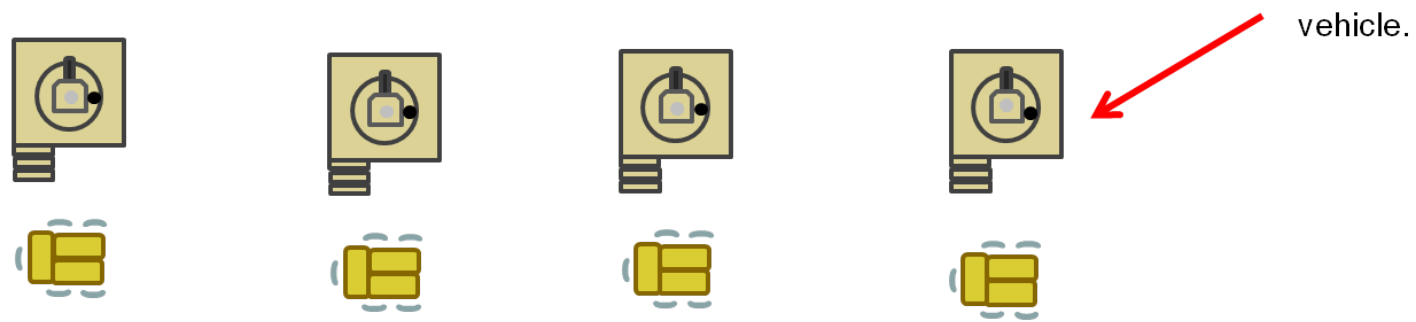

Figure 6. Modified divided small group setting in Bradley BRITE.

In sum, it appears that the most common instructional style used to engage students was problem-solving, where instructors directed students to complete tasks and answer questions. In turn, as might be expected, interactions between observing students and their instructors were largely answering questions and completing directed tasks. Other behaviors that were tracked to better understand the nature of ongoing student engagement (e.g., offering peers help, or selfadopting a leadership role) occurred infrequently. The major observation emerging from these small group observations revolves around the way the limited technology implementation impacted group settings and training interactions.

\section{BRITE Technology Assessment}

The final objective of this research was to examine the effectiveness and other impacts of the BRITE technologies employed in the observed Test 91M class (i.e., 06M) on established training outcomes.

Controlling for individual differences. Before any causal inference regarding the impact of BRITE upon performance can be made, it is necessary to determine if there were any significant pre-existing differences between the participating classes (i.e., in prior knowledge, GT scores, or experience) that could have impacted our findings. A multivariate ANOVA (see Table E-17) showed there were no significant differences between the Soldiers in these two conditions.

Performance comparison for Bradley Control vs. BRITE. While the performance (Go Percent) was virtually identical for the Bradley Control vs. BRITE classes (see Table E-18), there were indications that the BRITE technology appeared to help individuals who were lower in experience, prior knowledge, and ability. First, sticking solely to the performance data from the two courses, it appears while the mean Go Percent rates are the same, there are differences 
in the ranges of these rates. In the Bradley Control class, the minimum score is $58 \%$, while in the Bradley BRITE it is 75\%. This, along with the near identical profiles of the two classes on the individual difference measures, suggests that poorer performers appear to gain more from the BRITE condition than the remaining Soldiers in the class.

Second, consider the pattern of correlations seen in Figure 2. In the Bradley BRITE class, the correlations between predictor and criterion variables were attenuated and in one instance reversed. This is consistent with a training effect that is impacting the scores of poorer performers more than other individuals in the same group.

Finally, bringing all observing Soldiers together in a single, large group under the tutelage of other instructors, allowed instructors to focus their complete attention to a single student in the HOT or on the equipment. Rather than having to divide their attention between a student directly engaged in a training activity and those observing the training, they could work at length and in greater depth with a single student without concern that it was taking away from the observing students' training experiences.

\section{Qualitative Training Observation Themes and Issues}

As described earlier, qualitative assessments were collected from SME observers at the end of each scheduled training day and week. Daily summary conclusions and observations were recorded in Part IV of the observation instrument (see Appendix B). This form included 12 questions asking the observer to subjectively rate his overall impressions of the day's activities. In addition, the observers provided weekly, written summaries of their observations reflecting their consolidated thoughts and impressions of the training events observed during the previous week. When combined, these subjective assessments identified a number of training themes and issues shared by both training programs and unique to each AIT course.

Shared observation themes and issues. Soldier engagement appeared to be highest during tasks requiring the direct participation of the entire group or team, such as pulling or reinstalling an engine or replacing a shock absorber or torsion bar. These types of training events required the trainer and all members of the student group to interact and communicate until the task was completed. These training events were consistently described by students as "interesting and enjoyable," as they required the students to actually use their tools and learned skills. In contrast to these active "wrench turning" tasks, more cognitively based tasks tended to be described by students as more difficult and less hands-on. Unlike the more applied tasks, these tasks involved a great deal of passive observation and tended to lose students' interest very quickly.

While "doing" clearly seemed to be the preferred method of training from both the point of view of students and instructors, limitations of available facilities and operational equipment frequently restricted the number of opportunities each student had to perform a scheduled task. As described earlier, largely passive observation of other students performing tasks was all too frequently the most common training experience during the day. This problem was exacerbated by the fact, based on training observations and feedback provided by instructors and staff, that training equipment and vehicles were often out of date and frequently not available to train all scheduled tasks due to a lack of adequate replacement parts. Access to updated simulators, i.e. 
fully instrumented hands-on trainers (HOTs), helped, at least partially, address some of these issues during training.

Training conducted using the HOTs consistently received positive comments from a majority of students during our observations. Based on student and instructor comments, the greatest strength of this training setting was that it allowed students to diagnose and work on problems without fear of destroying a costly component or vehicle. However, a number of significant issues were noted with the HOTs' operations during the course of our training observations. The following were identified by our SMEs as most noteworthy as they directly impacted the quality and duration of training opportunities provided to individual students in the HOTs:

- Computer software glitches required systems to be rebooted, which took a substantial amount of time away from training.

- Systems overheated and quit functioning during training events.

- Systems had been used so often for training that some of the components were worn out and would not function or seat properly.

- Students (and instructors) inadvertently broke a component resulting in unplanned downtime for the HOT and requiring the group to either move to another station, if available, or join another group.

- Previous classes or training groups failed to assemble or reconfigure all the components properly which required corrective action before any additional training could take place.

Observers also noted that, in addition to the number of functioning stations, student engagement in training events employing the HOTs and armored vehicles was frequently constrained by the physical configuration of the equipment and limited space within the vehicle or HOT. Observing students frequently found it difficult to see exactly what was going on within the vehicle or HOT, especially when trying to discern what the student inside the compartment was referencing, seeing on digital displays, and doing with various components, equipment, or cables. Under these circumstances, students became quickly disinterested in actively observing the activities within the compartment and spent much of their time simply talking or, at times unsuccessfully, trying to stay awake.

Instructors were consistently observed providing thorough, detailed answers to all student questions. Simple "yes" and "no" responses, with no elaboration, were very seldom heard during the training observations. The SME observers noted a consistent, conscientious effort on the part of all instructors to provide complete answers to student questions. The instructors seemed to go out of their way to provide detailed answers and to ensure everyone in the group understood, even to the point of frequently having the group huddle around the component, inspection point and breakout box, or schematic while the instructor clarified a point or answered the question. Additionally, the instructors seemed to rely upon the students' questions to gauge their level of comprehension. Most of the instructors routinely followed up with additional examples, reviewed previously covered materials or related content, and asked follow-up questions of their own to ensure students adequately understood the explanation or relationship between presented examples. 
Unique 91A observation themes and issues. Instructors seemed to have been provided the latitude to readily adapt training to fit individual student needs or adjust to unforeseen issues regarding the availability of training equipment, instructors, or students. Training observers frequently noted the following efforts by instructors to adapt to emerging situations and to ensure all students were actively engaged during training:

- While an instructor was on/in the tank or HOT working with a single student, the remaining students were actively working on another assigned task or training problem.

- All students were directed on/in the tank or HOT to accomplish a single task or separated into smaller groups or pairs to complete multiple related tasks concurrently, as the instructor moved between tasks as needed to observe each activity and maintain direct control of the training condition and progress. Additionally, instructors often rotated students between the tasks and required crew roles.

- A Soldier or pair of Soldiers was directed to work on a task on their own on/in the tank or $\mathrm{HOT}$, while the instructor devoted his attention to working with the remaining students at the table.

Student groups were often observed working on tasks that, while part of the TSP Training Annex, were not scheduled as the primary focus of that specific training session or day.

Instructors appeared free to alter the planned sequence of tasks for the day or the week based on equipment availability, student progress, or even their own discretion. Observers noted that the instructors carefully tracked the progress of each student to assure satisfactory completion of all required tasks in accordance with the standards and conditions set in the approved TSPs.

As discussed earlier, availability of parts for repairing the aging tank fleet hindered training and extended time required for evaluations due to restricted numbers of operational stations or the limited availability of an essential subsystem, part, or tool. Typical examples noted by training observers included:

- During fire control maintenance training, a single commander's control handle was passed between three tanks. This tool is an essential component in the conduct of a number of common troubleshooting tasks and the instructors only had one available for training use during three consecutive training days.

- An unexpected fault occurred in a tank turret during the practical evaluations, burning out a breakout box and removing the tank from further evaluations and training, thus slowing throughput.

- During hull training, instructors had to correct multimeter readings or verbally inform students of the "results" of a test process because of preexisting unreconciled faults on the available tanks.

- During suspension training, parts had been removed and replaced by students so often that connectors and threads were too worn to be properly secured, thus reducing the realism of the training. Specifically, observers noted that a number of transmission bolts, bolts on suspension parts and assemblies, and solenoid connectors on the transmission were too worn and broken to meet operational and training standards. 
As they distracted instructors and students from the task at hand, these issues delayed training, created unrealistic conditions for training, and provided these developing vehicle maintainers with a training experience that fell short of the conditions and standards required by the POI and TSPs.

Unique 91M observation themes and issues. In contrast to their 91A counterparts, observers noted that 91M instructors appeared to have very little latitude to vary from the prescribed instruction schedule. Typically, instructors were held to planned training schedules where instructors were expected to teach the same content during the same time blocks. In many cases when a group completed a planned training session earlier than scheduled, they had to wait for the remaining groups to catch up before proceeding to the next task. Depending on how far they were ahead of any remaining groups, instructors rotated the students through previously completed tasks, reviewed course materials with the students, began preparing them for the next scheduled task, or simply left them to their own discretion until they could move on to the next scheduled event.

Consistent with their 91A counterparts, the most commonly observed small group training strategy used by instructors was to work directly with a student to perform a task or troubleshoot a procedure on/in a vehicle or HOT while the remainder of the group passively observed. Most of the instructors seemed continually challenged to both observe the focal student's actions and keep the remaining students actively engaged in the training. Troubleshooting task steps and procedures were particularly lengthy, providing extensive periods where students attempted to observe training activities inside the vehicle or HOT. While observing students were supposed to be actively following the focal student's actions, most engaged in social chatter or passively sat, waiting for their turn and trying to stay awake. There were long periods of time where there were no interactions between the instructors and the observing students. It readily appeared that once the observing students believed they understood the task, either by performing the process themselves or by observing other students perform it repeatedly, they quickly lost interest in the training session.

Focusing on training conducted using the BRITE technologies, it appeared that training conducted using the MCT was not well received by students. Regardless of how instructors attempted to use the MCT, the majority of students only passively observed the training, if at all. At most, only one or two students were actively involved at the Smartboard trying to demonstrate the troubleshooting procedures needed to resolve a presented problem using an electronic schematic. Some of the most significant issues with the MCT seemed to have more to do with the manner in which the technology was employed than the equipment's capabilities. Issues that observers most frequently noted included:

- The MCT was only observed being used in large group settings and was not observed being directly used by an instructor with individual small training groups.

- Instructors appeared to lack adequate training on the MCT's capabilities and operations, troubleshooting procedures, and training content. Frequently, students seemed to know more about its operation than many of the instructors, which appeared to reduce the motivation of many instructors to experiment with the device. 
- Students at the board frequently blocked other students' view of what exactly they were doing. Frequently, they were not required to verbally walk through their actions or problem solving process as they completed the task for the benefit of observing students.

- Diagrams and schematics presented on the board were often hard to read from various sitting positions and, at times, students had to refer to a paper copy to determine what exactly was written or displayed on the board.

- Instructors were actively involved with one or two students at the board and largely ignored the rest of the class.

- The board was frequently used as a "babysitter" for a majority of the students, while individual instructors worked with a single student back at their training stations.

- After a few repetitions of using the MCT for the same type of training activities, the excitement of a new piece of equipment wore off and students became disinterested.

- Limited, repetitive activities were conducted using the board, as it was mainly used to provide live-feeds from the portable helmet camera and trace wiring faults with a digital highlighter.

Attempts to use the MCT were only observed in conjunction with training on the HOTs. There were a number of issues noted by observers during the use of live feeds during training on HOTs. While the HOT has more internal room than an actual BFV, it is still a cramped, constrained operating environment. When the helmet camera was placed on a student performing a task, the following issues emerged:

- The feed from the mounted camera was often not focused on what the student was doing. For example, a task may require a student to disconnect a cable by reaching around or behind a component in such a way that even the student performing the tasks cannot see well. In such confined conditions, the student simply could not position his head for the camera to capture what is happening.

- When strapped to a student's head, the camera was often an obstruction to a student's movements and endangered the equipment as it frequently knocked into a number of components.

- The camera's display could not adequately capture what the student read from a manual or a digital display.

- Unless the student or instructor narrated exactly what was taking place, observing students were frequently lost and unable to follow the procedure.

- Audio feed from inside the HOT was terrible and, even with narration, it was consistently hard to hear and understand what was happening inside the HOT.

\section{Focus Group Interview Themes and Findings}

To gather data during the focus group interview sessions, an interviewer and a researcher took notes on the discussion. Their notes were compared, consolidated, and transcribed into central files for each class which were then reviewed by other members of the research team to verify their accuracy, consistency, and comprehensiveness. During the discussions that followed, the research team distilled the themes into essential points that described similarities and differences among the comments from the sessions. This qualitative data provided insights 
into how Soldiers and instructors viewed the training during AIT in general, and the employment of BRITE technologies, specifically.

Soldier focus group interviews. As described previously, interviews were conducted with each of the observed Soldier focus groups, comprised of three to five Soldiers each. Fifteen interview sessions were conducted with eight groups from the 91M (BFV) classes and seven from the 91A classes. A total of 69 Soldiers, 35 91A students and 34 91Ms, were interviewed.

Shared interview themes. The Soldiers we interviewed indicated they generally had adequate hands-on time with the equipment, with the exception of when groups expanded to more than four students or when the tasks became more complex. As tasks increased in complexity, they took more time to complete and provided fewer opportunities for everyone. They also described how students in a group were often distributed throughout the other groups during an instructor's absence. This increased the number of students in that group during that portion of training and decreased the amount of time each student had performing hands-on tasks.

Students readily admitted they became easily bored and disinterested while waiting their turn to participate in hands-on training. When asked how they typically used this dead time, the most common responses were nearly equally divided between talking with other students about non-training related issues, sleeping, and trying to stay awake. The students we interviewed indicated that keeping them more involved in hands-on training through additional instructors, additional equipment, and smaller group sizes would greatly benefit training and relieve these periods of boredom.

Students' comments regarding use of technical equipment varied depending on the type of equipment and how it was employed during their training. For example, students in the Abrams maintenance classes positively described the use of vehicle digital trainers (VDTs) in their training, but expressed concerns with how the software handled errors. Their counterparts in the BFV maintenance classes reported not using VDTs during any portion of their hull and turret training. Overall, the students we interviewed preferred training on live vehicles as opposed to using any of the other training aids, virtual or real. A major exception to this perspective was the students' reactions to the HOTs. Students generally liked the HOT because it closely resembled a live vehicle, while still requiring active hands-on wrench turning and use of maintenance equipment. Further, as a simulator, it significantly reduced their fears of making a mistake that would damage a live vehicle.

Unique 91A themes. There were some notable differences in student responses regarding the use of VDTs during Abrams training. Students in 91A07 described the VDT as a negative training aid that hindered their learning, while those from 91A08 described it in positive terms. Students in 91A07 discussed how they were frequently frustrated with the simulated troubleshooting capabilities of the VDT for training. Specifically, they reported that the software would lock them out once it detected they had performed a step incorrectly, but it would not identify the exact incorrect action. Even after the instructor reset the simulation, students still did not know what they had performed incorrectly and frequently committed the same error. Therefore, they gave the simulator low marks. However, students in 91A08, in contrast, gave the 
system high marks. Based on further elaboration, the difference appeared to be that the 91A08 class primarily used the VDT capabilities that allowed for familiarization with identified tank components prior to the students training on the actual equipment. The students seemed to find this capability helpful and did not experience the same frustrations with the VDT as members of the 91A07 class who had attempted to complete more complex, scenario-based problems presented in the VDT.

Unique 91M themes. Regarding the employment of the MCT in Bradley classes, students stated that the biggest issue they had was with the manner in which the MCT was employed rather than the equipment itself. Students generally did not like the use of the MCT in their classes. They indicated that the use of the helmet camera was useless unless there was an instructor narrating the procedure. Even then, watching the live feed quickly became boring and monotonous, as students quickly became disinterested after only a few repetitions.

Students seemed to be split on the use of the MCT for tracing schematics. Students that had experienced actively tracing wiring faults on the board felt it was somewhat useful, while other students who spent much of the time observing saw very little benefit in the exercise. The students also recommended training instructors on the use and operation of the technology, as some students were more knowledgeable than their instructors on its operations and interactive features.

There was also a wide difference in student responses about the common core training. As the name implies, this was the basic, foundational classes the Soldiers completed before beginning their hands-on training. Many students found this common core training to be of great benefit, while others within the same class found it to be the least interesting, most boring part of the course. These students felt that much of the material was useless and indicated that many of the things learned in these initial classes were not used or referenced during the rest of their training.

Trainer/instructor focus group interviews. As described earlier, three different groups of instructors were interviewed: (1) 91M BFV instructors, (2) 91A Abrams hull instructors, and (3) 91A Abrams turret instructors. The same group of 91A instructors conducted hull and turret training in both observed classes. Researchers conducted six interview sessions with focus groups of four instructors each. Two sessions were conducted with BFV maintenance instructors for classes 05M and 06M. Four sessions were conducted with Abrams maintenance instructors assigned to classes 07A and 08A (two for turret instructors and two for hull instructors). Unless otherwise stated, the results summarized in this section reflect the information gained from all Abrams instructors.

Shared interview themes. Instructors reported that they were asked to provide little to no input during the process of assigning Soldiers to their small training groups. According to the instructors we interviewed, the composition of the small training groups was based on students' scores on their first common core test in academics, their initial Army Physical Fitness Test (APFT) scores, and group diversity considerations. The instructors pointed out that while some classes used additional criteria for assigning Soldiers to their training groups, including 
subjective judgments regarding how well the Soldiers appeared to work together, attempts were made to evenly distribute capabilities and balance demonstrated skill levels across the groups.

The instructors felt the criteria consistently failed to reflect the Soldiers' actual potential for learning and performing maintenance tasks. They indicated that early academic test results and general physical fitness scores do not consistently translate to the kind of hands-on maintenance abilities needed to succeed in training. They indicated that prior mechanical experience and familiarization with vehicle maintenance tools and equipment would be better indicators of key abilities. According to the instructors we interviewed, many students have little to no practical prior experience with schematics, wiring diagrams, tools, mechanics, system troubleshooting, or mechanical repairs before reporting to AIT.

Most of the instructors we interviewed felt they were able to identify those students that could learn and perform tasks quickly and those that would require additional attention early on in the training cycle. However, they had great difficulty in explaining exactly how they could determine this or what criteria they consistently monitored to ascertain a student's potential for later success in training. During this discussion, they highlighted the following as being good indicators of later performance:

- Observing body language as a reflection of confidence and noting how long it took for a student to complete tasks.

- Observing which students take the lead and which ones often choose to observe others working on a group task.

- Observing students' interest in ongoing tasks.

- Observing the number and nature of questions asked by individual students during training sessions.

The instructors we interviewed highlighted a number of issues that challenged their abilities to adjust training to meet the needs of their Soldiers. In addition to more traditional constraints, such as resource limitations, condition of available equipment, and other scheduled requirements that took Soldiers away from training, the instructors pointed out how language barriers, previously diagnosed hyperactivity conditions requiring medication, and other learning factors, such as apparent learning disabilities and concentration issues, impacted training. During our discussion, they reported frequently using the following techniques in order to overcome these challenges and to meet their Soldiers' unique training needs:

- Had other students wait until a struggling student catches up.

- Made a slower student the initial demonstrator, thus giving that student additional opportunities to perform the task later, as time permits and after observing the remaining students complete the task.

- Ensured a struggling student was last to perform hands-on training so the student could observe and learn from others prior to attempting the task, as well as giving the instructor more opportunities to spend additional time with that student during the session.

- Provided struggling students more opportunities than others to perform tasks, as time permitted.

- Frequently, verbally quizzed the students on content already covered. 
- Paired weaker students with stronger ones who could act as peer coaches.

- Had students explain a previously reviewed process and answer questions.

Instructors' opinions varied greatly when asked to identify what was most challenging and what was easiest for students to learn during training. In general, complex system tasks requiring a number of inputs from related subsystems and new tasks that required greater integration of multiple content areas and skills, such as analytical problem solving, logic, and critical thinking skills with limited or no prior review, seem to give students the most difficulty. They emphasized that students were most attentive and engaged in learning when performing hands-on tasks. Simple tasks that were relatively easy to grasp caused students to quickly become bored and disengaged in training, especially when required to passively observe others perform the task while waiting for their turn.

Unique 91A themes. The instructors we interviewed emphasized that, with the exception of a single EIM group in each class, program managers generally attempted to evenly distribute student capabilities across the groups within each class. It's important to keep in mind that while EIM Soldiers were placed in each of the training groups in $91 \mathrm{M}$ classes, they were placed in a separate group in 91A classes. This allowed this group to pursue an accelerated training schedule, receive training on a number of additional vehicle issues and types beyond the established POI, and be used as a reliable source of peer coaches by other instructors.

The Abrams instructors interviewed in this effort indicated that the performance of EIM groups has been, at best, unpredictable in their content areas. They acknowledged that the EIM group members tended to:

- Be older (24 - 27), more mature, and more focused on training.

- Have more formal education (including some college).

- Grasped concepts earlier and better than other Soldiers in their class.

However, they also pointed out that they found most EIM groups were:

- Frequently less capable or about equal to their classmates in actual task performance as a mechanic.

- Not necessarily sharper or more capable than their peers, but more consistently able to read better.

Unique 91M themes. The Bradley maintenance instructors we interviewed indicated they observed no real positive impact resulting from the use of the MCT. They stated it was most effective during the first time through a demonstration. After that its use became too repetitious. Overall, the instructors felt that the MCT was a good idea but was not employed in the right way. They felt that with better software, better instructor training on the use of the Smartboard and its full capabilities, more MCTs (one per group), and more advanced capabilities (such as student interactive tablets with the board) the MCT could be a useful tool. Specifically, they indicated that MCT activities were:

- Too repetitious. Students were done with a procedure after seeing it through one time. 
- Hard to see when students were standing in front at the Smartboard while using it.

- A challenge for an instructor to keep all students interested and involved in training. Difficult enough with a small group of 4 to 5 students, attempting the same with a 1:30 instructor to student ratio at the MCT was impossible.

- Time consuming. Training time was allotted for each procedure but currently is not structured to include Smartboard time.

- No better than trying to watch it live due to the problems experienced trying to use the helmet camera.

\section{Conclusions and Recommendations}

\section{Conclusions}

The intent of this effort was to address gaps identified in previous tailored training research in institutional training programs and examine specific training issues raised by the 381st AR BN, Fort Benning, GA. Given the Armor School's interest in identifying or developing more effective predictive measures for their courses, this effort provided a unique opportunity to assess the effectiveness of various types of prior knowledge predictors administered early in a course to predict later performance at different stages of training. The armor vehicle maintenance AIT courses examined in this research also provided an excellent opportunity to observe how small groups function in technical military courses and further examine the nature of tailored training strategies employed in these settings. Finally, the timing of this effort provided our team with the chance to assess the impact of the initial deployment of the centerpiece of the BN's BRITE technology initiative, i.e. a MCT, on training strategies and outcomes.

Performance predictor measures. As described earlier, about $80 \%$ of the scheduled training in the armor vehicle maintenance courses we examined occured in assigned small group settings. Identifying technically stronger and weaker students as early as possible is critical to the training strategies employed in both courses. Whether creating EIM groups that can be placed in an expanded, accelerated training program (i.e., 91A) or attempting to balance the number of stronger and weaker students within each training group to enhance opportunities for peer coaching (i.e., 91M), the need for well-defined, reliable predictor measures to assign students as required is paramount.

Based on our research, assignment to the small training groups in the participating classes was based on measures readily available before the start of small group hands-on training. Although instructors and course leaders also used individual subjective assessments of students' relative compatibility and other various implicitly derived attributes, the most consistent measures used were the most convenient: GT scores, students' scores on their first common core test in academics, initial APFT scores, and group diversity considerations. According to our interviews, these measures were originally believed to be predictive of later training performance and adequate for identifying stronger and weaker students early in training. Our research clearly showed that these predictive performance measures' predictive value was not validated by later student performance. We found that early common core academic test results and APFT scores 
had little to do with a student's demonstrated ability to learn and perform maintenance tasks well.

Our research indicated that measures designed to discern a student's entering knowledge of and ability to complete basic underlying tasks relevant to later learning content are much more predictive of later performance at different stages of training. In fact, our research indicated measures developed with an understanding of the critical basic skills and concepts that underlie key performance activities and more complex skills are superior to established, standardized cognitive tests and basic experiential background assessments. Although the strategy of relying on GT scores as an indicator of general cognitive ability was consistent with previous research, it lacks the more detailed insight needed for instructors to effectively tailor training and group composition on the basis of applied skill aptitudes. Thus, assessing students' knowledge of and ability to identify basic tools, demonstrate the use of selected tools, demonstrate an understanding of basic electrical components and functions (e.g., completing a simple circuit or accurately interpreting a basic electrical schematic), or past mechanical experiences were more effective predictors of later performance in the armor vehicle maintenance courses we examined.

Tailored training. Our research focused on determining how instructors attempted to tailor their training interactions with students observing hands-on training while waiting for their turn on the equipment. Although rarely the focus of previous tailored training research, these interactions are critical to the emerging training experiences and outcomes in these group training settings. Also, the normally high level of instructor-student interaction in the one-onone or one-on-two instructional group and the physical impossibility of placing an observer in a position to accurately document the interactions occurring within both subgroups without disrupting training constrained our research options. However, given its unique focus, this research addressed an often ignored aspect of group training settings and expands our understanding of how instructors tailor training to keep subgroups of students engaged when not participating in hands-on training.

Given the physical constraints of the equipment and setting, it's not surprising that many instructors participating in this research found effectively addressing their Soldiers' needs by dividing their attention between two subgroups an often impossible task. The situation was exacerbated by the fact that the equipment's design frequently prevented or hindered the ability of observing Soldiers to learn vicariously from another Soldier's actions. Thus, it was not surprising to learn that the Soldiers largely bided their time in casual activities unrelated to the scheduled training events as they waited their turn on the equipment. However, even within this constrained environment, most instructors took direct actions to keep Soldiers engaged during training. Our results indicated that providing problems for observing Soldiers to work on and asking them simple, direct questions were the most common strategies for instructors to gauge their comprehension and understanding of the ongoing training event.

Our research also indicated that strict adherence to all groups sequentially advancing through planned training schedules at the same pace severely limited instructors' ability to tailor training to their Soldiers' needs and progress. Without the ability to quickly adjust content delivery to match the pace of the training group's accomplishments, or to take advantage of unanticipated resources, instructors are left with very few options other than simple repetition of 
a completed task or using questions to keep their students engaged throughout the training day. The ability of 91A instructors to alter or overlap the sequence of training events within broadly defined boundaries was key to their effectiveness to tailor training in a manner that enhanced the level of student engagement throughout the training day. Without this ability to adjust scheduled training events and engage students concurrently on multiple tasks, instructors have very limited means to tailor training to meet the needs of all the students in their group. Often, students are left to passively observe other students performing a procedure. This not only leads to boredom and loss of interest by students, it undermines an instructor's ability to spend greater time with struggling students without adversely impacting the training experiences and opportunities of other students.

BRITE. As described earlier in this report, the MCT was most frequently used in two ways: first, as a tool to have students troubleshoot presented electrical problems or trace and interpret wiring problems on a schematic diagram and secondly, to display live video feed from the mounted helmet camera. Due to the fact that only a single MCT was available, students were usually brought together in a large group or half class training group to use the MCT.

Regardless of how the MCT was employed, the vast majority of students in the MCT group were still only able to passively observe the training without active facilitation by instructors not engaged in the hands-on training. The degree to which facilitation strategies were effective depended upon the ability of instructors, either individually or in collaboration, to engage a large group of students in active learning using the MCT, the availability of preprogrammed content, and the level of comfort an instructor had with operating and troubleshooting the MCT. Unfortunately, the instructors' capabilities in each of these areas were greatly constrained by the facts that there was only one MCT available, instructors had not received any in-depth training on the MCT's capabilities and operation prior to its employment, and a lack of time to develop and integrate preprogrammed, validated content and tailored training strategies for exploiting the MCT during training prior to this research. Thus, it was not surprising that, after the first few iterations of limited preprogrammed content or presented schematic problems, the observing group generally became disinterested, distracted, and focused on unrelated activities, e.g. informal social exchanges and extended personal breaks away from the training area, other than focusing on or contributing to training.

Given these constraints and limitations, it's surprising that any positive trends or outcomes were noted regarding the BRITE employment during this effort. Yet, there are indications that this technology, centered on the use of a single MCT, appeared to help individuals who were lower in experience, prior knowledge, and demonstrated ability prior to engaging in small group training. Although our data was limited to a single Test class, the average minimum Go Percent rate was higher in the BRITE group than the Control. While more extensive research and data is needed to discern the scope and consistency of this trend, it appears that bringing all observing Soldiers together in a single, large group under the tutelage of other instructors, allowed instructors to focus their complete attention to a single student in the HOT or on the equipment. In this research and consistent with long-established learning strategies, lower performing and less knowledgeable students appeared to benefit most from the greater opportunities for focused, in-depth, individual tutoring created when an instructor can 
dedicate full attention to a single student rather than attempting to divide attention between two different subgroups.

\section{Recommendations}

Although this effort represents a limited examination of prior knowledge predictors tailored to applied military training settings, tailored strategies for small group training in field settings, and the initial employment of MCT platforms in technical military training, its findings provide a number of recommendations for Army training units.

Predictor measures. Army training units considering options for developing tailored predictor measures for their programs should carefully review their course content and learning outcomes to identify the critical basic concepts and skills that enable student success during training. Based on our research, experienced instructors and training developers have a good understanding of the basic skills that are most relevant to critical learning objectives and enable students to excel in training. In this effort, prior mechanical and electrical experience and familiarization with vehicle maintenance tools and equipment were effective predictors of later success in armored vehicle maintenance training. Our research indicates that this practical knowledge is a more effective basis for developing appropriately tailored measures for predicting later student performance than GT scores alone, published standardized instruments or other measures of convenience, such as prior assignment or deployment history or APFT scores.

In extensive, complex training programs, units should consider tailoring these measures not for the entire course, but for the most difficult or crucial portions of the course which they most need to tailor to individual student's strengths and weaknesses. This approach will allow for more in-depth assessment of prior knowledge and skills directly relevant to the most critical or challenging portions of the course.

Tailored small group training. One of the key recommendations emerging from this research is that units interested in enhancing their ability to tailor small group training should seek to increase the degree of flexibility given to instructors. Our research indicated that the more instructors were given the opportunity to simultaneously multitask groups or subgroups of students and to deviate, within specified boundaries, from established training schedules, the better they were at tailoring training to increase student engagement, meet the needs of all their students, and to adjust to unplanned resource constraints, e.g. nonavailability of equipment, equipment failures, and lack of functional replacements.

BRITE. Although a very limited, initial assessment of novel learning technologies applied to a field training setting, our research indicates BRITE, specifically the employment of a MCT, holds a great deal of potential. However, this technology must be purposefully integrated within the training with careful consideration of its purpose and relationship to other ongoing training activities. Instructors must be fully trained on all aspects of the technology's operation, correction, and capabilities. A simple familiarization review is not sufficient for instructors to gain the expertise and confidence they needed to exploit these new capabilities in their training and efforts to enhance students' learning experiences. 
Finally, in addition to ensuring sufficient, current, preprogrammed content and materials are made available to instructors to support training and fulfill the technology's intended use, training content must be varied in form and difficulty. While there is some value in limited repetition of critical skills or knowledge concepts, units must be aware of how routine repetition of basic materials adversely impacts student engagement. Also, instructors must be trained on how to use the technology to individually or collaboratively facilitate training and student engagement in different group and training settings.

\section{Limitations}

Every research effort has limitations, which future research should attempt to address and refine. This research was admittedly limited in scope as a result of its focus on Abrams and BFV maintainers' training and the number of available classes and participants. A more comprehensive effort should be made to expand the number and variability of AIT units participating in research building upon this foundation. Additionally, this effort provides an initial assessment of how tailored training, student engagement, and training interactions vary with group size and composition, based on students’ prior knowledge, experience, and early demonstrated performance. Future efforts should employ more comprehensive research strategies to comprehensively assess the complex interactions and engagement strategies associated with the multiple group training settings we observed in this effort.

Due to the need to compare the effectiveness of multiple types of predictor measures to predict later student performance, the number and variety of content related and unit derived items was limited. Future research should build upon the findings of this effort to expand our understanding of how to develop and validate these types of focused instruments, in terms of targeted knowledge concepts and skills. This research should also expand our understanding of how to better use the outcomes from these measures to effectively tailor subsequent training.

As frequently recognized in this report, this research provides a limited assessment of the initial BRITE employment within armored vehicle maintenance training. Consistent with the unit's original plans, additional MCTs have been subsequently purchased and employed by the units since the completion of this initial effort. Future research should be conducted to assess the impact of the full employment of the matured technology, varied preprogrammed content, and refined instructor training. It should also seek to expand the number of participants to determine if the trends noted in this research regarding the technology's impact on lower performing students are statistically significant. 


\section{References}

Chen, S. Y., \& Paul, R. J. (2003). Editorial: Individual differences in web-based instruction—an overview. British Journal of Educational Technology, 34, 385-392.

Chi, M. T. H. (2009). Active-constructive-interactive: A conceptual framework for differentiating learning activities. Topics in Cognitive Science, 1, 73-105.

Chi, M. T. H., \& Roy, M. (2010). How adaptive is an expert human tutor? In V. Aleven, J. Kay, \& J. Mostow (Eds.), International conference on intelligent tutoring systems, (pp. 401-412). Berlin: Springer-Verlag.

Chi, M. T. H., Siler, S. A., Jeong, H., Yamauchi, T., \& Hausmann, R. G. (2001). Learning from human tutoring. Cognitive Science, 25, 471-533.

Cohen, E. G. (1994). Restructuring the classroom: Conditions for productive small groups. Review of Educational Research, 64, 1-35.

Craig, S. D., Chi, M. T. H., \& VanLehn, K. (2009). Improving classroom learning by collaboratively observing human tutoring videos while problem solving. Journal of Educational Psychology, 101, 779-789.

Drucker, E. H. \& O'Brien, R. E. (1982). Mission-based analyses of armor training requirements, Vol 1. (Research Product 82-10). Alexandria, VA: U.S. Army Research Institute for the Behavioral and Social Sciences. (DTIC No. ADA166253)

Dyer, J. L., Singh, H., \& Clark, T. L. (2005). Computer-based training approaches for training interactive digital map displays. (Research Report 1842). Arlington, VA: US Army Research Institute for the Behavioral and Social Sciences. (DTIC No. ADA440171)

Dyer, J. L., Wampler, R. L., \& Blankenbeckler, P. N. (2011). Tailored training in Army courses. (Research Report 1950). Arlington, VA: U.S. Army Research Institute for the Behavioral and Social Sciences (DTIC No. ADA552439)

Ekstrom, R. B., French, J. W., Harman, H. H., \& Derman, D. (1976). Manual for kit of factor-referenced cognitive tests. Princeton, NJ: Educational Testing Service.

Graesser, A. C., \& Person, N. K. (1994). Question asking during tutoring. American Educational Research Journal, 31, 104-137. 
Heuckeroth, O. H., \& Smith, N. D. (1990). Relationship between vehicle identification performance and the Armed Services Vocational Aptitude Battery (ASVAB) (TR 882). Alexandria, VA: U.S. Army Research Institute for the Behavioral and Social Sciences. (DTIC No. ADA221558)

Jensen, A. R. (1998). The g factor: The science of mental ability. Westport, CT: Praeger.

Leibrecht, B. C., Goodwin, G. A., Wampler, R. L., \& Dyer, J. L. (2007). Techniques and practices in the training of digital operator skills. (Research Report 1878). Arlington, VA: U.S. Army Research Institute for the Behavioral and Social Sciences. (DTIC No. ADA 474556)

Palumbo, M. V., Miller, C. E., Shalin, V. J., \& Steele-Johnson, D. (2005). The impact of job knowledge in the cognitive ability-performance relationship. Applied H. R. M. Research, 10, $13-20$.

Renkl, A., Atkinson, R. K., Maier, U. H., \& Staley, R. (2002). From example study to problem solving: Smooth transitions help learning. The Journal of Experimental Education, 70, 293315.

Roth, J. T., Cherry, W. P., \& Strasel, H. C. (1988). Training systems concept for the armored family of vehicles with consideration of the roles of embedded training and stand-alone training devices. (Research Product 88-21). Alexandria, VA: U.S. Army Research Institute for the Behavioral and Social Sciences. (DTIC No. ADA206381)

Sanders, W. R. (2001). Cognitive psychology principles for digital systems training. (Research Report 1773). Alexandria, VA: U.S. Army Research Institute for the Behavioral and Social Sciences. (DTIC No. ADA391035)

Schaefer, P. S., Blankenbeckler, N. P., \& Brogdon, C. J. (2011). Measuring noncommissioned officer knowledge and experience to enable tailored training. (Research Report 1952). Arlington, VA: U.S. Army Research Institute for the Behavioral and Social Sciences. (DTIC No. ADA552941)

Schaefer, P. S., Blankenbeckler, N. P., \& Lipinski, J. L. (2011). Measuring officer knowledge and experience to enable tailored training. (Research Report 1953). Arlington, VA. U.S. Army Research Institute for the Behavioral and Social Sciences. (DTIC No. ADA552440)

Schaefer, P. S., \& Dyer, J. L. (2013). Defining tailored training approaches for Army institutional training. (Research Report 1965). Fort Belvoir, VA: US Army Research Institute for the Behavioral and Social Sciences.

Schmidt, F. L., Hunter, J. E., \& Outerbridge, A. N. (1986). Impact of job experience and ability on job knowledge, work sample performance, and supervisory ratings of job performance. Journal of Applied Psychology, 71, 432-439. 
U.S. Department of the Army (2010). Index and description of Army training devices. (DA Pamphlet 350-9). Washington, DC: Author.

U.S. Department of the Army (2011). United States Army learning concept for 2015. (TRADOC Pamphlet 525-8-2). Fort Monroe, VA: Training and Doctrine Command.

Thorndike, R. L. (1985). The central role of general ability in prediction. Multivariate Behavioral Research, 20, 241-254.

VanLehn, K. (2011). The relative effectiveness of human tutoring, intelligent tutoring systems and other tutoring systems. Educational Psychologist, 46, 197-221. 


\section{Acronyms}

\begin{tabular}{|c|c|}
\hline AAR & After Action Review \\
\hline ALC & Army Learning Concept \\
\hline ALM & Army Learning Model \\
\hline AIT & Advanced Individual Training \\
\hline APFT & Army Physical Fitness Test \\
\hline AR & Arithmetic Reasoning section of the ASVAB \\
\hline AR BN & Armor Battalion \\
\hline ARI & U.S. Army Research Institute for the Behavioral and Social Sciences \\
\hline ASVAB & Armed Services Vocational Aptitude Battery \\
\hline $\mathrm{BFV}$ & Bradley Fighting Vehicle \\
\hline BRITE & Blended Rotation Interactive Technology Environment \\
\hline CDR & Commander \\
\hline DA & Department of the Army \\
\hline DCG-IMT & Deputy Commanding General for Initial Military Training \\
\hline EIM & Excellence in Maintenance \\
\hline ETS & Education Testing Service \\
\hline GT & General Technical section of the ASVAB \\
\hline HOT & Hands-on Trainer \\
\hline HOTT & Hands-on Turret Trainer \\
\hline IMT & Initial Military Training \\
\hline MCT & Mobile Classroom Trainer \\
\hline MOS & Military Occupational Specialty \\
\hline MM & Mechanical Maintenance section of the ASVAB \\
\hline $\mathrm{N}$ & Number (in sample) \\
\hline ODS & Operation Desert Storm \\
\hline OTD & Ordnance Training Detachment \\
\hline PE & Practical Exercise \\
\hline POI & Program of Instruction \\
\hline$r$ & Pearson’s Correlation \\
\hline SD & Standard Deviation \\
\hline SEP & System Enhanced Package \\
\hline
\end{tabular}


SME

SPSS

TMDE

TR

TRADOC

TSP

VDT

VE
Subject Matter Expert

Statistical Package for the Social Sciences

Test, Measurement, and Diagnostic Equipment

TRADOC Regulation

U.S. Army Training and Doctrine Command

Training Support Package

Vehicle Digital Trainer

Word Knowledge and Paragraph Comprehension sections of the ASVAB 
APPENDIX A

\section{BACKGROUND QUESTIONNAIRE}


Purpose: We want to see what relevant knowledge, skills, and experiences you have when entering this course. We fully expect that Soldiers will differ on these dimensions, ranging from much to little or none.

\section{Background Questionnaire}

Name:

Class/Date:

Answer each of the following questions based on all your personal experience, civilian and military, to date.

1. Based on your actual experience, which of the following platforms are you completely confident in your ability to use without assistance? (Circle all that are appropriate)

(a) desktop computer/personal computer or laptop

(b) smart phone (includes iPhone and Android)

(c) interactive tablets

(d) other (please specify):

2. Which of the following best describes your current expertise with computers and software packages? (Check only one answer.)

(a) ___ Limited experience with computers

(b) __ Good with one type of software package (such as word processing, spreadsheet, Power Point slides)

(c) ___ Good with several software packages

(d) _ Can program in one language (e.g., Cobol, Basic, Java) and use several software packages

(e) __ Can program in several languages and use several software packages

(f) ___ Expert---Bill Gates would hire me 
3. How often have you engaged in routine vehicle maintenance tasks (e.g., changed oil filter, replaced tires) on each of the following vehicle types? How recently have you maintained this vehicle type? (Circle only one answer in the second column. If you chose 'never' in the second column, ignore the third column and proceed to the next vehicle type.)

\begin{tabular}{|c|c|c|}
\hline Vehicle Type & $\begin{array}{c}\text { Frequency of Maintenance (Circle } \\
\text { One) }\end{array}$ & $\begin{array}{c}\text { I Have Maintained This Vehicle } \\
\text { Type in The Last: }\end{array}$ \\
\hline $\begin{array}{c}\text { Typical civilian vehicle (e.g., } \\
\text { pickup truck, motorcycle, car) }\end{array}$ & $\begin{array}{c}\text { Weekly / Monthly / Less Often / } \\
\text { Never }\end{array}$ & $\begin{array}{c}\text { Week / Month / Six Months / } \\
\text { Longer }\end{array}$ \\
\hline $\begin{array}{c}\text { Farm equipment (e.g., tractor) } \\
\text { Weekly / Monthly / Less Often / } \\
\text { Never }\end{array}$ & $\begin{array}{c}\text { Week / Month / Six Months / } \\
\text { Longer }\end{array}$ \\
\hline $\begin{array}{c}\text { Construction equipment (e.g., } \\
\text { bulldozer) }\end{array}$ & $\begin{array}{c}\text { Weekly / Monthly / Less Often / } \\
\text { Never }\end{array}$ & $\begin{array}{c}\text { Week / Month / Six Months / } \\
\text { Longer }\end{array}$ \\
\hline $\begin{array}{c}\text { Recreational vehicle (e.g., four } \\
\text { wheeler) }\end{array}$ & Weekly / Monthly / Less Often / \\
Never & $\begin{array}{c}\text { Week / Month / Six Months / } \\
\text { Longer }\end{array}$ \\
\hline
\end{tabular}

4. How often have you engaged in complex maintenance tasks (e.g., changed transmission, installed new engine) on each of the following vehicle types? How recently have you maintained this vehicle type? (Circle only one answer in the second column. If you chose 'never' in the second column, ignore the third column and proceed to the next vehicle type.)

\begin{tabular}{|c|c|c|}
\hline Vehicle Type & $\begin{array}{c}\text { Frequency of Maintenance (Circle } \\
\text { One) }\end{array}$ & $\begin{array}{c}\text { I Have Maintained This } \\
\text { Vehicle Type in The Last: }\end{array}$ \\
\hline $\begin{array}{c}\text { Typical civilian vehicle (e.g., pickup } \\
\text { truck, car) }\end{array}$ & $\begin{array}{c}\text { Weekly / Monthly / Less Often / } \\
\text { Never }\end{array}$ & $\begin{array}{c}\text { Week / Month / Six Months } \\
\text { / Longer }\end{array}$ \\
\hline $\begin{array}{c}\text { Farm equipment (e.g., tractor) } \\
\text { Weekly / Monthly / Less Often / } \\
\text { Never }\end{array}$ & $\begin{array}{c}\text { Week / Month / Six Months } \\
\text { / Longer }\end{array}$ \\
\hline $\begin{array}{c}\text { Construction equipment (e.g., } \\
\text { bulldozer) }\end{array}$ & $\begin{array}{c}\text { Weekly / Monthly / Less Often / } \\
\text { Never }\end{array}$ & $\begin{array}{c}\text { Week / Month / Six Months } \\
\text { / Longer }\end{array}$ \\
\hline $\begin{array}{c}\text { Recreational vehicle (e.g., four } \\
\text { wheeler) }\end{array}$ & $\begin{array}{c}\text { Weekly / Monthly / Less Often / } \\
\text { Never }\end{array}$ & $\begin{array}{c}\text { Week / Month / Six Months } \\
\text { / Longer }\end{array}$ \\
\hline
\end{tabular}


5. How often have you engaged in routine electrical work (e.g., replacing spark plugs, dealt with home power box)? How recently have you done such a task? (Circle only one answer in the second column. If you chose 'never' in the second column, ignore the third column and proceed to the next electrical task.)

\begin{tabular}{|c|c|c|}
\hline Electrical Task & Frequency of Task (Circle One) & $\begin{array}{c}\text { I Have Done This Task in the } \\
\text { Last: }\end{array}$ \\
\hline Replace spark plugs & $\begin{array}{c}\text { Weekly / Monthly / Less Often / } \\
\text { Never }\end{array}$ & $\begin{array}{c}\text { Week / Month / Six Months } \\
\text { / Longer }\end{array}$ \\
\hline Dealt with home power box & $\begin{array}{c}\text { Weekly / Monthly / Less Often / } \\
\text { Never }\end{array}$ & $\begin{array}{c}\text { Week / Month / Six Months } \\
\text { / Longer }\end{array}$ \\
\hline
\end{tabular}

6. How often have you ever engaged in complex electrical work (e.g., replaced an electrical system in a car, solved an electrical problem using schematic diagrams)? How recently have you done such a task? (Circle only one answer in the second column. If you chose 'never' in the second column, ignore the third column and proceed to the next electrical task.)

\begin{tabular}{|c|c|c|}
\hline Electrical Task & Frequency of Task (Circle One) & $\begin{array}{c}\text { I Have Done This Task in the } \\
\text { Last: }\end{array}$ \\
\hline $\begin{array}{c}\text { Replaced the electrical system, or } \\
\text { a good portion of it, in a car }\end{array}$ & $\begin{array}{c}\text { Weekly / Monthly / Less Often / } \\
\text { Never }\end{array}$ & $\begin{array}{c}\text { Week / Month / Six Months } \\
\text { / Longer }\end{array}$ \\
\hline $\begin{array}{c}\text { Solved electrical problem using } \\
\text { schematic diagrams [Please } \\
\text { identify source: house, car, } \\
\text { tractor, etc.: }\end{array}$ & $\begin{array}{c}\text { Weekly / Monthly / Less Often / } \\
\text { Never }\end{array}$ & $\begin{array}{c}\text { Week / Month / Six Months } \\
\text { / Longer }\end{array}$ \\
\hline
\end{tabular}

7. Have you ever performed a diagnostic test on a vehicle? Yes No

If yes, please indicate type(s) of vehicle(s) and diagnostic procedure(s) in the space below:

8. Have you ever read a technical manual to troubleshoot a vehicle? Yes No If yes, please indicate the context (e.g., you worked at Auto Zone). 
We know that your knowledge of how to maintain a vehicle such as the Abrams tank or Bradley Fighting Vehicle is unique, and can be limited or extensive. Because learning about electronics is a central part of this course, we want a snapshot of what you already know about this area. Please answer the questions below to the best of your ability. If you do not know the answer, please mark "Don't know". What you say will in no way impact your grade in the course and will not be shared with your instructors.

9.

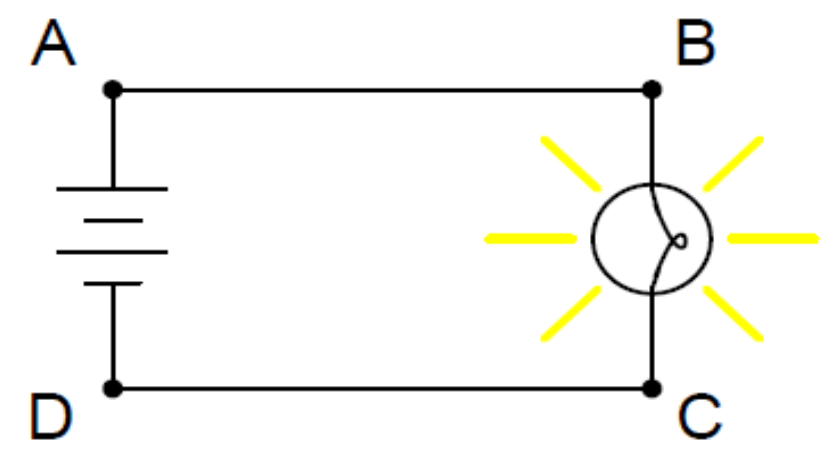

This circuit has four "test points" labeled with the letters A, B, C, and D. Assuming the circuit is functioning (light bulb is energized), determine whether or not there will be substantial voltage between the following sets of points:

- Between A and B:

- Between B and C:

Voltage

No Voltage No Voltage

Don't Know

- Between C and D.

Voltage

No Voltage

Don't Know

- Between D and A:

Voltage

No Voltage

Don't Know

- Between A and C:

Voltage No Voltage

Don't Know

- Between D and B:

Voltage No Voltage

Don't Know

Don't Know 
10. Examine this schematic diagram:

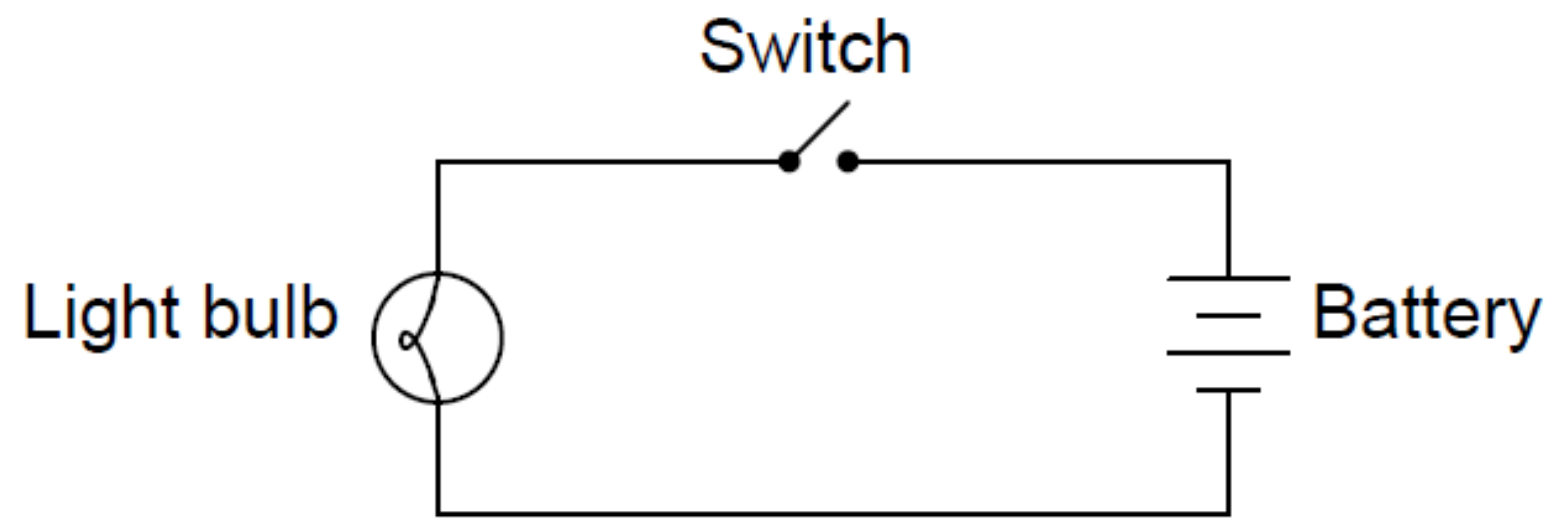

Now, without moving the following components, show how they may be connected together with wires to form the same circuit depicted in the schematic diagram above. Please draw lines indicating the wires.

Light bulb
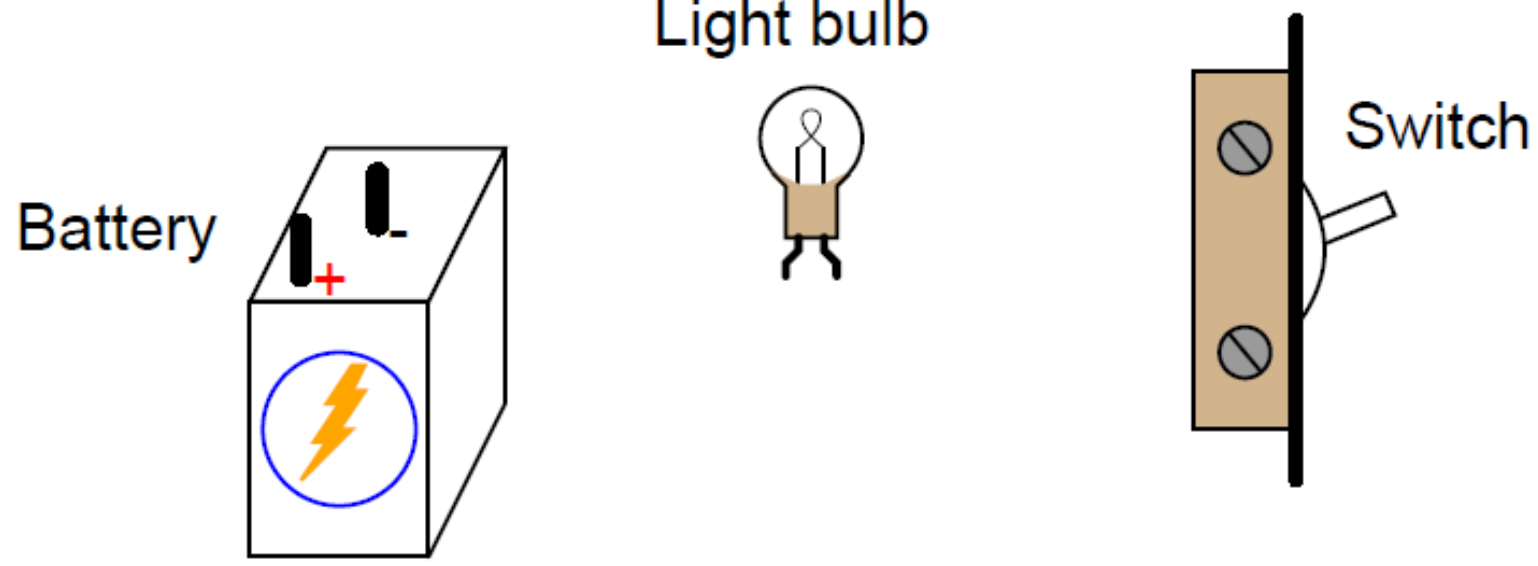

Don't Know 
11. Identify the "circuit symbol" with its corresponding component.

A.

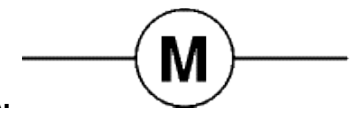

B.

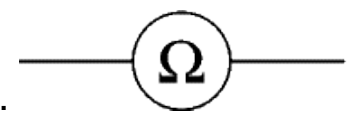

C.

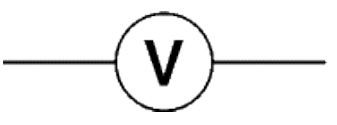

D.

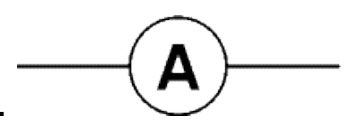

E.

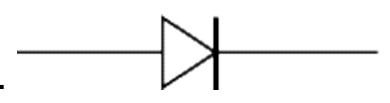

F.

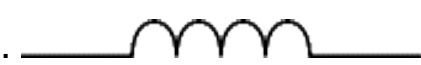

G.

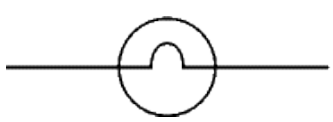

H.

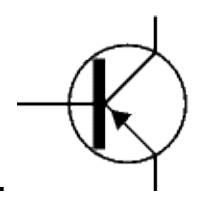

I.

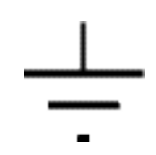

Earth (Ground)

Motor

Transistor PNP

Diode

Lamp (Indicator)

Ammeter

Voltmeter

Ohmmeter

Coil; Solenoid

Don't Know

Don't Know

Don't Know

Don't Know

Don't Know

Don't Know

Don't Know

STOP NOW. DO NOT PROCEED WITHOUT FURTHER INSTRUCTIONS. 


\section{APPENDIX B}

\section{TRAINING OBSERVATION FORMS}


Tailored Training in Armor Vehicle Mnx, 1Jun 12

Circle: 91A 91MCNTRL 91MBRITE

Observer:

Date:

Part I: Training Setting

Training Observation Packet

\section{Iraining Setting}

1. Class \#:

Lesson \# and Title:

2. Location: (classroom/HOTS/equipment bay)

3. \# of instructors: \# of students:

4. (if applicable) \# of workstations/operational HOTS/vehicle stations:

5. Briefly describe the training site (to include key training resources/equipment).

6. Total observation period (24hour): to

7. Circle which of the following training events are planned/scheduled for the training day: Standard Class Practical Exercise Test Review Practical Eval Test (academic) Other:

If other than standard classroom, provide general diagram of site/training area with emphasis on the relative position of Soldiers and Instructor(s) at the beginning of actual training (not administrative announcements or activities): 
Tailored Training in Armor Vehicle Mnx, 1Jun 12

SHEET NUMBER: — Observer: Date:

Part II: Training Class/Session Observations (use for all intact small groups (i.e. instr working with entire or 3-5 of small group) and larger, content related interactions only) \begin{tabular}{|l|l|l|l|l|l|}
\hline Training Group Size (TGS) & EC - entire class & HC - half of class & LG - large group (app 6-10; less than $1 / 2$ class) & SG - small group (3-5) \\
\hline
\end{tabular}

\begin{tabular}{|l|l|l|l|l|l|}
\hline \hline Instruction Code (InstrC) & D1- demonstration & D2 - guided demo & GD - guided discussion & Ot - Other: & BRK (min) - break (duration) \\
\cline { 1 - 3 } RC - review/reinforce content & L1 - lecture & ID - informal discussion & PS - problem solving & & ETD - end of tng day \\
\hline
\end{tabular}

\begin{tabular}{|l|l|l|l|}
\hline Trainer/Instructor Interaction Codes: & E-Provides additional examples & Student Interaction Codes (focus on your assigned small group of Soldiers): \\
\hline A-Asks question & $\begin{array}{l}\text { C-Reviews previous/related } \\
\text { content }\end{array}$ & A - Asks question & $\begin{array}{l}\text { H-Accepts help/support from } \\
\text { peer(s) }\end{array}$ \\
\hline P-Provides feedback on action/performance & $\begin{array}{l}\text { L-Designates a task or group } \\
\text { leader }\end{array}$ & Q-Answers or responds to a question & $\begin{array}{l}\text { T-Completes/attempts a directed } \\
\text { task }\end{array}$ \\
\hline $\begin{array}{l}\text { R-Restates or refocuses the } \\
\text { question/problem }\end{array}$ & T - Directs a task & $\begin{array}{l}\text { L-Takes leadership role or initiative (w/o being } \\
\text { directed) }\end{array}$ & Ot - Other: \\
\hline S-Directly answers the student's question & Ot - Other: & O- Offers/provides help or support to peer(s) & \\
\hline
\end{tabular}

Identify the number of times each type of content related interaction behavior occurs by adding a simple marl by the appropriate interaction code each ti

\begin{tabular}{|c|c|c|c|c|c|c|c|c|c|c|c|}
\hline \multirow{2}{*}{ TGS } & \multirow{2}{*}{$\begin{array}{l}\text { Time } \\
\text { (24hr) } \\
\text { (Note tlme } \\
\text { directed } \\
\text { TGS } \\
\text { changed) }\end{array}$} & \multirow{2}{*}{$\begin{array}{l}\text { InstrC (coded llst of } \\
\text { observed inatruction } \\
\text { actlvitles. Enter gerlise } \\
\text { on saparatet line for } \\
\text { each directed change } \\
\text { in TGS.) }\end{array}$} & \multirow{2}{*}{$\begin{array}{l}\text { Trainer } \\
\text { ALL } \\
\end{array}$} & \multicolumn{2}{|c|}{$\begin{array}{l}\text { Student \# } \\
\text { Initiated Interaction: }\end{array}$} & \multicolumn{2}{|c|}{$\begin{array}{l}\text { Student \# } \\
\text { Initiated Interaction: }\end{array}$} & \multicolumn{2}{|c|}{$\begin{array}{l}\text { Student \# } \\
\text { Initiated Interaction: }\end{array}$} & \multicolumn{2}{|c|}{$\begin{array}{l}\text { Student \# } \\
\text { Initiated Interaction: }\end{array}$} \\
\hline & & & & Trainer & Student & Trainer & Student & Trainer & Student & Trainer & Student \\
\hline & & & $\begin{array}{l}A \\
P \\
R \\
S \\
E \\
C \\
L \\
T \\
O T\end{array}$ & $\begin{array}{l}A \\
P \\
R \\
S \\
E \\
C \\
L \\
T \\
O\end{array}$ & $\begin{array}{l}\text { A } \\
Q \\
\text { L } \\
\circ \\
H \\
T \\
\text { Ot }\end{array}$ & $\begin{array}{l}\text { A } \\
P \\
R \\
S \\
E \\
C \\
L \\
T \\
\text { Ot }\end{array}$ & $\begin{array}{l}A \\
Q \\
L \\
\circ \\
H \\
T \\
\text { Ot }\end{array}$ & $\begin{array}{l}\text { A } \\
P \\
R \\
S \\
E \\
C \\
\text { L } \\
T \\
\text { Ot }\end{array}$ & $\begin{array}{l}\text { A } \\
Q \\
\text { L } \\
0 \\
H \\
T \\
\text { Ot }\end{array}$ & $\begin{array}{l}\text { A } \\
P \\
R \\
S \\
E \\
C \\
\text { L } \\
T \\
\text { Ot }\end{array}$ & $\begin{array}{l}\text { A } \\
Q \\
L \\
\text { L } \\
0 \\
H \\
T \\
\text { Ot }\end{array}$ \\
\hline & & & $\begin{array}{l}A \\
P \\
R \\
S \\
E \\
C \\
L \\
T \\
O t\end{array}$ & $\begin{array}{l}A \\
P \\
R \\
S \\
E \\
C \\
L \\
T \\
O\end{array}$ & $\begin{array}{l}A \\
Q \\
L \\
\circ \\
H \\
T \\
\text { Ot }\end{array}$ & $\begin{array}{l}A \\
P \\
R \\
S \\
E \\
C \\
L \\
T \\
\text { Ot }\end{array}$ & $\begin{array}{l}\text { A } \\
Q \\
L \\
\circ \\
H \\
T \\
\text { Ot }\end{array}$ & $\begin{array}{l}A \\
P \\
R \\
S \\
E \\
C \\
L \\
T \\
O t\end{array}$ & $\begin{array}{l}A \\
Q \\
L \\
\circ \\
H \\
T \\
\text { Ot }\end{array}$ & $\begin{array}{l}A \\
P \\
R \\
S \\
E \\
C \\
L \\
T \\
O t\end{array}$ & $\begin{array}{l}\text { A } \\
Q \\
\text { L } \\
0 \\
H \\
T \\
\text { Ot }\end{array}$ \\
\hline
\end{tabular}


Tailored Training in Armor Vehicle Mnx, 1Jun 12

SHEET NUMBER: — Observer:
Date:

Part Il: Training Class/Session Observations (use for all intact small groups (i.e. instr working with entire or 3-5 of small group) and larger, content related interactions only) \begin{tabular}{|l|l|l|l|l|l|}
\hline Training Group Size (TGS) & EC - entire class & HC - half of class & LG - large group (app 6-10; less than 1/2 class) & SG - small group (3-5) \\
\hline
\end{tabular}

\begin{tabular}{|c|c|c|c|c|c|}
\hline Instruction Code (InstrC) & D1-demonstration & D2 - guided demo & GD - guided discussion & Ot - Other: & BRK (min) - break (duration) \\
\hline
\end{tabular}
\begin{tabular}{|l|l|l|l|}
\hline Trainer/Instructor Interaction Codes: & E-Provides additional examples & Student Interaction Codes (focus on your assigned small group of Soldiers): \\
\hline A
\end{tabular}

\begin{tabular}{|l|l|l|l|}
\hline Trainer/Instructor Interaction Codes: & E-Provides additional examples & Student Interaction Codes (focus on your assigned small group of Soldiers): \\
\hline A-Asks question & $\begin{array}{l}\text { C-Reviews previous/related } \\
\text { content }\end{array}$ & A-Asks question & $\begin{array}{l}\mathrm{H}-\text { Accepts help/support from } \\
\text { peer(s) }\end{array}$ \\
\hline P-Provides feedback on action/performance & $\begin{array}{l}\text { L-Designates a task or group } \\
\text { leader }\end{array}$ & Q-Answers or responds to a question & $\begin{array}{l}\text { T-Completes/attempts a directed } \\
\text { task }\end{array}$ \\
\hline $\begin{array}{l}\text { R-Restates or refocuses the } \\
\text { question/problem }\end{array}$ & T - Directs a task & $\begin{array}{l}\text { L-Takes leadership role or initiative (w/o being } \\
\text { directed) }\end{array}$ & Ot - Other: \\
\hline S-Directly answers the student's question & Ot - Other: & O- Offers/provides help or support to peer(s) & \\
\hline
\end{tabular}

\begin{tabular}{l|l|l} 
S - Directly answers the student's question & Ot - Other: & 0 - Offers/provides help or support to peer(s)
\end{tabular}

Identify the number of times each type of content related interaction behavior occurs by adding a simple mark by the appropriate inter action code each time it is observed. These marks will be tallied at the

\begin{tabular}{|c|c|c|c|c|c|c|c|c|c|c|c|}
\hline \multirow[b]{2}{*}{ TGS } & \multirow{2}{*}{$\begin{array}{l}\text { Time } \\
\text { (24hr) } \\
\text { (Not) time } \\
\text { directed } \\
\text { TGS } \\
\text { changed) }\end{array}$} & \multirow{2}{*}{ 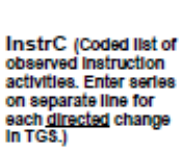 } & \multirow{2}{*}{$\begin{array}{l}\text { Trainer } \\
\text { ALL } \\
\end{array}$} & \multicolumn{2}{|c|}{$\begin{array}{l}\text { Student \# } \\
\text { Initiated Interaction: }\end{array}$} & \multicolumn{2}{|c|}{$\begin{array}{l}\text { Student \# } \\
\text { Initiated Interaction: }\end{array}$} & \multicolumn{2}{|c|}{$\begin{array}{l}\text { Student \# } \\
\text { Initiated Interaction: }\end{array}$} & \multicolumn{2}{|c|}{$\begin{array}{l}\text { Student \# } \\
\text { Initiated Interaction: }\end{array}$} \\
\hline & & & & $\begin{array}{l}\text { Trainer } \\
\end{array}$ & Student & Trainer & Student & Trainer & Student & Trainer & Student \\
\hline & & & $\begin{array}{l}A \\
P \\
R \\
S \\
E \\
C \\
L \\
T \\
O t\end{array}$ & $\begin{array}{l}\text { A } \\
P \\
R \\
S \\
E \\
C \\
\text { L } \\
T \\
\text { Ot }\end{array}$ & $\begin{array}{l}\text { A } \\
Q \\
\text { L } \\
0 \\
H \\
T \\
\text { Ot }\end{array}$ & $\begin{array}{l}\text { A } \\
P \\
R \\
S \\
E \\
C \\
\text { L } \\
T \\
\text { Ot }\end{array}$ & $\begin{array}{l}\text { A } \\
Q \\
L \\
\circ \\
H \\
T \\
O t\end{array}$ & $\begin{array}{l}\text { A } \\
P \\
R \\
S \\
E \\
C \\
\text { L } \\
T \\
\text { Ot }\end{array}$ & $\begin{array}{l}\text { A } \\
Q \\
L \\
\circ \\
H \\
T \\
\text { Ot }\end{array}$ & $\begin{array}{l}\text { A } \\
P \\
R \\
S \\
E \\
C \\
\text { L } \\
T \\
\text { Ot }\end{array}$ & $\begin{array}{l}\text { A } \\
Q \\
L \\
O \\
H \\
T \\
O t\end{array}$ \\
\hline & & & $\begin{array}{l}A \\
P \\
R \\
S \\
E \\
C \\
L \\
T \\
O t\end{array}$ & $\begin{array}{l}A \\
P \\
R \\
S \\
E \\
C \\
L \\
T \\
O t\end{array}$ & $\begin{array}{l}A \\
Q \\
L \\
\circ \\
H \\
T \\
\text { Ot }\end{array}$ & $\begin{array}{l}A \\
P \\
R \\
S \\
E \\
C \\
L \\
T \\
\text { Ot }\end{array}$ & $\begin{array}{l}\text { A } \\
Q \\
L \\
\circ \\
H \\
T \\
O t\end{array}$ & $\begin{array}{l}A \\
P \\
R \\
S \\
E \\
C \\
L \\
T \\
O t\end{array}$ & $\begin{array}{l}A \\
Q \\
L \\
O \\
H \\
T \\
\text { Ot }\end{array}$ & $\begin{array}{l}A \\
P \\
R \\
S \\
E \\
C \\
L \\
T \\
O t\end{array}$ & $\begin{array}{l}\text { A } \\
Q \\
L \\
\text { L } \\
0 \\
H \\
T \\
\text { Ot }\end{array}$ \\
\hline
\end{tabular}


Tailored Training in Armor Vehicle Mnx, 1Jun 12

SHEET NUMBER: — Observer:
Date:

Part lla: Divided Small Group Observations (use for all divided small groups (i.e. Instr working with 1 to 2 students with others observing); content related interactions only) \begin{tabular}{|l|l|l|l|l|l|}
\hline Instruction Code (InstrC) & D1 - demonstration & D2 - guided demo & GD - guided discussion & Ot - Other. & BRK (min) - break (duration) \\
\cline { 1 - 2 } RC - review/reinforce content & L1 - lecture & ID - informal discussion & PS - problem solving & & ETD of thy day
\end{tabular}

\begin{tabular}{|c|c|c|c|}
\hline Trainer/Instructor Interaction Codes: & C-Reviews previous/related content & \multicolumn{2}{|c|}{ Observing Student Interaction Codes (focus only on content based interactions): } \\
\hline A-Asks question & $\mathrm{L}$-Designates a task or group leader & A-Asks instructor a question & Q-Answers or responds to instr question \\
\hline $\begin{array}{l}\text { H-Highlights points from focal group thg } \\
\text { scenario and actions }\end{array}$ & D-Designates a peer instructor & $\begin{array}{l}\mathrm{L}-\text { Takes leadership role or initiative } \\
\text { (w/o being directed) }\end{array}$ & $\mathrm{T}-$ Completes/attempts a directed task \\
\hline $\begin{array}{l}\text { T-Directs a task or provides a problem to be } \\
\text { solved }\end{array}$ & $\begin{array}{l}\text { B-Control behavior, refocus attention on } \\
\text { tng contentlevent }\end{array}$ & $\begin{array}{l}\text { O-Offers/provides help or support to } \\
\text { peer(s) }\end{array}$ & Ot - Other (specify) \\
\hline $\begin{array}{l}\text { S-Directly answers an observing student's } \\
\text { question }\end{array}$ & Ot - Other: & H-Accepts help/support from peer(s) & \\
\hline
\end{tabular}
question

Identify the number of times each type of content related inter action behavior occurs by adding a simple mark by the appropriate interaction code each time it is observed. These marks will be tallied at the end of the day for data entry. Due to the need to attend to 2 subgroups at the same time, focus on changes in the instructional strategy by the instructor with the focal training student(s) and interactions with he observig strd dise The trainig setting and reduce the noise generated by a

\begin{tabular}{|c|c|c|c|c|c|c|c|c|c|c|c|}
\hline \multirow{2}{*}{$\begin{array}{l}\text { Student } \\
\text { \#in } 1-1 \\
\text { or } 1-2 \\
\text { thg } \\
\text { winstr }\end{array}$} & \multirow{2}{*}{$\begin{array}{l}\text { Time } \\
\text { (24hr) } \\
\text { (Note } \\
\text { time focal } \\
\text { student(s) } \\
\text { change) }\end{array}$} & \multirow{2}{*}{$\begin{array}{l}\text { Trainer: Instruction } \\
\text { w/Focal } \\
\text { Student'Pair }\end{array}$} & \multirow{2}{*}{$\begin{array}{l}\text { Trainer: } \\
\text { Interaction with } \\
\text { Remaining/Observing } \\
\text { Students } \\
\text { ALL Observing Students } \\
\end{array}$} & \multicolumn{2}{|c|}{ Student \# } & \multicolumn{2}{|c|}{ Student \# } & \multicolumn{2}{|c|}{ Student \# } & \multicolumn{2}{|c|}{ Student \# } \\
\hline & & & & Trainer & Student & Trainer & Student & Trainer & Student & Trainer & Student \\
\hline & & $\begin{array}{l}\text { D1 } \\
\text { D2 } \\
\text { GD } \\
\text { RC } \\
\text { L1 } \\
\text { ID } \\
\text { PS } \\
\text { Ot }\end{array}$ & $\begin{array}{l}\text { A } \\
\text { H } \\
\text { T } \\
\text { S } \\
\text { C } \\
\text { L } \\
\text { D } \\
\text { B } \\
\text { Ot }\end{array}$ & $\begin{array}{l}\text { A } \\
\text { H } \\
\text { T } \\
\text { S } \\
\text { C } \\
\text { L } \\
\text { D } \\
\text { B } \\
\text { Ot }\end{array}$ & $\begin{array}{l}\text { A } \\
\text { L } \\
O \\
H \\
Q \\
\text { T } \\
\text { Ot }\end{array}$ & $\begin{array}{l}\text { A } \\
H \\
\text { T } \\
\text { S } \\
\text { C } \\
\text { L } \\
\text { D } \\
\text { B } \\
\text { Ot }\end{array}$ & $\begin{array}{l}\text { A } \\
\text { L } \\
O \\
H \\
Q \\
\text { T } \\
\text { Ot }\end{array}$ & $\begin{array}{l}\text { A } \\
H \\
\text { T } \\
\text { S } \\
\text { C } \\
\text { L } \\
\text { D } \\
\text { B } \\
\text { Ot }\end{array}$ & $\begin{array}{l}\text { A } \\
\text { L } \\
O \\
H \\
Q \\
T \\
\text { Ot }\end{array}$ & $\begin{array}{l}\text { A } \\
\text { H } \\
\text { T } \\
\text { S } \\
\text { C } \\
\text { L } \\
\text { D } \\
\text { B } \\
\text { Ot }\end{array}$ & $\begin{array}{l}\text { A } \\
\text { L } \\
0 \\
H \\
\text { Q } \\
T \\
\text { Ot }\end{array}$ \\
\hline & & $\begin{array}{l}\text { D1 } \\
D 2 \\
\text { GD } \\
\text { RC } \\
\text { L1 } \\
\text { ID } \\
\text { PS } \\
\text { Ot }\end{array}$ & $\begin{array}{l}\text { A } \\
\text { H } \\
\text { T } \\
\text { S } \\
\text { C } \\
\text { L } \\
\text { D } \\
\text { B } \\
\text { Ot }\end{array}$ & $\begin{array}{l}\text { A } \\
\text { H } \\
\text { T } \\
\text { S } \\
\text { C } \\
\text { L } \\
\text { D } \\
\text { B } \\
\text { Ot }\end{array}$ & $\begin{array}{l}\text { A } \\
\text { L } \\
0 \\
H \\
Q \\
T \\
\text { Ot }\end{array}$ & $\begin{array}{l}\text { A } \\
\text { H } \\
\text { T } \\
\text { S } \\
\text { C } \\
\text { L } \\
\text { D } \\
\text { B } \\
\text { Ot }\end{array}$ & $\begin{array}{l}\text { A } \\
\text { L } \\
0 \\
H \\
Q \\
T \\
\text { Ot }\end{array}$ & $\begin{array}{l}\text { A } \\
\text { H } \\
\text { T } \\
\text { S } \\
\text { C } \\
\text { L } \\
\text { D } \\
\text { B } \\
\text { Ot }\end{array}$ & $\begin{array}{l}\text { A } \\
\text { L } \\
O \\
H \\
\text { Q } \\
\text { T } \\
\text { Ot }\end{array}$ & $\begin{array}{l}\text { A } \\
\text { H } \\
\text { T } \\
\text { S } \\
\text { C } \\
\text { L } \\
\text { D } \\
\text { B } \\
\text { Ot }\end{array}$ & $\begin{array}{l}\text { A } \\
\text { L } \\
0 \\
H \\
Q \\
T \\
\text { Ot }\end{array}$ \\
\hline
\end{tabular}


Tailored Training in Armor Vehicle Mnx, 1Jun 12

Part III: Practical Evaluation Observation

SHEET NUMBER:

Observ:

Evaluation Topic/Task: different, please briefly describe how they differed

Were all Soldiers presented the same evaluation scenario/task? (circle one) Yes No If

\begin{tabular}{|c|c|c|c|c|}
\hline $\begin{array}{l}\text { Time } \\
\text { Observation } \\
\text { Start/stop } \\
\text { (24hr) }\end{array}$ & Obs Setting: & $\begin{array}{l}\text { Trainerilnstructor Role(s): } \\
\text { Identify frequency each of the } \\
\text { following qoles are observed: } \\
\text { Q- Answers Questions } \\
\text { C- Reviews Content } \\
\text { P- Provides Feedback } \\
\text { I-Provides Instruction } \\
\text { O- Observe Soldiers } \\
\text { (passive presence; noneval) } \\
\text { Ot - Other: }\end{array}$ & $\begin{array}{l}\text { Peer coaching or } \\
\text { instruction observed? } \\
\text { Yes/No } \\
\text { If yes, then identify obs of. } \\
\text { P- } 1 \text { on } 1 \text { (pair) } \\
G-S m a l \text { Group (3.5) } \\
O t-\text { Other. }\end{array}$ & $\begin{array}{l}\text { Narrative Observations/Descriptions/Comments (including specific topic(s), if any. } \\
\text { reviewed in PreEval and Post Eval sessions): }\end{array}$ \\
\hline & $\begin{array}{l}\text { PreEval Review/Prep Area } \\
\text { \# Instructors Present: }\end{array}$ & $\begin{array}{l}Q \\
C \\
P \\
1 \\
0 \\
O t\end{array}$ & $\begin{array}{l}P \\
G \\
O t\end{array}$ & \\
\hline & $\begin{array}{l}\text { Post Eval Area } \\
\text { \# Instructors Present: } \\
\text { If thg conducted, identify topic \& } \\
\text { describe content in comments. Also, } \\
\text { describe ting setting. }\end{array}$ & $\begin{array}{l}Q \\
c \\
P \\
1 \\
0 \\
\text { Ot }\end{array}$ & $\begin{array}{l}P \\
G \\
O t\end{array}$ & \\
\hline & $\begin{array}{l}\text { Post Eval Review/AAR } \\
\text { \# Instructors Present: } \\
\text { Session conducted (circle one): } \\
\text { 1-1 with primary small group instr } \\
\text { In small group with primary small } \\
\text { group instr } \\
\text { Other (specify): }\end{array}$ & $\begin{array}{l}Q \\
C \\
P \\
1 \\
0 \\
O \\
O t\end{array}$ & $\begin{array}{l}P \\
G \\
O t\end{array}$ & \\
\hline
\end{tabular}


Tailored Training in Armor Vehicle Mnx, 1Jun 12

SHEET NUMBER:

Observer:

Date:

Part IV: Overall Conclusions and Assessment/Final Notes

Complete this part at the end of the day's observations by reflecting upon the entire training day and across all observed individual or group activities and training interactions.

\begin{tabular}{|c|c|c|c|c|c|c|}
\hline \multicolumn{2}{|c|}{$Q \#$} & \multirow{2}{*}{$\begin{array}{l}\text { Observation } \\
\text { Soldier/Soldier training interactions were most often: } \\
1 \text { - Directed by the instructor } \\
2 \text { - Initiated by the Soldiers } \\
4-\text { Not Observed }\end{array}$} & \multirow[t]{2}{*}{1} & \multirow[t]{2}{*}{2} & \multirow[t]{2}{*}{3} & \multirow[t]{2}{*}{4} \\
\hline 1 & & & & & & \\
\hline 2 & & $\begin{array}{l}\text { Soldier/instructor training interactions were most often: } \\
1 \text { - Initiated by the instructor } \\
2 \text { - Initiated by the Soldiers } \\
4-\text { Not Observed }\end{array}$ & & & & \\
\hline 4 & & $\begin{array}{l}\text { In } 4 a \text { through } 4 \text { f rate the frequency you observed the identified types of tailored } \\
\text { training strategies using the following scale: } \\
\qquad 1 \text {-Seldom/Rarely, } 2 \text {-Sometimes, } 3 \text { - Regularly, } 4 \text { - Not observed }\end{array}$ & & & & \\
\hline & $4 a$ & $\begin{array}{l}\text { Scaffolding (Instructor enables the student to master a task or concept that the student is initially } \\
\text { unable to grasp on their own by temporarily modeling or providing prompts, cues, and feedback on } \\
\text { those skills or steps that are currently beyond the student's demonstrated capability. Once the student } \\
\text { begins to show they can accomplish the steps or task, the instructor withdraws their help (often } \\
\text { referred to as "fading" or removing the scaffolding) to allow the student to proceed on their own.) }\end{array}$ & & & & \\
\hline & $4 b$ & $\begin{array}{l}\text { Backwards Fading (Instructor provides a complete demonstration of the task or procedure, } \\
\text { followed by a progressive reduction of instructor guidance and an increasingly autonomous role by the } \\
\text { student in subsequent repetitions of the task.) }\end{array}$ & & & & \\
\hline & $4 c$ & $\begin{array}{l}\text { Didactic / Lecture (Instructor provides information with little to no opportunity for } \\
\text { student/instructor interaction or discussion beyond the clarification of presented facts or points.) }\end{array}$ & & & & \\
\hline & $4 d$ & $\begin{array}{l}\text { Comprehension Gauging (Instructor confirms students are attending to and following the } \\
\text { presented content; may or may not involve a brief knowledge check of recent content) }\end{array}$ & & & & \\
\hline & $4 \mathrm{e}$ & $\begin{array}{l}\text { Simple (Yes / No) ( simple and direct assessment of or reaction to the accuracy of a student's } \\
\text { answer, explanation, statement, etc., with no further elaboration) }\end{array}$ & & & & \\
\hline & $4 f$ & Other (specify): & & & & \\
\hline 5 & & $\begin{array}{l}\text { Did the instructors direct individual Soldiers to assume specific roles within the } \\
\text { group (e.g., peer instructor, group leader, etc.)? } \\
\begin{array}{l}1-\text { Yes } \\
2-\text { No }\end{array}\end{array}$ & & & & \\
\hline & $5 a$ & If the answer to question 5 is yes, what roles were directed? & & & & \\
\hline & $5 b$ & If yes to (5), on what basis were the Soldiers chosen for these roles (if discernible): & & & & \\
\hline & $5 c$ & $\begin{array}{l}\text { What, if any, impact did these roles have on Soldier behavior and interaction (if } \\
\text { none, so indicate)? }\end{array}$ & & & & \\
\hline 6 & & $\begin{array}{l}\text { Were there occasions in which Soldiers observed other Soldiers perform a task } \\
\text { while assembled in their intact small group or larger groups? } \\
\begin{array}{l}1-\text { Yes } \\
2-\text { No }\end{array}\end{array}$ & & & & \\
\hline & $6 a$ & $\begin{array}{l}\text { If the answer to question } 6 \text { is yes, approximately how many times was this } \\
\text { observed? }\end{array}$ & & & & \\
\hline
\end{tabular}


Tailored Training in Armor Vehicle Mnx, 1Jun 12

\begin{tabular}{|c|c|c|c|c|c|c|}
\hline \multicolumn{2}{|c|}{$Q \#$} & Observation & 1 & 2 & 3 & 4 \\
\hline 7 & & $\begin{array}{l}\text { To what extent did the Soldiers appear passive and inattentive to the team's } \\
\text { actions or class activities? (includes social loafing, nonparticipation or lack of overt } \\
\text { engagement in training activities, etc.) } \\
\quad 1 \text {-Seldom/Rarely, } 2 \text { - Sometimes, } 3 \text { - Regularly, } 4 \text { - Not observed }\end{array}$ & & & & \\
\hline \multirow[t]{2}{*}{8} & & $\begin{array}{l}\text { Were Soldiers observed coming together as a group or in pairs to work on a task } \\
\text { or review covered material without being directed to do so by the instructor? } \\
\begin{array}{l}1-\text { Yes } \\
2 \text { - No }\end{array}\end{array}$ & & & & \\
\hline & $8 a$ & $\begin{array}{l}\text { If yes to item } 8 \text {, rate the frequency Soldiers were observed working together in } \\
\text { groups/pairs using the following scale: } \\
1 \text {-Seldom/Rarely, } 2 \text {-Sometimes, } 3 \text { - Regularly, } 4 \text { - Not observed }\end{array}$ & & & & \\
\hline 9 & & $\begin{array}{l}\text { Rate the overall level of Soldier engagement during the day's training using the } \\
\text { following scale: } \\
\begin{array}{l}\text { 1- Low (Passively received instruction) } \\
2 \text { - Average } \\
3 \text { - High (Consistently and actively engaged in all training events/activities) } \\
4 \text { - Not observed }\end{array}\end{array}$ & & & & \\
\hline \multirow[t]{2}{*}{10} & & $\begin{array}{l}\text { Overall, reflecting upon the day's training, the instructor's comments and } \\
\text { feedback focused on the Soldiers' (check all observed categories ): } \\
1 \text { - Comprehension of Material } \\
2 \text { - Task Performance } \\
3 \text { - Attention to Ongoing Training Event } \\
4 \text { - Active Participation in Training Event } \\
5 \text { - Conduct/Discipline Issues (during training) } \\
6 \text { - Overall Course Progress } \\
7 \text { - Sequence of Training Activities } \\
8 \text { - Nontraining Issues (e.g. external conduct, quality of life) }\end{array}$ & & & & \\
\hline & $10 \mathrm{a}$ & $\begin{array}{l}\text { Of the categories checked in item } 10 \text { above, circle the ONE that reflects the } \\
\text { dominate/primary/most frequently observed focus of the instructor's comments } \\
\text { and feedback throughout the day. }\end{array}$ & & & & \\
\hline \multirow[t]{6}{*}{11} & & $\begin{array}{l}\text { BRITE class only! In 11a through 11e, rate the frequency each of the following } \\
\text { BRITE training options was used during the training day using the following scale: } \\
1 \text { - Seldom/Rarely, } 2 \text { - Sometimes, } 3 \text { - Regularly, } 4 \text { - Not observed }\end{array}$ & & & & \\
\hline & $11 \mathrm{a}$ & Live feed instruction demonstration or guided demonstration & & & & \\
\hline & $11 b$ & Live feed one-on-one or one-on-two training & & & & \\
\hline & $11 \mathrm{c}$ & Training presentation (on task) & & & & \\
\hline & $11 \mathrm{~d}$ & Current Training presentation (specify topic(s)) & & & & \\
\hline & $11 \mathrm{e}$ & Other (specify) & & & & \\
\hline
\end{tabular}


Tailored Training in Armor Vehicle Mnx, 1Jun 12

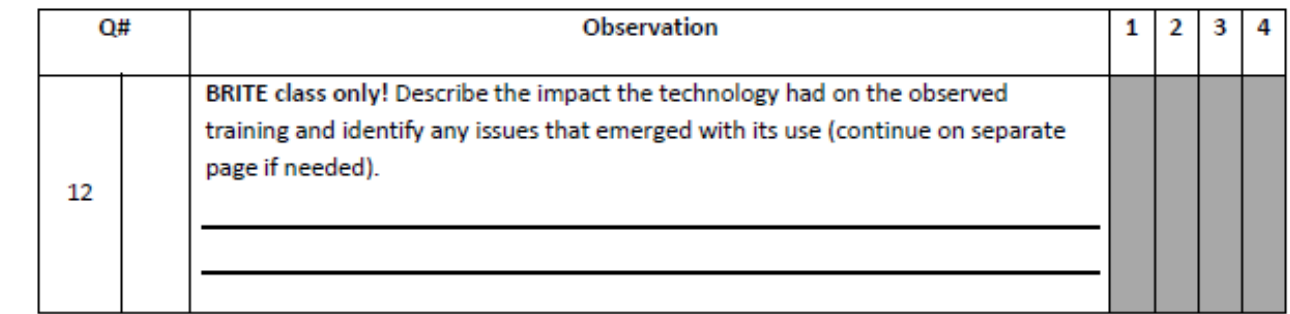

Provide any additional comments, observations, or clarifications regarding the day's training events: 
APPENDIX C

TRAINING CONFIGURATIONS

C-1 


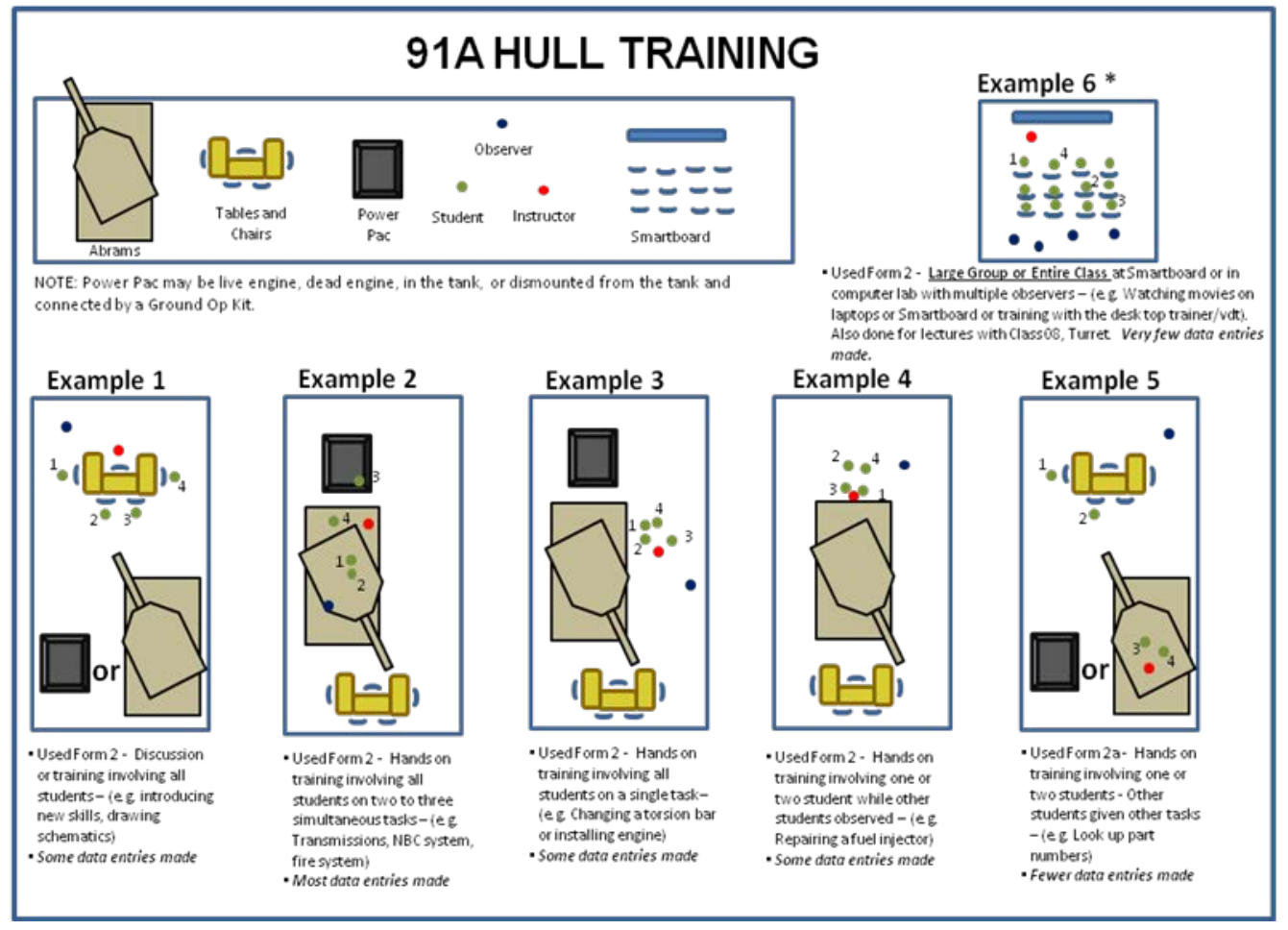

Figure C-1. 91A hull training layout.

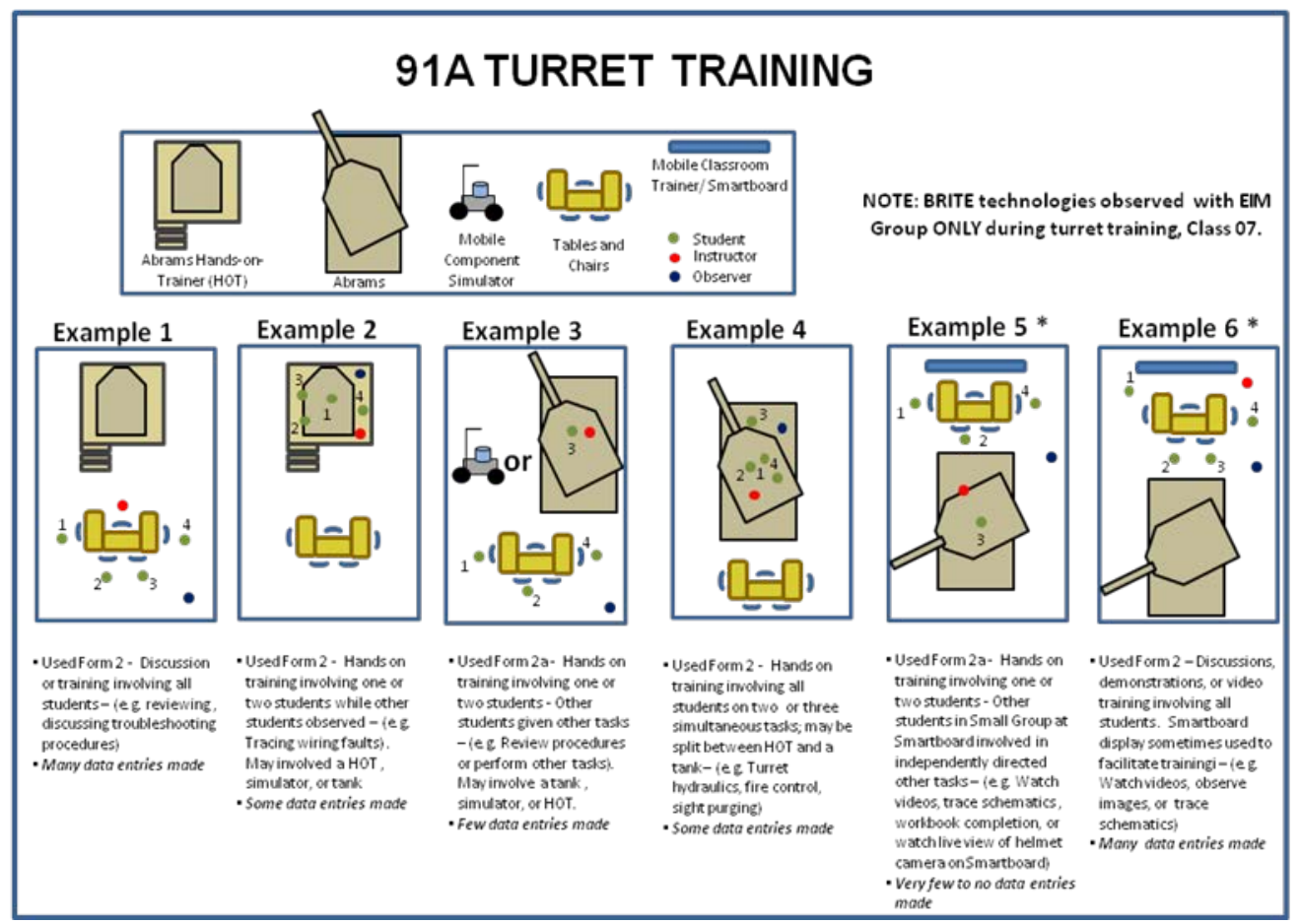

Figure $\boldsymbol{C}$-2. 91A turret training layout. 


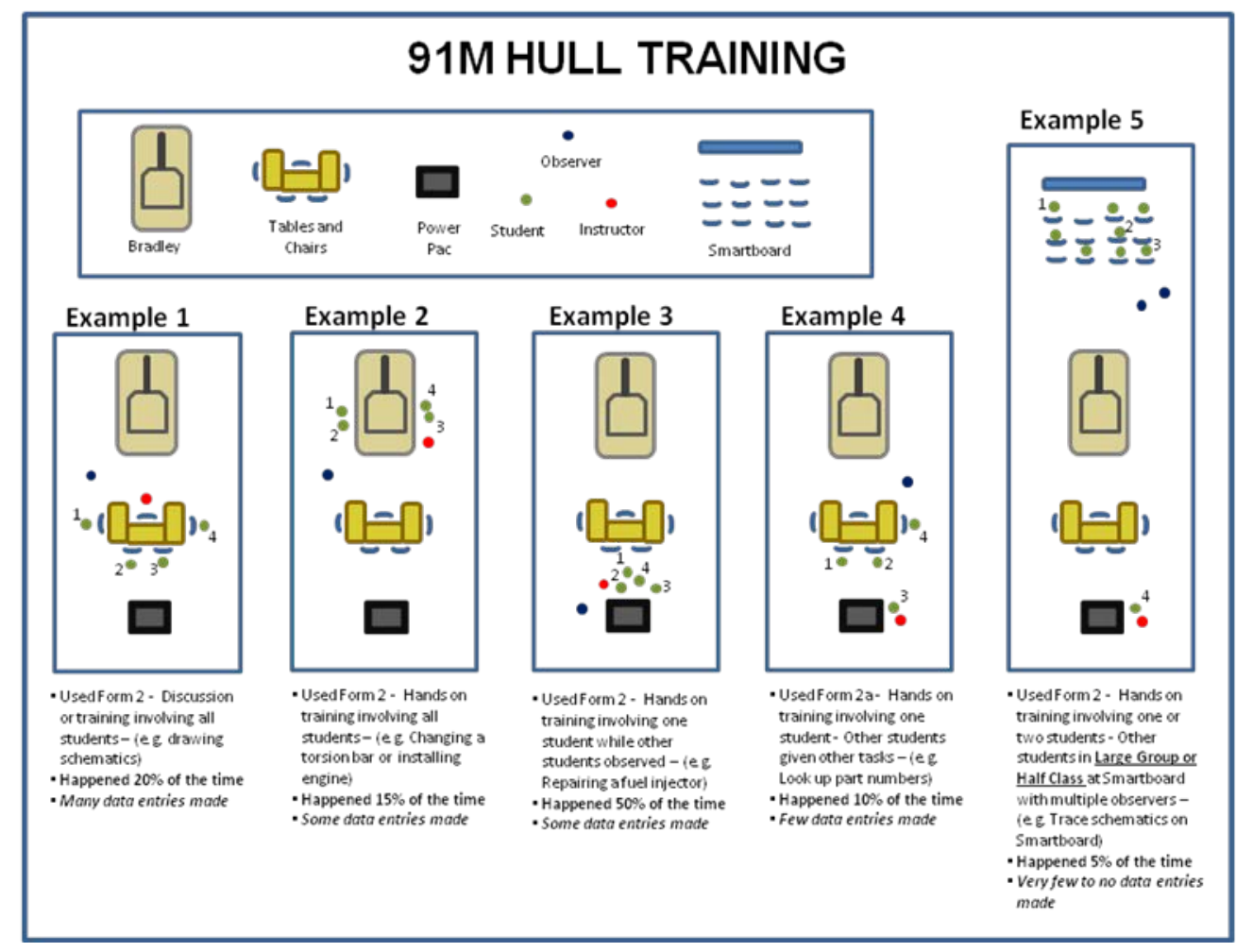

Figure C-3. 91M hull training layout.

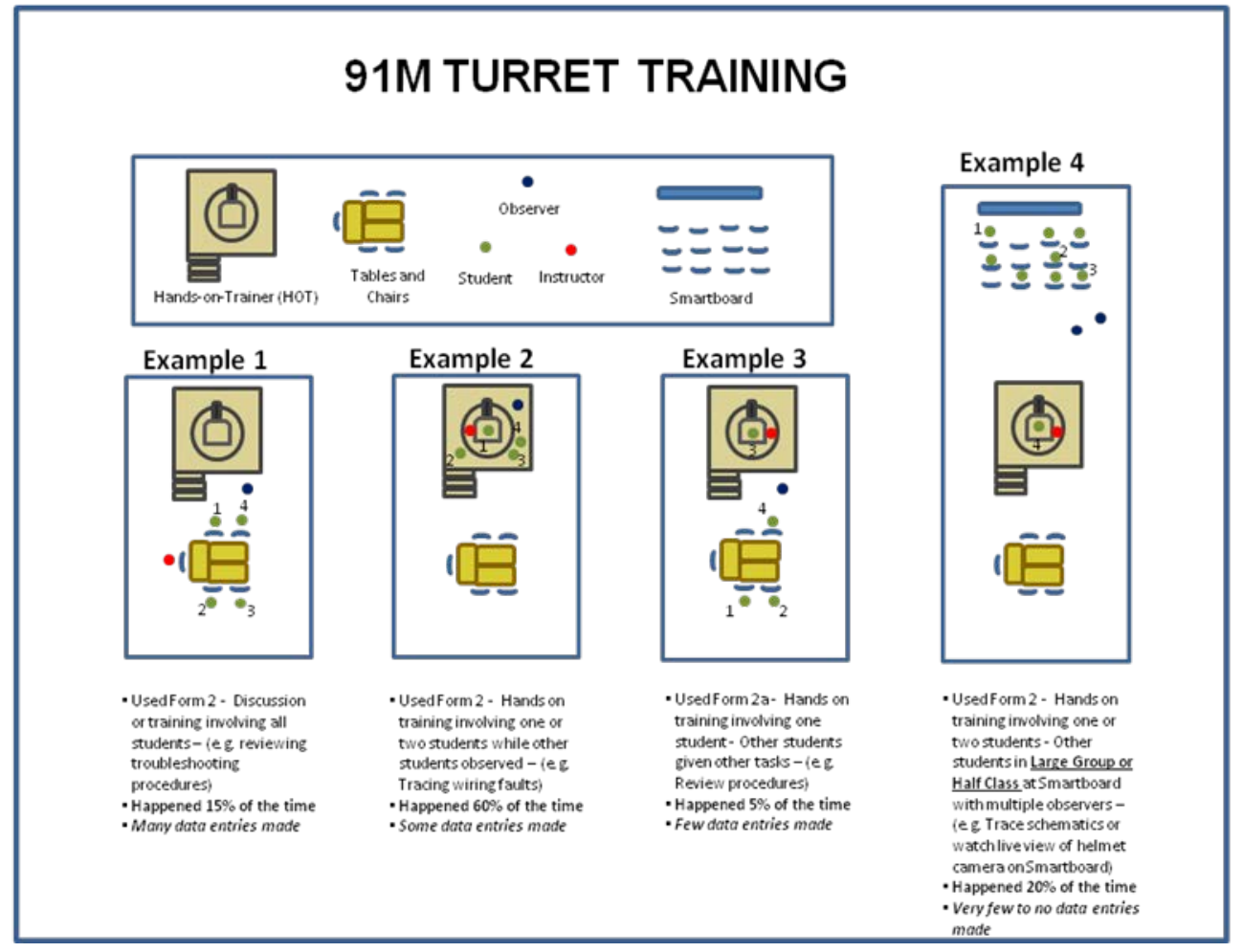

Figure C-4. 91M turret training layout. 


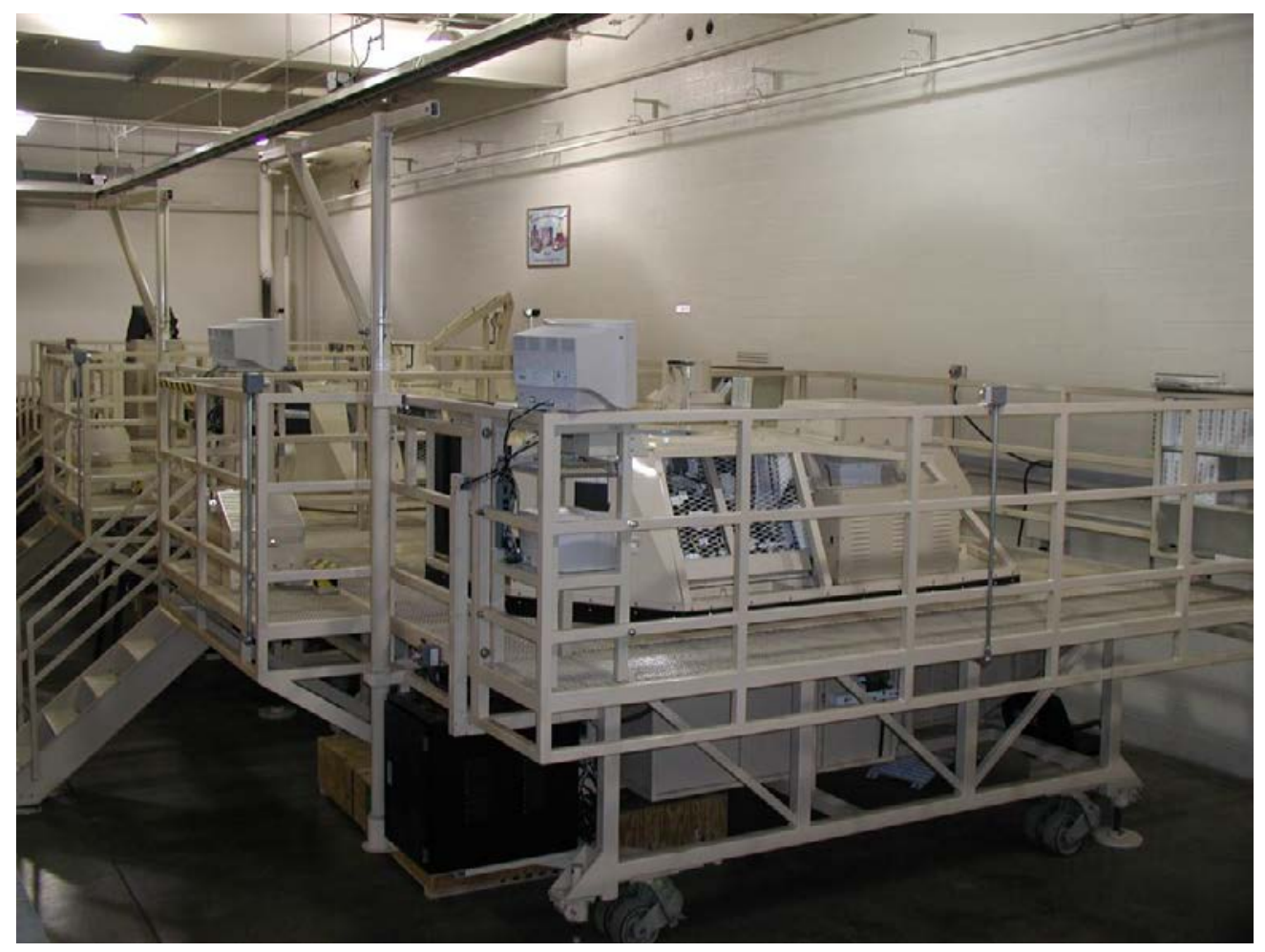

Figure C-5. M1A2 Abrams SEP Hands-on Trainer (HOT).

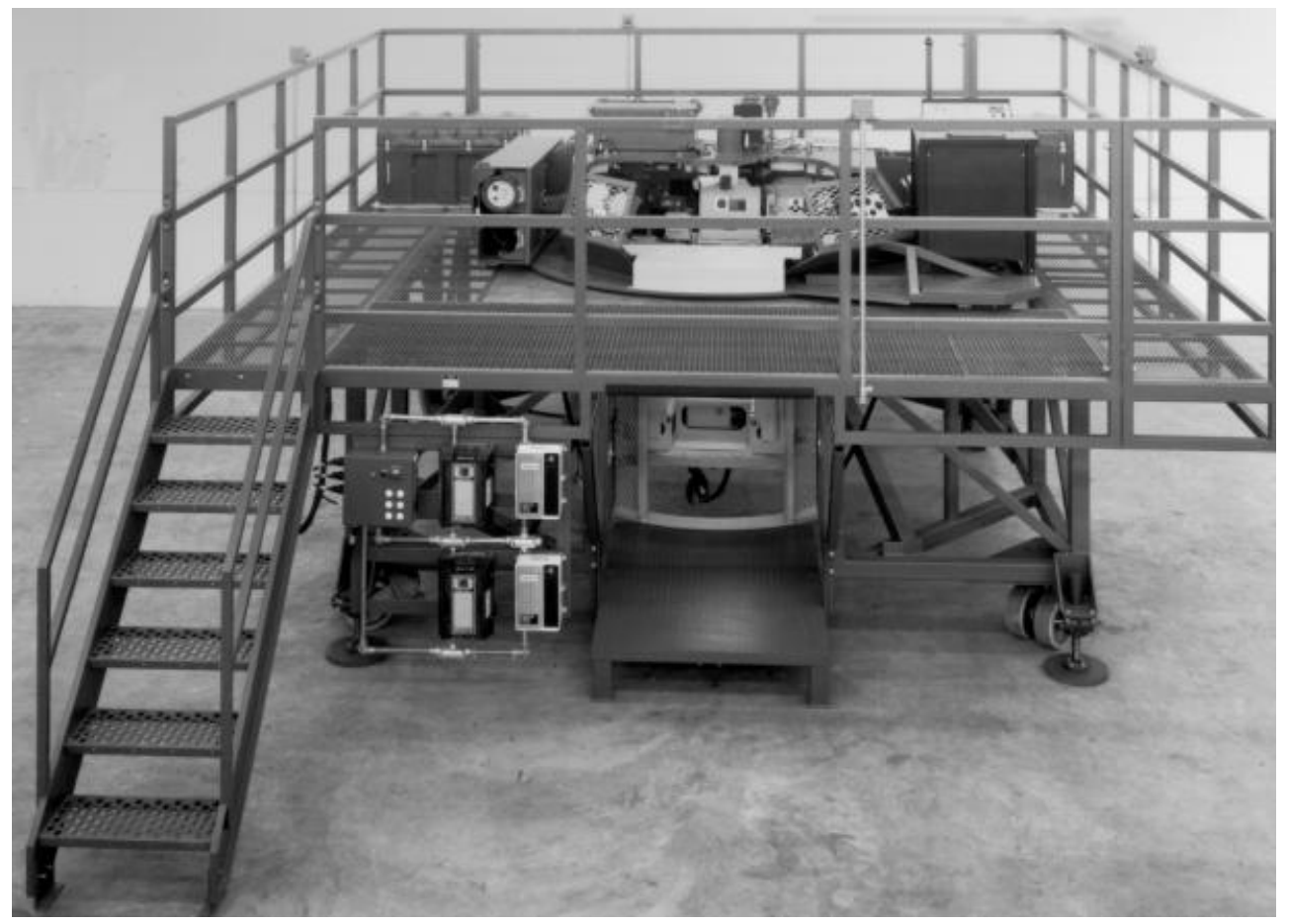

Figure C-6. M2A1/M3A1 BFV Hands-on Trainer (HOT). 


\section{APPENDIX D}

FOCUS GROUP INTERVIEW PROTOCOLS 


\section{Tailored Training in Vehicle Maintenance Course SOLDIER'S FOCUS GROUP PROTOCOL}

Circle: 91A 91M-Control 91M-BRITE Course \#/ Group:

Facilitator:

Date:

\section{INSTRUCTIONS FOR FACILITATOR/INTERVIEWER}

- Introduce the session (see below) including its role in this assessment of tailored training (and BRITE technology if applicable).

- Ensure careful notes are taken, preferably by a team member when available.

- Dialogue with the participants using the questions that begin on the next page as a guide ensuring the questions shown in bold are covered adequately and the remaining questions asked as time permits.

- Adjust to the group's interests and strengths: follow up their comments, pursue detail if something's especially important to a participant.

- Keep an eye on the clock so you can stay on schedule (1hr session).

- Ensure no instructors or anyone in the Soldiers' chain of command is in the room during the interviews.

\section{INTRODUCTION OUTLINE}

- This focus group is a part of an ARI research effort examining tailored training in vehicle maintenance advanced individual training (AIT) courses, as well as assessing the impact of BRITE on $91 \mathrm{M}$ training.

- Focus group goal = provide additional insights to clarify the frequency and impact of tailored training in the development and training of Army maintenance professionals.

- Focus group method = collaborative brainstorming + story telling. Everyone contributes.

- Scheduled topics = flexible. Your issues/concerns are important, too.

- Your comments = confidential. We will protect your anonymity and privacy as described in the informed consent. We also expect everyone to respect the opinions offered during this session and to ensure any comments or opinions provided during this session remain confidential.

- Any questions before we start? 
FOCUS GROUP QUESTIONS

\section{Small Group Experience}

1. Did the instruction provide for adequate one-on-one time with the instructor?

2. Were your individual questions or training needs consistently addressed in a timely manner during training? If not, then why not?

3. Did the instruction provide for adequate practice and practical application time performing the new skills or applying newly learned knowledge?

4. What did you rely upon MOST during the course to answer any questions you had or to overcome any problems you experienced with the course content?

5. Reflect for a moment on the times you were in small groups (4-5 Soldiers) during training and answer the following:

- To what degree did everyone seem to have an opportunity to take a leadership role?

- While waiting your turn during a training session, how did you spend your time and energy... passively observing the training, paying very close attention to the training, discussing points observed in the training with other group members, talking with other group members on topics other than the task at hand, or simply trying to stay awake?

- During the sessions you just discussed, what could have been done to increase the degree to which you were actively engaged either individually or as a group in the training at hand?

6. What training techniques did your trainers use that really seemed to help you learn?

7. Did the instructional support you received consistently increase your confidence and competency in the skills trained? Consider any counseling, coaching, mentoring, testing and feedback you received during training.

8. Were there any particular exercises or training activities that seemed to benefit you the most? How about, the least? 


\section{Course Content}

Answer questions 9 through 12 regarding the training you received on the following systems:

- Hull

- Pack (engine and transmission)

- Hydraulics

- Electrical
- Turret

- Fire Control System

- Armament

9. Which blocks of training or subjects were the most difficult for you? Why?

10. Which blocks of training or subjects were the easiest for you? Why?

11. On the whole, how confident do you feel that the course prepared you with the knowledge, skills, and attributes important for your duties as an Abrams Tank/ Bradley Fighting Vehicle maintainer?

12. Which blocks of training were most interesting or enjoyable for you? What made them more enjoyable as opposed to other blocks?

13. Which blocks of training were least interesting or enjoyable for you? What made them less enjoyable as opposed to other blocks?

14. Which training aids or simulators best helped you learn or strengthen your confidence in your maintenance skills? Describe them.

15. How did these training aids or simulators help you learn?

\section{BRITE Technology (91M BRITE Students Only)}

16. What did you think of the Smartboard when used with or without the camera?

\section{Did the Smartboard help you learn? If so, how?}

18. How did the instructor most often use the technology: to demonstrate new procedures, to allow you to observe other Soldiers during training, to test your knowledge, or to reinforce previously covered material? Were there any other ways the instructor used the technology during your training? Please describe.

19. How else could the BRITE technology best be utilized during the course to help you become more proficient? 
Recommendations

20. (91M BRITE only) Should the unit continue to use the BRITE technology during future classes? Why or why not?

21. Which blocks of training or lessons, if any, should receive more training time?

22. Which blocks of training or lessons, if any, should receive less training time?

\section{End of Questions}




\title{
Tailored Training in Vehicle Maintenance Courses TRAINER'S/INSTRUCTOR"S INTERVIEW PROTOCOL
}

Circle: 91A 91M-Control 91M-BRITE

Course \#/ Group:

Facilitator:

Date:

\begin{abstract}
INSTRUCTIONS FOR FACILITATOR
- Introduce the session (see below) including its role in this assessment of tailored training (and BRITE technology if applicable).

- Ensure careful notes are taken, preferably by a team member when available.

- Dialogue with the participants using the questions that begin on the next page as a guide ensuring the questions shown in bold are covered adequately and the remaining questions asked as time permits.

- Keep an eye on the clock so you can stay on schedule (1hr session).

- Ensure no other instructors, students, or anyone in the participant's chain of command is in the room during the interviews.
\end{abstract}

\section{INTRODUCTION OUTLINE}

- This trainer interview is a part of an ARI research effort examining tailored training in vehicle maintenance advanced individual training (AIT) courses, as well as assessing the impact of BRITE on 91M training.

- Trainer interview goal = provide additional insights to clarify the frequency and impact of tailored training in AIT and its impact on operational excellence and the development of trained maintenance professionals.

- Scheduled topics = flexible. Your issues/concerns are important, too.

- Your comments = confidential. We will protect the anonymity and confidentiality of your comments as described in the informed consent.

- Any questions before we start? 


\section{TRAINER INTERVIEW QUESTIONS}

\section{Small Group Process}

1. What part did you play in the selection of the Soldiers for each small group?

- Exactly what criteria were used to divide the Soldiers into the small groups?

2. Was the number of high and low performing Soldiers balanced in each group? If not, why not?

3. How would you adjust the selection process, if at all?

Tailored Training

4. Within your primary small group, how did you identify the Soldiers that needed additional attention during training?

5. When you identified these Soldiers, how did you tailor or adapt training to ensure they understood the subject? How did you track their subsequent performance/progress?

6. What training techniques did you use that really seemed to help your students learn? Were there any particular exercises or training activities that seemed to benefit them the most?

7. Which blocks of training were the most challenging or difficult for students to learn or comprehend? Why?

8. In relation to the small groups (4-5 Soldiers) used during training, answer the following questions:

- While waiting their turn during a training session, how did Soldiers spend their time and energy....passively observing the training, paying very close attention to the training, discussing points observed in the training with other group members, talking with other group members on topics other than the task at hand, or simply trying to stay awake?

- During the training sessions just discussed, what else could have been done to increase the degree to which Soldiers were actively engaged either individually or as a group in the training at hand?

- To what degree did each student seem to have an opportunity to take a leadership role during training?

9. Without identifying any specific Soldier, did any of your students have any unique issues (e.g. previously diagnosed learning problems like ADHD or 
dyslexia, ESL or other language problems, reading problems, etc.) that hindered their ability to learn or keep pace with the training? If so, how were you able to identify the problem and address these unique issues during training?

10. Which blocks of training were the most challenging or difficult for you to instruct? Why?

\section{BRITE Technology}

11. How did you use the following technologies during training?
- The Mobile Classroom Trainer?
- The Desktop Trainer?
- Other technical training aids?

12. Comparing the BRITE class to your experience with previous classes, did you notice any impact the new technology had in the Soldiers' ability to learn and perform?

13. Where did the BRITE technology seem to be most effective during training?

14. Where did the BRITE technology seem to be least effective during training?

15. How would you improve the use of the BRITE technology within the POI?

16. What, if any, changes to the BRITE technology and its capabilities would you recommend as result of your experiences?

\section{Excellence in Maintenance (EIM) Group}

17. Have you instructed both standard small groups and EIM small groups in the past?

18. (If the instructor has experience with both groups) Compare the differences in instructing both groups. Consider:

- Speed of learning - Soldier attentiveness

- Soldier preparation - Subject comprehension

- Time on task - Soldier performance

19. How did your interaction with the EIM Soldiers differ from your interactions with other small groups? 
APPENDIX E

RESULTS/TABLES

E-1 
Table E-1.

Historical Versus Participating Course Comparisons

\begin{tabular}{|c|c|c|c|c|}
\hline \multicolumn{5}{|c|}{ Abrams } \\
\hline Variable & Historical & Participating & $F$ Test & $P$ value \\
\hline GT Score & $\begin{array}{c}\mathrm{M}=102.86 \\
\underline{\mathrm{SD}}=7.47 \\
\underline{N}=59\end{array}$ & $\begin{array}{c}\underline{M}=105.33 \\
\underline{S D}=13.05 \\
N=57\end{array}$ & 1.58 & $>.05$ \\
\hline Go Percent & $\begin{array}{l}\underline{\mathrm{M}}=94.18 \\
\underline{\mathrm{SD}}=7.00 \\
\underline{\mathrm{N}}=59\end{array}$ & $\begin{array}{l}\mathrm{M}=97.86 \\
\underline{\mathrm{SD}}=5.00 \\
\underline{N}=57\end{array}$ & 11.62 & $<.05$ \\
\hline \multicolumn{5}{|c|}{ Bradley } \\
\hline Variable & Historical & Participating & $F$ Test & $P$ value \\
\hline GT Score & $\begin{array}{l}\underline{\mathrm{M}}=105.45 \\
\underline{\mathrm{SD}}=10.17 \\
\underline{\mathrm{N}}=115\end{array}$ & $\begin{array}{c}\underline{\mathrm{M}}=103.98 \\
\underline{\mathrm{SD}}=10.35 \\
\underline{N}=85\end{array}$ & 1.01 & $>.05$ \\
\hline Go Percent & $\begin{aligned} \underline{M} & =89.76 \\
\underline{\mathrm{SD}} & =10.35 \\
\underline{N} & =115\end{aligned}$ & $\begin{array}{l}\underline{M}=93.08 \\
\underline{S D}=8.30 \\
\underline{N}=85\end{array}$ & 10.01 & $<.05$ \\
\hline
\end{tabular}

Table E-2.

Vehicle Maintenance Experience Item Statistics

\begin{tabular}{|c|c|c|c|}
\hline $\begin{array}{l}\text { Question } \\
\text { Number }\end{array}$ & $\begin{array}{c}\text { Item } \\
\text { Description }\end{array}$ & $\begin{array}{l}\text { Most Frequent } \\
\text { Response }\end{array}$ & Frequency* \\
\hline 1 & Platform confidence & $\mathrm{C}$ & 47.80 \\
\hline 2 & Experience with computers & $\mathrm{C}$ & 48.10 \\
\hline \multirow[t]{5}{*}{3} & Routine Maintenance On... & & \\
\hline & Typical Civilian Vehicle & Monthly & 42.30 \\
\hline & Farm Equipment & Never & 69.60 \\
\hline & Construction Equipment & Never & 82.80 \\
\hline & Recreational Vehicle & Less Often & 57.70 \\
\hline \multirow[t]{5}{*}{4} & Complex Maintenance On... & & \\
\hline & Typical Civilian Vehicle & Never & 48.10 \\
\hline & Farm Equipment & Never & 87.10 \\
\hline & Construction Equipment & Never & 90.40 \\
\hline & Recreational Vehicle & Never & 79.70 \\
\hline \multirow[t]{3}{*}{5} & Routine Electrical Work & & \\
\hline & Replace Spark Plugs & Less Often & 32.2 \\
\hline & Dealt With Home Power Box & Never & 44.40 \\
\hline \multirow[t]{3}{*}{6} & Complex Electrical Work & & \\
\hline & Replace Car Electrical System & Never & 71.30 \\
\hline & Use Diagrams to Solve Problem & Never & 72.10 \\
\hline 7 & Diagnostic on Vehicle & No & 63.20 \\
\hline 8 & Tech Manual Troubleshoot Vehicle & No & 67.90 \\
\hline
\end{tabular}

*Note: Indicates percentage of responses represented by mode Respondent $N=171$. 
Table E-3.

Soldiers' Prior Knowledge Summary

\begin{tabular}{|c|c|c|}
\hline $\begin{array}{c}\text { Question } \\
\text { Number }\end{array}$ & $\begin{array}{c}\text { Item } \\
\text { Number/Description }\end{array}$ & Mean \\
\hline 9 & $\begin{array}{c}\text { Where Substantial } \\
\text { Voltage }\end{array}$ & 17.20 \\
\hline 9 & Between A \& B & 70.10 \\
\hline & Between B \& C & 9.00 \\
\hline & Between C \& D & 28.60 \\
\hline & Between D \& A & 33.80 \\
\hline & Between A \& C & 30.70 \\
\hline 10 & Between D \& B & 36.80 \\
\hline 11 & Draw Circuit & \\
\hline & Match Circuit \& & Component \\
\hline & A & 23.40 \\
\hline & B & 50.60 \\
\hline & C & 16.00 \\
\hline & D & 13.50 \\
\hline & E & 24.80 \\
\hline & F & 52.80 \\
\hline & G & 56.60 \\
\hline & H & 48.10 \\
\hline & I & 39.20 \\
\hline
\end{tabular}

Note: $\mathrm{N}=171$ respondents.

Mean $=$ Percent correct responses . 
Table E-4.

Abrams Correlation Table

\begin{tabular}{|c|c|c|c|c|c|c|c|c|}
\hline & & Go Pct & GT Score & XP Index & PK Index & FD & $\mathbf{B M}$ & $\mathbf{C P}$ \\
\hline \multirow[t]{3}{*}{ Go Pct. } & Pearson r & 1 & .149 & .083 & $.223^{* *}$ & .092 & .086 & .119 \\
\hline & Sig. (2-tailed) & & .076 & .324 & .007 & .274 & .313 & .168 \\
\hline & $\mathrm{N}$ & 160 & 142 & 143 & 143 & 142 & 141 & 136 \\
\hline \multirow[t]{3}{*}{ GT Score } & Pearson r & .149 & 1 & .056 & $.367^{* *}$ & $.450^{* *}$ & $.310^{* *}$ & $.349^{* *}$ \\
\hline & Sig. (2-tailed) & .076 & & .504 & .000 & .000 & .000 & .000 \\
\hline & $\mathrm{N}$ & 142 & 149 & 142 & 142 & 142 & 142 & 137 \\
\hline \multirow[t]{3}{*}{ XP Index } & Pearson r & .083 & .056 & 1 & $.248^{* *}$ & .048 & .018 & $.184^{*}$ \\
\hline & Sig. (2-tailed) & .324 & .504 & & .001 & .539 & .816 & .021 \\
\hline & $\mathrm{N}$ & 143 & 142 & 164 & 164 & 163 & 162 & 157 \\
\hline \multirow[t]{3}{*}{ PK Index } & Pearson r & $.223^{* *}$ & $.367^{* *}$ & $.248^{* *}$ & 1 & $.288^{* *}$ & $.216^{* *}$ & $.221^{* *}$ \\
\hline & Sig. (2-tailed) & .007 & .000 & .001 & & .000 & .006 & .005 \\
\hline & $\mathrm{N}$ & 143 & 142 & 164 & 164 & 163 & 162 & 157 \\
\hline \multirow[t]{4}{*}{ FD } & Pearson r & .092 & $.450^{* *}$ & .048 & $.288^{* *}$ & 1 & $.265^{* *}$ & $.314^{* *}$ \\
\hline & Sig. (2-tailed) & .274 & .000 & .539 & .000 & & .001 & .000 \\
\hline & & 142 & 142 & 163 & 163 & 163 & 162 & 157 \\
\hline & $\mathrm{N}$ & .086 & $.310^{* *}$ & .018 & $.216^{* *}$ & $.265^{* *}$ & 1 & $.265^{* *}$ \\
\hline \multirow[t]{3}{*}{ BM } & Pearson r & .313 & .000 & .816 & .006 & .001 & & .001 \\
\hline & Sig. (2-tailed) & 141 & 142 & 162 & 162 & 162 & 162 & 157 \\
\hline & $\mathrm{N}$ & .119 & $.349^{* *}$ & $.184^{*}$ & $.221^{* *}$ & $.314^{* *}$ & $.265^{* *}$ & 1 \\
\hline \multirow[t]{3}{*}{$\mathbf{C P}$} & Pearson r & .168 & .000 & .021 & .005 & .000 & .001 & \\
\hline & Sig. (2-tailed) & 136 & 137 & 157 & 157 & 157 & 157 & 157 \\
\hline & $\mathrm{N}$ & 1 & .149 & .083 & $.223^{* *}$ & .092 & .086 & .119 \\
\hline
\end{tabular}

Note: Go Pct. = Go Percent. XP Index = Experience Index. PK Index = Prior Knowledge Index. FD = Following

Directions Test. BM = Building Memory Test. $\mathrm{CP}=$ Choosing a Path Test.

** Correlation is significant at the 0.01 level (2-tailed).

* Correlation is significant at the 0.05 level (2-tailed). 
Table E-5.

Bradley Control Correlation Table

\begin{tabular}{|c|c|c|c|c|c|c|c|c|}
\hline & & Go Pct & GT Score & XP Index & PK Index & FD & $\mathbf{B M}$ & $\mathbf{C P}$ \\
\hline \multirow[t]{3}{*}{ Go Pct. } & Pearson r & 1 & .237 & $.325^{*}$ & $.393^{* *}$ & .186 & .184 & .219 \\
\hline & Sig. (2-tailed) & & .081 & .018 & .004 & .186 & .197 & .143 \\
\hline & $\mathrm{N}$ & 58 & 55 & 53 & 53 & 52 & 51 & 46 \\
\hline \multirow[t]{3}{*}{ GT Score } & Pearson r & .237 & 1 & .233 & $.395^{* *}$ & $.395^{* *}$ & $.344^{*}$ & .257 \\
\hline & Sig. (2-tailed) & .081 & & .104 & .005 & .005 & .015 & .088 \\
\hline & $\mathrm{N}$ & 55 & 55 & 50 & 50 & 50 & 50 & 45 \\
\hline \multirow[t]{3}{*}{ XP Index } & Pearson r & $.325^{*}$ & .233 & 1 & $.337^{*}$ & .188 & .022 & .120 \\
\hline & Sig. (2-tailed) & .018 & .104 & & .014 & .182 & .877 & .427 \\
\hline & $\mathrm{N}$ & 53 & 50 & 53 & 53 & 52 & 51 & 46 \\
\hline \multirow[t]{3}{*}{ PK Index } & Pearson r & $.393^{* *}$ & $.395^{* *}$ & $.337^{*}$ & 1 & $.462^{* *}$ & $.372^{* *}$ & .160 \\
\hline & Sig. (2-tailed) & .004 & .005 & .014 & & .001 & .007 & .287 \\
\hline & $\mathrm{N}$ & 53 & 50 & 53 & 53 & 52 & 51 & 46 \\
\hline \multirow[t]{4}{*}{ FD } & Pearson r & .186 & $.395^{* *}$ & .188 & $.462^{* *}$ & 1 & .238 & .236 \\
\hline & Sig. (2-tailed) & .186 & .005 & .182 & .001 & & .093 & .115 \\
\hline & & 52 & 50 & 52 & 52 & 52 & 51 & 46 \\
\hline & $\mathrm{N}$ & .184 & $.344^{*}$ & .022 & $.372^{* *}$ & .238 & 1 & $.313^{*}$ \\
\hline \multirow[t]{3}{*}{$\mathbf{B M}$} & Pearson r & .197 & .015 & .877 & .007 & .093 & & .034 \\
\hline & Sig. (2-tailed) & 51 & 50 & 51 & 51 & 51 & 51 & 46 \\
\hline & $\mathrm{N}$ & .219 & .257 & .120 & .160 & .236 & $.313^{*}$ & 1 \\
\hline \multirow[t]{3}{*}{$\mathbf{C P}$} & Pearson r & .143 & .088 & .427 & .287 & .115 & .034 & \\
\hline & Sig. (2-tailed) & 46 & 45 & 46 & 46 & 46 & 46 & 46 \\
\hline & $\mathrm{N}$ & 1 & .237 & $.325^{*}$ & $.393^{* *}$ & .186 & .184 & .219 \\
\hline
\end{tabular}

Note: Go Pct. $=$ Go Percent. XP Index $=$ Experience Index. PK Index = Prior Knowledge Index. FD = Following

Directions Test. $\mathrm{BM}=$ Building Memory Test. $\mathrm{CP}=$ Choosing a Path Test.

** Correlation is significant at the 0.01 level (2-tailed).

* Correlation is significant at the 0.05 level (2-tailed). 
Table E-6.

Bradley BRITE Correlation Table

\begin{tabular}{|c|c|c|c|c|c|c|c|c|}
\hline & & Go Pct & GT Score & XP Index & PK Index & FD & $\mathbf{B M}$ & $\mathbf{C P}$ \\
\hline \multirow[t]{3}{*}{ Go Pct. } & Pearson r & 1 & .001 & -.097 & .157 & .194 & .182 & .102 \\
\hline & Sig. (2-tailed) & & .996 & .608 & .407 & .304 & .336 & .594 \\
\hline & $\mathrm{N}$ & 33 & 30 & 30 & 30 & 30 & 30 & 30 \\
\hline \multirow[t]{3}{*}{ GT Score } & Pearson r & .001 & 1 & .122 & .374 & $.525^{* *}$ & $.437^{*}$ & $.481^{* *}$ \\
\hline & Sig. (2-tailed) & .996 & & .537 & .050 & .004 & .020 & .010 \\
\hline & $\mathrm{N}$ & 30 & 30 & 28 & 28 & 28 & 28 & 28 \\
\hline \multirow[t]{3}{*}{ XP Index } & Pearson $\mathrm{r}$ & -.097 & .122 & 1 & .185 & .220 & .338 & .117 \\
\hline & Sig. (2-tailed) & .608 & .537 & & .329 & .243 & .068 & .537 \\
\hline & $\mathrm{N}$ & 30 & 28 & 30 & 30 & 30 & 30 & 30 \\
\hline \multirow[t]{3}{*}{ PK Index } & Pearson r & .157 & .374 & .185 & 1 & .356 & .360 & $.362^{*}$ \\
\hline & Sig. (2-tailed) & .407 & .050 & .329 & & .053 & .051 & .049 \\
\hline & $\mathrm{N}$ & 30 & 28 & 30 & 30 & 30 & 30 & 30 \\
\hline \multirow[t]{4}{*}{ FD } & Pearson r & .194 & $.525^{* *}$ & .220 & .356 & 1 & $.516^{* *}$ & $.669^{* *}$ \\
\hline & Sig. (2-tailed) & .304 & .004 & .243 & .053 & & .004 & .000 \\
\hline & & 30 & 28 & 30 & 30 & 30 & 30 & 30 \\
\hline & $\mathrm{N}$ & .182 & $.437^{*}$ & .338 & .360 & $.516^{* *}$ & 1 & $.608^{* *}$ \\
\hline \multirow[t]{3}{*}{$\mathbf{B M}$} & Pearson $r$ & .336 & .020 & .068 & .051 & .004 & & .000 \\
\hline & Sig. (2-tailed) & 30 & 28 & 30 & 30 & 30 & 30 & 30 \\
\hline & $\mathrm{N}$ & .102 & $.481^{* *}$ & .117 & $.362^{*}$ & $.669^{* *}$ & $.608^{* *}$ & 1 \\
\hline \multirow[t]{3}{*}{$\mathbf{C P}$} & Pearson $\mathrm{r}$ & .594 & .010 & .537 & .049 & .000 & .000 & \\
\hline & Sig. (2-tailed) & 30 & 28 & 30 & 30 & 30 & 30 & 30 \\
\hline & $\mathrm{N}$ & 1 & .001 & -.097 & .157 & .194 & .182 & .102 \\
\hline
\end{tabular}

Note: Go Pct. $=$ Go Percent. XP Index $=$ Experience Index. PK Index $=$ Prior Knowledge Index. FD = Following Directions Test. BM = Building Memory Test. $\mathrm{CP}=$ Choosing a Path Test.

** Correlation is significant at the 0.01 level (2-tailed).

* Correlation is significant at the 0.05 level (2-tailed).

Table E-7.

Abrams Group Size Frequency

\begin{tabular}{|c|c|c|}
\hline Group Size & Number & \% of Total \\
\hline Divided Small Group & 477 & 75 \\
\hline Small Group & 130 & 20 \\
\hline Large Group & 4 & 1 \\
\hline Half Class & 1 & 0 \\
\hline Entire Class & 26 & 4 \\
\hline Totals: & 638 & 100 \\
\hline
\end{tabular}


Table E-8.

Bradley Control Group Size Frequency

\begin{tabular}{|c|c|c|}
\hline Group Size & Number & \% of Total \\
\hline Divided Small Group & 152 & 71 \\
\hline Small Group & 59 & 27 \\
\hline Large Group & 3 & 1 \\
\hline Half Class & 1 & 0 \\
\hline Entire Class & 0 & 0 \\
\hline Totals: & 215 & 100 \\
\hline
\end{tabular}

Table E-9.

Bradley BRITE Size Frequency

\begin{tabular}{|c|c|c|}
\hline Group Size & Number & \% of Total \\
\hline Divided Small Group & 9 & 7 \\
\hline Small Group & 70 & 57 \\
\hline Large Group & 19 & 16 \\
\hline Half Class & 17 & 14 \\
\hline Entire Class & 7 & 6 \\
\hline Totals: & 122 & 100 \\
\hline
\end{tabular}

Table E-10.

Instructional Styles in Abrams Divided Small Groups

\begin{tabular}{|c|c|c|c|}
\hline Code & Instructional Style & Number & \% of Total \\
\hline D1 & Demonstration & 2 & 0 \\
\hline D2 & Guided Demonstration & 10 & 3 \\
\hline GD & Guided Discussion & 9 & 3 \\
\hline RC & Review/reinforce Content & 17 & 5 \\
\hline L1 & Lecture & 0 & 0 \\
\hline ID & Informal Discussion & 9 & 3 \\
\hline PS & Problem Solving & 288 & 84 \\
\hline Ot & Other & 6 & 2 \\
\hline & Totals & 341 & 100 \\
\hline
\end{tabular}


Table E-11.

\section{Trainer Interactions in Abrams Divided Small Groups}

\begin{tabular}{|l|l|c|c|}
\hline Code & Trainer/Instructor & Number & \% of Total \\
\hline A & Asks question & 17 & 15 \\
\hline P & Provides feedback on action/performance & 0 & 0 \\
\hline R & Restates or refocuses the question/problem & 0 & 0 \\
\hline S & Directly answers the student's question & 0 & 0 \\
\hline E & Provides additional examples & 0 & 0 \\
\hline C & Reviews previous/related content & 3 & 3 \\
\hline L & Designates a task or group leader & 0 & 0 \\
\hline T & Directs a task & 97 & 83 \\
\hline Ot & Other: $\quad$ Totals: & 0 & 0 \\
\hline & & 117 & 100 \\
\hline
\end{tabular}

Table E-12.

\section{Student Interactions in Abrams Divided Small Groups}

\begin{tabular}{|l|l|c|c|}
\hline Code & Student Interaction Codes & Number & \% of Total \\
\hline L & Takes leadership role or initiative (w/o being directed) & 0 & 0 \\
\hline $\mathbf{O}$ & Offers/provides help or support to peer(s) & 331 & 5 \\
\hline $\mathbf{A}$ & Asks question & 1513 & 23 \\
\hline $\mathbf{Q}$ & Answers or responds to a question & 2421 & 36 \\
\hline $\mathbf{H}$ & Accepts help/support from peer(s) & 271 & 4 \\
\hline $\mathbf{T}$ & Completes/attempts a directed task & 1668 & 25 \\
\hline Ot & Other: & 329 & 5 \\
\hline & Totals: & 6681 & 100 \\
\hline
\end{tabular}

Table E-13.

Instructional Styles in Bradley Control Divided Small Groups

\begin{tabular}{|c|c|c|c|}
\hline Code & Instructional Style & Number & \% of Total \\
\hline D1 & Demonstration & 0 & 3 \\
\hline D2 & Guided Demonstration & 4 & 0 \\
\hline GD & Guided Discussion & 0 & 4 \\
\hline RC & Review/reinforce Content & 7 & 0 \\
\hline L1 & Lecture & 0 & 3 \\
\hline ID & Informal Discussion & 5 & 90 \\
\hline PS & Problem Solving & 139 & 0 \\
\hline Ot & Other & 0 & 100 \\
\hline & Totals & 155 & \\
\hline
\end{tabular}


Table E-14.

\section{Trainer Interactions in Bradley Control Divided Small Groups}

\begin{tabular}{|l|l|c|c|}
\hline Code & Trainer/Instructor & Number & \% of Total \\
\hline A & Asks question & 68 & 33 \\
\hline P & Provides feedback on action/performance & 0 & 0 \\
\hline R & Restates or refocuses the question/problem & 0 & 0 \\
\hline S & Directly answers the student's question & 0 & 0 \\
\hline E & Provides additional examples & 0 & 0 \\
\hline C & Reviews previous/related content & 50 & 24 \\
\hline L & Designates a task or group leader & 0 & 0 \\
\hline T & Directs a task & 88 & 43 \\
\hline Ot & Other: $\quad$ Totals: & 0 & 0 \\
\hline & & 206 & 100 \\
\hline
\end{tabular}

Table E-15.

\section{Student Interactions in Bradley Control Divided Small Groups}

\begin{tabular}{|l|l|c|c|}
\hline Code & Student Interaction Codes & Number & \% of Total \\
\hline L & Takes leadership role or initiative (w/o being directed) & 9 & $<1$ \\
\hline $\mathbf{O}$ & Offers/provides help or support to peer(s) & 186 & 6 \\
\hline $\mathbf{A}$ & Asks question & 715 & 24 \\
\hline $\mathbf{Q}$ & Answers or responds to a question & 1109 & 38 \\
\hline $\mathbf{H}$ & Accepts help/support from peer(s) & 149 & 5 \\
\hline $\mathbf{T}$ & Completes/attempts a directed task & 758 & 26 \\
\hline Ot & Other: & 12 & $<1$ \\
\hline & Totals: & 2938 & 100 \\
\hline
\end{tabular}

Table E-16.

\section{Instructional Styles in Bradley BRITE Divided Small Groups}

\begin{tabular}{|c|c|c|c|}
\hline Code & Instructional Style & Number & \% of Total \\
\hline D1 & Demonstration & 0 & 0 \\
\hline D2 & Guided Demonstration & 0 & 11 \\
\hline GD & Guided Discussion & 0 & 0 \\
\hline RC & Review/reinforce Content & 0 & 0 \\
\hline L1 & Lecture & 0 & 0 \\
\hline ID & Informal Discussion & 0 & 89 \\
\hline PS & Problem Solving & 0 & 0 \\
\hline Ot & Other & 0 & 100 \\
\hline & Totals & 9 & \\
\hline
\end{tabular}


Table E-17.

\section{Trainer Interactions in Bradley BRITE Divided Small Groups}

\begin{tabular}{|l|l|c|c|}
\hline Code & Trainer/Instructor & Number & \% of Total \\
\hline A & Asks question & 126 & 92 \\
\hline P & Provides feedback on action/performance & 0 & 0 \\
\hline R & Restates or refocuses the question/problem & 0 & 0 \\
\hline S & Directly answers the student's question & 0 & 0 \\
\hline E & Provides additional examples & 0 & 0 \\
\hline C & Reviews previous/related content & 6 & 4 \\
\hline L & Designates a task or group leader & 0 & 0 \\
\hline T & Directs a task & 5 & 4 \\
\hline Ot & Other: $\quad$ Totals: & 0 & 0 \\
\hline & & 137 & 100 \\
\hline
\end{tabular}

Table E-18.

\section{Student Interactions in Bradley BRITE Divided Small Groups}

\begin{tabular}{|l|l|c|c|}
\hline Code & Student Interaction Codes & Number & \% of Total \\
\hline L & Takes leadership role or initiative (w/o being directed) & 10 & $<1$ \\
\hline $\mathbf{O}$ & Offers/provides help or support to peer(s) & 82 & 4 \\
\hline $\mathbf{A}$ & Asks question & 392 & 19 \\
\hline $\mathbf{Q}$ & Answers or responds to a question & 930 & 45 \\
\hline $\mathbf{H}$ & Accepts help/support from peer(s) & 103 & 5 \\
\hline $\mathbf{T}$ & Completes/attempts a directed task & 536 & 26 \\
\hline Ot & Other: & 0 & 0 \\
\hline & Totals: & 2053 & 100 \\
\hline
\end{tabular}

Table E-19.

Bradley BRITE vs. Control Individual Difference Comparisons

\begin{tabular}{|c|c|c|c|c|}
\hline \multicolumn{5}{|c|}{ Abrams } \\
\hline Variable & Bradley Control & Bradley BRITE & $F$ Test & $P$ value \\
\hline GT Score & $\begin{array}{c}\underline{M}=102.94 \\
\underline{S D}=9.15 \\
\underline{N}=50\end{array}$ & $\begin{array}{c}\underline{M}=106.29 \\
\underline{S D}=11.85 \\
\underline{N}=28\end{array}$ & 1.94 & $>.05$ \\
\hline Prior Knowledge & $\begin{aligned} \underline{\mathrm{M}} & =5.70 \\
\underline{\mathrm{SD}} & =3.86 \\
\underline{\mathrm{N}} & =50\end{aligned}$ & $\begin{aligned} \underline{\mathrm{M}} & =5.61 \\
\underline{\mathrm{SD}} & =5.09 \\
\underline{\mathrm{N}} & =28\end{aligned}$ & .000 & $>.05$ \\
\hline Experience & $\begin{array}{l}\mathrm{M}=22.20 \\
\underline{\mathrm{SD}}=7.38 \\
\mathrm{~N}=50\end{array}$ & $\begin{array}{l}\mathrm{M}=22.21 \\
\underline{\mathrm{SD}}=7.17 \\
\mathrm{~N}=28\end{array}$ & .008 & $>.05$ \\
\hline
\end{tabular}


Table E-20.

Bradley BRITE vs. Control Individual Performance Comparison

\begin{tabular}{|c|c|c|c|c|}
\hline \multicolumn{5}{|c|}{ Abrams } \\
\hline Variable & Bradley Control & Bradley BRITE & F Test & $P$ value \\
\hline Go Percent & $\underline{\mathrm{M}}=92.6$ & $\underline{\mathrm{M}}=93.1$ & .06 & $>.05$ \\
& $\underline{\mathrm{SD}}=1.2$ & $\underline{\mathrm{SD}}=1.6$ & & \\
& $\underline{\mathrm{N}}=58$ & $\underline{\mathrm{N}}=33$ & & \\
\hline
\end{tabular}

